
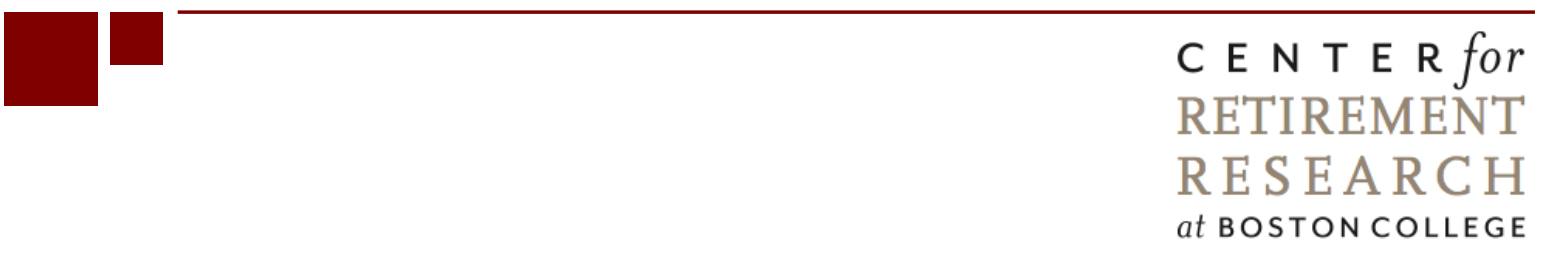

\title{
POST-WAR TRENDS IN LABOR INCOME IN THE SOCIAL SECURITY EARNINGS RECORDS
}

\author{
Gary Burtless and Kan Zhang \\ CRR WP 2015-7 \\ Submitted: March 2014 \\ Released: June 2015 \\ Center for Retirement Research at Boston College \\ Hovey House \\ 140 Commonwealth Avenue \\ Chestnut Hill, MA 02467 \\ Tel: 617-552-1762 Fax: 617-552-0191 \\ http://crr.bc.edu
}

Gary Burtless is the John C. and Nancy D. Whitehead Chair in Economic Studies at The Brookings Institution. Kan Zhang is a senior research assistant at The Brookings Institution. The research reported herein was performed pursuant to a grant from the U.S. Social Security Administration (SSA) funded as part of the Retirement Research Consortium. The opinions and conclusions expressed are solely those of the authors and do not represent the opinions or policy of SSA, any agency of the federal government, The Brookings Institution, or Boston College. Neither the United States Government nor any agency thereof, nor any of their employees, makes any warranty, express or implied, or assumes any legal liability or responsibility for the accuracy, completeness, or usefulness of the contents of this report. Reference herein to any specific commercial product, process or service by trade name, trademark, manufacturer, or otherwise does not necessarily constitute or imply endorsement, recommendation or favoring by the United States Government or any agency thereof.

(C) 2015, Gary Burtless and Kan Zhang. All rights reserved. Short sections of text, not to exceed two paragraphs, may be quoted without explicit permission provided that full credit, including (C) notice, is given to the source. 


\begin{abstract}
About the Center for Retirement Research
The Center for Retirement Research at Boston College, part of a consortium that includes parallel centers at the University of Michigan and the National Bureau of Economic Research, was established in 1998 through a grant from the Social Security Administration. The Center's mission is to produce first-class research and forge a strong link between the academic community and decision-makers in the public and private sectors around an issue of critical importance to the nation's future. To achieve this mission, the Center sponsors a wide variety of research projects, transmits new findings to a broad audience, trains new scholars, and broadens access to valuable data sources.
\end{abstract}

Center for Retirement Research at Boston College

Hovey House

140 Commonwealth Ave

Chestnut Hill, MA 02467

Tel: 617-552-1762 Fax: 617-552-0191

http://crr.bc.edu

Affiliated Institutions:

The Brookings Institution

Massachusetts Institute of Technology

Syracuse University

Urban Institute 


\begin{abstract}
The Earnings Public-Use File (EPUF) contains complete information on annual Social Security-covered earnings for a sample of 3.13 million Americans who had earnings in at least one year between 1951 and 2006. The panel data are used to examine patterns and trends in lifetime earnings. The EPUF data show the increasing convergence of female and male lifetime earnings patterns across a number of dimensions: (1) the shape and level of the average ageearnings profile; (2) the age at first entry into covered employment; and (3) the age of labor force exit. The full lifetime earnings profiles for birth cohorts that entered work after 1951 and exited before 2006 reveal associations between workers’ ages of labor force entry and exit and the peak earnings they attain during their careers. We find that workers who enter employment at older ages and exit at earlier ages on average earn lower incomes in their 40s than those who enter employment earlier and exit later. Among men born between 1941 and 1945, those who began working between ages 20 and 22 earned about one-fifth less when they were in their 40s compared with men who had their first covered earnings when they were 15. The EPUF data show a clear and strong positive association between workers' age of exit from covered employment and their earnings in mid-career. Workers who retire later, up through about age 62, tend to earn higher incomes during their 40s than workers who retire closer to age 50. For each birth cohort we examine and for both sexes, we find that workers who have a high level of earnings in years when they are employed also tend to have the longest careers. We also report the average and net return that successive cohorts of workers obtain on their Social Security contributions.
\end{abstract}




\section{Introduction}

The release of the U.S. Social Security Administration's (SSA) Earnings Public-Use File (EPUF) offers an unparalleled source of information for analyzing trends in lifetime earnings patterns. The file contains summary earnings information on individual-level Social-Securitycovered earnings before 1951, as well as individual-year data on covered earnings between 1951 and 2006 (Compson 2011). The data set includes information for a random sample of 3.13 million Americans who had covered earnings in at least one year between 1951 and 2006. During this period, there were 10 recessions, a notable rise in women's employment and relative earnings, an increase in early retirement followed by a trend toward later retirement, and a substantial increase in annual wage inequality. Each trend has affected the shape of workers' career earnings paths, aggregate earnings subject to the Social Security tax, the accumulation of Social Security earnings credits, and Social Security benefit payments. Shifts in lifetime earnings patterns may have affected the relative attractiveness of defined contribution pension plans, which are increasingly important, compared with traditional defined benefit plans, including Social Security.

The EPUF has important advantages, compared with more familiar sources of information about earnings and career work patterns, such as the March Current Population Survey. The EPUF contains information about workers' annual labor income, up to the Social Security annual earnings cap, for all calendar years between 1951 and 2006. Even though the earnings data have been "perturbed” slightly to protect the confidentiality of earners, the resulting file almost certainly contains more accurate information about earned income below the taxable cap than earnings data provided in U.S. Census Bureau interviews. The EPUF also has important limitations. The only demographic identifiers are workers' gender and year of birth. Users do not know where workers live, their family circumstances, or, indeed, whether they are alive in the years after their last reported earnings. Nor do we know in which years earners or non-earners in the file collected a Social Security benefit, possibly based on another person’s earnings record.

In the remainder of this paper, we consider four topics on which earnings data in the EPUF can shed light. First, we examine the evolution of age-earnings profiles separately for men and women. Second, we use the voluminous earnings data to evaluate the shift in women's relative earnings over their careers in comparison with men's earnings at the same stages of their 
careers. Third, we examine the link between the ages of entry and exit into Social-Securitycovered employment and the level of earnings that workers attain in the middle of their careers. Finally, we consider the potential returns that successive birth cohorts could obtain on their contributions to the Old-Age and Survivors Insurance (OASI) program, based solely on their expected benefits as retired workers without dependents. While this offers an incomplete accounting of total expected returns on Social Security taxes, the changing pattern of returns offers insight into the interaction between shifting career earnings patterns and worker returns under Social Security.

\section{Age-earnings profiles}

Figure 1 shows the age-earnings profiles of workers in Social-Security-covered employment in selected calendar years over five decades, 1951-2001. We calculated median earnings amounts for workers with positive reported earnings, by year of age, in six calendar years. Earnings amounts have been converted into 2010 prices using the Bureau of Labor Statistics' CPI-U-RS deflator. The top panel of Figure 1 shows age-earnings profiles among men; the lower panel shows equivalent results for women. The results for men are affected by the Social Security taxable earnings cap, especially in years before the mid-1970s. The effect of the cap is vividly illustrated in the age profiles for 1951, 1961, and 1971. Note, for example, that in 1971 men between 29 and 58 have the same median capped earnings, about $\$ 38,500$ measured in 2010 prices. This was, of course, the maximum wage amount subject to the Social Security payroll tax in 1971. The taxable earnings cap has no effect on our estimate of women's median earnings. The bottom panel accurately captures the growth in women's median real earnings in successive decades and at successive ages. In 1951 women's median earnings were relatively flat from ages 22 through 62. By 2001, the shape of the age profile of women's earnings looked much more similar to that of men.

The age-earnings profile in Figure 1 is based on cross-sectional data in each of six years. Figure 2 examines the age earnings profile of a single birth year cohort - the one born in 1936 . This cohort turned 15 in 1951, the first year of annual earnings available in the EPUF, and reached 70 in 2006, the last year with earnings data in the file. Each panel of Figure 2 shows the mean, median, and maximum reported capped earnings of workers with reported earnings at the indicated ages. The annual earnings amount in this chart is measured as a percent of the 
economy-wide average wage as estimated by the SSA. SSA's estimate of the economy-wide annual wage accounts for estimated wage earnings above the taxable earnings cap (Social Security Administration 2013, 2.14-2.17). Note that in the lower panel of Figure 2 the median female earner in this birth cohort never earned enough to approach the maximum taxed earnings amount. In contrast, the median male earner in the cohort had earnings close to or above the maximum taxable amount at every age between 27 and 37. One lesson of Figure 2 is that the Social Security taxable earnings cap places severe limits on our ability to measure average and median earnings among prime-age working men in years before the mid-1970s.

To deal with these limitations, we can use career earnings profiles from a number of birth year cohorts to form an estimate of the typical median earnings of workers at a given age. We derived such estimates using capped earnings information for four sets of birth cohorts: 1925-39, 1940-54, 1955-69, and 1970-82. At each year of age, we calculated the average of the median earnings amounts for members of the cohorts, measured as a percentage of the economy-wide average wage when an individual birth-year cohort attained the indicated age. In calculating this average, we excluded estimates affected by the Social Security taxable earnings cap. The estimates displayed in Figure 3 thus show the average age-median earnings profiles of four groups of birth cohorts, largely purged of the effects of the taxable earnings cap. The top panel shows results for male earners, and the bottom panel shows results for women. Measured relative to the economy-wide average wage, the earnings profiles of men and women have moved in the opposite direction. At most ages beyond 28, median male earnings have declined over time; in contrast, median earnings of women have increased. The basic shape of women's age-earnings profile has also changed. The dip in earnings after age 25, which is noticeable among working women born between 1925 and 1939, is absent from the earnings profiles of younger cohorts. It is possible, of course, that the earnings dip would be evident if our estimate of women's earnings included zero earnings amounts for women who temporarily ceased working in their mid- or late-20s. Even so, the sustained rise in employment among mothers during the three decades after 1970 means that the earnings dip must be smaller in recent cohorts compared with earlier ones.

The implications of Figure 3 for the relative median earnings of women compared with men are displayed in Figure 4. At each age between 22 and 70, we show the ratio of the median earnings of women in the indicated birth cohorts to the median earnings of men in the same 
cohorts. As in Figure 3, the results in Figure 4 are calculated to minimize the effects of the earnings top code on the estimated earnings ratios. For all the birth cohorts shown, women's median earnings represent a relatively high percentage of male median earnings at age 22 but then decline at higher ages. The decline was especially sharp for women born between 1925 and 1939. Successive cohorts have suffered smaller reductions in their relative earnings. Note that the median earnings of working women begins to rise compared with that of men at some age after women reach their mid- to late 30s among the earlier cohorts. However, it is only at ages past 65 that median women's earnings climb to 80 percent of the median earnings of the men who continue to work.

Figure 5 shows women's relative earnings at positions in addition to the mid-point of the distribution. The top panel shows relative earnings at the $10^{\text {th }}$ and $25^{\text {th }}$ percentiles in addition to the median; the bottom panel shows relative earnings at the $75^{\text {th }}$ and $90^{\text {th }}$ percentiles as well as the median. Note that the bottom panel shows these earnings ratios only for the period after 1974, that is, in the years when increases in the taxable earnings cap made it possible to observe the $75^{\text {th }}$ percentile of the male earnings distribution. (Male earnings at the $90^{\text {th }}$ percentile are observable only starting in 1989.) The results in Figure 5 show that in the lower ranks of the earnings distribution, the ratio of female to male earnings remained comparatively stable between 1951 and the early 1970s. Women’s earnings then began to climb relative to men’s, a trend that continued through the beginning of the last decade, though at a slower rate than in the period from the mid-1970s through the early 1990s. The lower panel shows that these trends are mirrored in the top half of the female earnings distribution, though the improvement in women's relative earnings gains has been slower at the $90^{\text {th }}$ percentile of the distribution than it has been in the middle and at the bottom.

\section{Career earnings patterns}

The EPUF not only provides earnings information on a remarkably large number of workers from each birth cohort, it also provides detailed information on the shape of worker careers that is not easy to duplicate in other publicly available files. For example, it contains data on earnings early in workers' careers for cohorts reaching age 30 over much of the past half century. The EPUF contains earnings data starting at age 15 for birth cohorts born in 1936 and later years. Figure 6 shows the average age of first earnings for successive cohorts born from 1936 through 1964. About 93 percent of workers in these cohorts who eventually have earnings 
in the EPUF reported their first earned income between ages 15 and 30. Workers represented in Figure 6 are limited to this sample. The figure shows the average age of first earnings in successive birth cohorts. The age of labor force entry rose in the early 1950s (that is, for cohorts born between 1936 and 1944), and then began a period of sustained decline. Males born in the early 1960s on average reported their initial earnings at approximately the same age as workers born in the Great Depression. A notable feature of the chart is the convergence in labor force entry patterns of young women and young men.

For birth cohorts whose prime working years are spanned by the EPUF, we can calculate the number of years in which they received Social-Security-covered earnings during their potential careers. Workers born between 1933 and 1944 have at least 48 years of potential earnings in the file. Figure 7 shows the distribution of years of covered earnings for all sample members who reported earnings in at least one year. Results are shown separately for women and men. About half of men had covered earnings in at least 40 years. About one in 10 male earners and 17 percent of female earners received earnings in nine or fewer years. It is unclear, however, whether the low number of earnings years is explained by joblessness, by employment in a job not covered by Social Security, or by early death.

Career earnings records can be used to determine and analyze the last age at which workers report covered earnings. Figure 8 shows tabulations for EPUF sample members who had at least a year of covered earnings. We analyze workers in three birth cohorts for which it is plausible to assume that nearly all workers will have ceased paid employment by 2006. The chart shows the percentage of workers in each cohort whose last year of covered earnings occurs at the age indicated on the horizontal axis. (The percentages indicated by the vertical axis are calculated over a sample of workers whose last year of covered earnings occurred between ages 50 and 70. For all birth cohorts, an overwhelming percentage of labor force exits occur in this age range.) The oldest cohort, born in 1901-1905, has an exceptionally large proportion of age65 retirements. Age 65 was, of course, the earliest age for entitlement to an unreduced retiredworker benefit. Nearly all workers who attain age 65 in a calendar year will be 64 during at least part of that calendar year. Among women in the oldest cohort, 62 was also a favored age to cease working. For the two younger cohorts born in 1911-1915 and 1926-1930, age-62 retirements became more popular among both women and men. Indeed, for the 1926-1930 cohort age 62 is a more popular job-leaving age than age 65. The rising popularity of age-62 retirements is 
undoubtedly linked to the introduction of early retirement benefits (at age 62) in Social Security. This reform was implemented in the mid-1950s for women and in the early 1960s for men.

Age of entry and mid-career earnings. Ages of labor force entry may be linked to the level of earnings that workers achieve later in their careers. To examine the association between age of entry and earnings in workers' later careers, we sorted workers into classes defined by their age of first covered earnings. For each of these ages, we calculated workers' average earnings between ages 40 and 49 . At each of those ages, we computed the ratio of a worker's annual earnings and the economy-wide average wage in that calendar year. We then calculated the average of these 10 years' ratios and used this as an index of the worker's average earnings level between ages 40 and 49 .

Figure 9 shows the average values of these estimates for three birth cohorts - workers born between 1936 and 1940, between 1941 and 1945, and between 1946 and 1950. The estimation sample consists of all workers in these birth cohorts who accumulated at least 10 years of covered earnings during their careers. Results in the top panel show the relationship between male workers' initial age of covered earnings and their average earnings in their 40s; results in the bottom panel show the same relationship among female workers. For both sexes, workers who begin to work at an earlier age tend to have higher earnings during their prime working years than workers who begin to work later. The relationship, however, is much stronger in the case of men than of women. Among men born between 1941 and 1945, those who began working between ages 20 and 22 earned about one-fifth less when they were in their 40s compared with men who had their first covered earnings when they were 15. In 2010, this would be the equivalent of an earnings difference of about $\$ 9,100$ per year, or $\$ 91,000$ over the decade between ages 40 and 49. Each year of delay in entering covered employment between ages 15 and 25 reduces male workers' annual earnings in their 40s by about $\$ 1,600$. The earnings losses associated with later entry into covered employment are comparable, though a bit smaller, for men born between 1936 and 1940 and between 1946 and 1950.

Among women, the penalty for delayed entry into covered employment is smaller than it is for men. In all three birth cohorts included in the chart, the women whose careers begin between ages 23 and 25 earn 12 percent lower earnings when they are in their 40s compared with women whose covered earnings begin at age 15 . This penalty, in percentage terms, is about half the earnings loss suffered by male earners for late entry into a career. It seems likely that 
women's earnings when they are in middle age are more affected by career interruptions when they are between 20 and 39 than by their age of first entry into employment. Men, who tend to have fewer lengthy career interruptions than women, may be more affected by delays in their early work experience.

Our finding that earnings in workers' mid-careers are strongly affected by their age of career entry is robust. We examined the impact of entry ages on earnings over a longer time span in workers' later career. The effects displayed in Figure 9 are confirmed when we measure average earnings over the 15-year period from age 40 to age 54. They are also confirmed when we exclude years in which workers earn no covered earnings from our calculation of workers’ average earnings later in their careers. Thus, our results are not due mainly to early death or to disability, which would tend to an increase the number of years that workers have no earnings at all. Finally, we examined the relationship between age of labor force entry and the peak earnings that workers achieve in their careers. There is a pronounced tendency for both men and women who begin covered employment at younger ages to attain higher peak earnings in their careers. Workers with covered earnings at age 15 or 16 attain higher peak earnings than workers entering the covered workforce at later ages. Relative to the economy-wide average wage, the peak career earnings of a man entering the workforce at 15 is about one-quarter greater than that of a man who enters the workforce at 20. For women, the peak earnings for someone who enters covered employment at 15 is about one-eighth greater than that of someone who delays entering employment until 20. These differences are startlingly large, and they are evident for all of the birth cohorts for which we can observe entry patterns into covered employment and several decades of earnings after labor force entry.

One possible explanation for the association between workers' entry ages and their later career earnings may be the expansion of employment covered by the Social Security system. Some classes of employment that may lead to low career earnings, including farm selfemployment and military service, only received coverage under Social Security in the mid1950s. However, we find evidence for a negative association between age of entry into covered employment and later career earnings even among birth cohorts reaching age 15 after the expansions of coverage were substantially complete. Thus, our analysis shows a powerful association between the age of first entry into employment and workers' later success in the job market. Workers, especially male workers, who enter paid employment after their middle or late 
teens tend to earn lower incomes in their peak earnings years than do workers who enter the workforce earlier.

Age of labor force exit and mid-career earnings. The EPUF data also permit us to examine the link between workers' mid-career earnings and their age of exit from covered employment. We classify workers within a given birth-year cohort by their last age of covered earnings. Workers in each birth-year and age-of-exit cell are ranked by their mid-career and peak career earnings, and we calculate the average mid-career and median peak earnings amount in the cell. Our main results focus on the average annual earnings of workers when they are between 40 and 49 years old. At each of those ages, we computed the ratio of a worker's annual earnings and the economy-wide average wage in that calendar year. We then calculated the average of these 10 years' ratios and used this as an index of workers' average earnings level while they were in their 40s. Again, we restrict the analysis to workers who have minimum of 10 years of covered earnings.

Figure 10 shows the results of our calculations of workers' average earnings between ages 40 and 49, separately for men and women and separately for three sets of birth-year cohorts. The tabulations show a clear and strong positive association between workers' age of exit from covered employment, indicated on the horizontal axis, and their earnings in mid-career. Workers who retire later up through about age 62 tend to earn higher incomes during their 40s than workers who retire closer to age $50{ }^{1}$ For the oldest male cohorts, it is plausible that the positive association between age of labor force exit and covered earnings between ages 40 and 49 is due to the legislated increases in the Social Security taxable earnings cap. Workers who remained in the workforce longer were more likely to work when the cap was relatively high, whereas workers who left the workforce at a younger age did not have the opportunity to earn exceptionally high covered earnings because the earnings cap was comparatively low. The experience of the youngest cohort, born between 1931 and 1935, suggests that the rising earnings cap plays only a minor role in this association, however. During the middle part of their careers, the earnings cap was uniformly high relative to the economy-wide average wage. Workers born between 1931 and 1935 who left covered employment later also tended to earn higher earnings

\footnotetext{
${ }^{1}$ We obtain similar results when we calculate workers' average earnings between ages 40 and 49 based solely on their average earnings in years when they have positive earnings.
} 
when they were in their 40s. We can also reduce the impact of the earnings cap on our estimates by examining the percentile rank of workers based on their earnings when they were in their 40s. ${ }^{2}$ Workers whose average earnings percentile score is higher tend to retire later than workers with a lower percentile score. Finally, we also calculated the peak career earnings of every male worker in a given birth cohort, where the peak earnings amount is calculated relative to the economy-wide average wage in a given calendar year. These calculations, too, suggest that men with higher peak career earnings tend to retire later than men who have a lower level of peak earnings.

The same strong association between the workforce exit age and mid-career earnings is also evident for women, relatively few of whom were affected by the earnings cap, even in years when the cap was low. Therefore, it seems quite likely that the positive association between later workforce exit and a higher level of peak career earnings represents a genuine characteristic of career earnings patterns rather than an artifact produced by legislated increases in the Social Security earnings cap.

The results in Figure 10 highlight a couple of differences between men and women and among different birth cohorts. The link between labor force exit and average mid-career earnings shows a more pronounced decline after age 62 among women than men. Among women, it seems plain that those with the highest average earnings when they were in their 40s tended to retire around age 62 or 63, and workers who left the workforce after age 63 tended to have lower earnings when they were in their 40s. There is some evidence for a similar link between male labor force exit after age 66 and men’s average earnings in midcareer, but the relationship is not as strong as it is among women. Interestingly, the pattern of this relationship for men and women born in 1931-1935 is more similar than it is for men and women born before 1931. This suggests that the determinants of labor force exits among more recent cohorts of women and men are more similar than was the case for earlier cohorts. This interpretation also seems consistent with the tabulations of exit ages displayed in Figure 8, where we also see a more similar pattern of labor force exit among men and women in the most recent retiree cohort.

\footnotetext{
${ }^{2}$ We calculate the percentile rank of male workers within each birth-year cohort as follows. Workers' average earnings, measured as a percentage of the economy-wide average wage, are calculated for the 10 years starting at age 40 as described in the text. Workers in the cohort who have a minimum of 10 years of covered earnings over their careers are then ranked by their average covered earnings in their 40s, and percentile scores are assigned to each worker based on the worker's average earnings within the sample of men who are born in the same year.
} 
The basic pattern displayed in Figure 10 implies that workers born between 1921 and 1936 who ceased working between ages 60 and 65 earned more on average while in their 40s than workers who exited the workforce between ages 50 and 59. This association is not hard to understand. Workers who earn lower wages usually face weaker financial incentives to stay in the workforce. If they stop working, they give up less potential earnings than workers the same age who earn more. This logic is particularly compelling in the case of workers whose earnings prospects are limited by poor health or a work disability. Workers in this situation who have earned Social-Security-covered wages for a minimum number of years are often eligible for Disability Insurance (DI) benefits if they stop working. The basic Social Security benefit formula is redistributive in favor of workers who have low earnings. As a percent of past covered earnings, DI benefits provide more generous payments to workers who earned low wages rather than high wages. This factor, too, might account for the fact that those who cease working in their 50s had lower earnings in their 40s than those who delay retirement until 60 or 65.

\section{Workers' average earnings and the length of their careers}

Because workers who begin to work early and workers who leave the labor force late earn higher annual wages than workers who start to work late and leave the workforce early, it seems plausible to expect that workers with longer careers earn higher average wages per year than workers with shorter careers. Earnings data in the EPUF file strongly confirm this expectation. After converting all earnings amounts into constant 2010 prices using the CPI-U-RS deflator, we calculated the mean earnings of each worker for the years before age 62 in which the worker had positive covered earnings. That is, our calculation of a worker's annual rate of earnings excluded years in which the worker had no earnings. Figure 11 shows the relationship between the number of years of reported positive earnings amounts up through age 62 (on the horizontal axis) and workers' average earnings in years when they had positive earnings (on the vertical axis). The results reflect earnings patterns for workers born in just three years, 1920, 1935 and 1945. However, the relationship between career length and average earnings is similar no matter which birth year we use. Workers with longer careers on average earn higher incomes in an average year when they have covered labor income. 
This relationship is not a surprise in the case of earners with short careers. These workers do not obtain the expected annual earnings gains that come with additional years of early work experience. ${ }^{3}$ In addition, a higher proportion of these earners' work years represent the first and last years of their careers, when they are likely to have earnings in fewer than 12 months. It is more impressive that the positive relationship between average annual earnings and career length continues past the $30^{\text {th }}$ and even the $40^{\text {th }}$ years of workers' careers. In fact, the rise in average earnings per added year of career length is greater in years 31 through 45 than it is in years 11 through 30. For the oldest birth cohorts, this pattern may be partly due to the low but rising level of maximum taxable earnings when these workers were in their highest earnings years, which typically occurs when workers are past age 40. If the capped earnings amount is climbing faster than average wage levels, many workers at the earnings cap will appear to obtain sizeable annual earnings gains even though their actual earnings are stable or even declining. This is less true for women and men in the youngest cohorts, because many fewer of them had covered earnings at the taxable earnings cap. For men born in 1945, for example, more than 75 percent of earners had covered earnings below the taxable cap in calendar years when the men were older than 34 . For women born in the same year, more than 90 percent of earners had covered earnings below the cap at those same ages. ${ }^{4}$ In sum, even when the overwhelming majority of workers do not have their middle and late career earnings capped by the taxable maximum earnings amount, we still observe that on average workers' per-year earnings rise with the duration of their careers.

Although the relationship between career length and average real earnings is not strictly linear, it is straightforward to calculate the average slope of the relationship. We have performed this calculation for workers in each of the 29 male and female birth cohorts between 1917 and 1945. The results are displayed in Figure 12. For male workers born in 1920, for example, each additional year of covered earnings in a career on average boosted workers' average annual earnings in a year with covered earnings by slightly less than $\$ 800$. For women born in the same

\footnotetext{
${ }^{3}$ The characteristic hump-shaped pattern of the age-earnings profile, as well as detailed analyses of the determinants of individual earnings, suggest that there are sizeable gains from additional experience early in workers' careers. However, annual earnings of workers typically fall after attaining a peak sometime between ages 35 and 55, even in the case of workers who remain continuously employed (Bosworth, Burtless, and Steuerle 2000).

${ }^{4}$ As an additional check on our basic result, we calculated the relationship between the length of workers' careers and the median rather than the mean annual earnings of workers in a given birth cohort. Especially for workers in recent cohorts, the earnings of the median earner are rarely if ever affected by the taxable earnings cap. We find a similar pattern of rising earnings with career length when we estimated the median earnings received by workers in a birth cohort who had successively longer careers.
} 
year, average annual earnings increased $\$ 625$ per year of covered earnings. The 90 percent confidence intervals around the slope coefficients are also displayed in the chart. The slope coefficients are highest for workers born before the middle 1920s and after 1940. Workers born in the early to middle 1930s saw the smallest gains in average earnings per year as a result of longer careers. These cohorts saw comparatively slow economy-wide real earnings gains during their peak earnings years. Another factor that may have contributed to the upward tilt in the slope for cohorts born after 1935 is the fact that the rise in the average retirement age after 1990 has been disproportionately concentrated among better educated and higher earning workers. Thus, people with higher mid-career earnings are more heavily represented among the workers with the longest careers.

The relationship between career length and average earnings gives rise to a powerful positive association between the duration of workers' careers and their average indexed monthly earnings, or AIME (Figure 13). A worker's AIME is the crucial determinant of his or her basic Old-Age Insurance (OAI) pension. Workers are not entitled to an OAI pension unless they accumulate at least 10 years of covered earnings. ${ }^{5}$ To calculate the AIME, annual earnings amounts obtained at ages before 60 are indexed to reflect economy-wide earnings growth in years before the worker turned 60. Earnings in the years with highest annual earnings amounts are then averaged and divided by 12 . In recent years, the 35 years with the highest indexed earnings amounts have been averaged in order to determine the AIME. We calculated workers' AIMEs using earnings up through the calendar year in which workers turned 61. Note that workers who had earnings in fewer than 35 years must include some years with zero earnings amounts when calculating the AIME. ${ }^{6}$ Not surprisingly then, the AIME rises rapidly up through the $35^{\text {th }}$ year of a worker's career, as years with zero earnings are replaced by years with positive amounts in the calculation of the AIME. After 35 years of covered earnings, however, the accumulation of an additional year of earnings will only change the AIME if the (indexed)

\footnotetext{
${ }^{5}$ Workers born before 1929 required fewer than 10 years - or 40 quarters of earnings credits - to become entitled to an OAI pension. We have only calculated AIMES in Figure 13 for workers who accumulated enough earnings credits to be eligible for an OAI pension at age 62. Note that workers born in 1920 could obtain an OAI pension after having earnings in just eight years rather than the 10 years required for the workers in the two younger birth cohorts.

${ }^{6}$ For workers born before 1929, a smaller number of years of covered earnings were averaged in order to calculate the AIME.
} 
amount earned in the most recent year is greater than the smallest (indexed) annual earnings amount that was used in the previous year's computation.

The results displayed in Figure 13 suggest that the AIME actually increases faster on average in years 36 through 45 than it does in years 10 through 35 of workers' careers. For men born in 1935, for example, the average AIME rises about $\$ 90$ per year for careers ending between the $10^{\text {th }}$ and $35^{\text {th }}$ years of workers' careers. For careers that end after the $35^{\text {th }}$ year, the AIME gain per added year in a career is about \$165. The difference is highly statistically significant. This pattern holds for both sexes and all birth years. This result does not mean individual workers see a faster rate of gain in their AIME from working a $36^{\text {th }}$ or $40^{\text {th }}$ year in covered employment as opposed to a $26^{\text {th }}$ or $30^{\text {th }}$ year. However, the workers who stop working after 36 or 40 years in covered employment typically earn considerably higher average incomes in years when they are employed than do workers who exit the labor force after just 26 or 30 years in covered employment. The positive association between the length of workers' careers and their average earnings in years when they are employed produces a strong positive association between workers’ AIMEs and the length of their work careers.

\section{Trends in Social Security contribution and benefit payout rates}

The EPUF file contains information on workers' taxable covered earnings but not on the amount of benefits they receive, making it impossible to determine workers' ex post returns on their contributions. It is possible, however, to calculate workers' contributions and some of their expected benefit payouts based on accumulated earnings at designated points in their careers. In the remainder of the paper we focus on workers' expected OAI benefits as a single retired worker. We compare these expected benefits to workers' OASI contributions. The comparison permits a calculation of the average and marginal payoff that workers obtain on their OASI contributions at successive ages in their careers.

The calculation is obviously incomplete. It ignores, for example, the survivor benefits that a deceased contributor to OASI may bequeath for the support of one or more surviving dependents. It also excludes the dependents' benefits received by an OAI pensioner who has an eligible spouse or child dependent. Because the EPUF file contains information about the annual amount and timing of workers' Social-Security-covered earnings but no information about the existence or ages of workers' dependents, it is impossible to predict the expected timing or 
annual amount of benefits such dependents would receive. For that reason, our prediction of future Social Security benefits is restricted to the expected OAI pension the worker would receive as a single worker. The calculation also ignores the possibility that workers eligible for their own OAI pension may instead receive a dependent's or survivor benefit based on the earnings record of a better paid spouse.

The missing information creates a systematic bias. On average, our estimates understate the total OASI benefits likely to be received based on the earnings records of highly paid workers, since these workers are more likely to have dependents and survivors who will derive benefits from their earnings records. On the other hand, our estimates overstate average benefit payouts for low-wage workers, who are the most likely to obtain benefits as a dependent or surviving spouse of a more highly paid worker.

To make the computations tractable, we calculate all benefits under the assumption that pensions are claimed at age 65. This was the earliest age of full benefit entitlement for workers born in 1937 or earlier years. Workers born between 1938 and 1942 were eligible for full benefits at a somewhat older age, while workers born between 1943 and 1954 must wait until age 66 to claim an unreduced OAI pension. Our calculations assume that workers born after 1937 accept a benefit that is lower than their Primary Insurance Amount (PIA), that is, the full pension they would receive if they claimed benefits at the normal retirement age. Our assumption about the timing of benefit take-up is not crucial. The great majority of OAI beneficiaries claim pensions before the normal retirement age. However, early claimants face a reduction in their monthly benefits that reflects the fact that they can expect to receive more monthly payments than workers who first claim a pension at the normal retirement age. Although the actuarial adjustment for early benefit claiming is not strictly aligned with workers' survival probabilities and the real interest rate we assume, the adjustment is close enough to actuarially fair that our results should be roughly accurate for workers who claim benefits between age 62 and the normal retirement age.

It is straightforward to calculate workers' expected OAI retired-worker pensions at successively later years in their work careers. We performed the calculations for workers born in 1917 and later years under Social Security’s 1978 New Start Method and using the worker’s reported earnings in 1951 and later years. The first benefit we calculated for each worker is the benefit that the worker became entitled to after obtaining 40 quarters of earnings credits. For 
workers born in 1929 and later years, this is the minimum number of quarters needed to qualify for an OAI pension. If a worker obtains 40 quarters of covered earnings at age $X$, then the worker's earnings up through that age are used to calculate the worker's real benefits at age 65, $\widehat{B(X)}$, assuming no other wages are earned after age $X$. The OAI benefit stream from age 65 until the worker's death is discounted to age 15 :

(1) Lifetime OAI benefits earned through age $X=\operatorname{OAI}(X)=\sum_{i=65}^{100} \frac{\widehat{B(X)}}{(1+\delta)^{i-15}} S_{i}$ where $\widehat{B(X)}=$ Estimated real benefit at age 65;

$S_{i}=$ Survival probability from age $X$ up through age $i$; and $\delta=$ Discount rate.

The calculation is repeated at successively higher ages at which the worker has earnings. Workers' survival probabilities are based on historical estimates and projections of cohort survival rates published by the Office of the Social Security Actuary (Bell and Miller 2005). We assume that all men in a given birth cohort and all women in a given birth cohort face the survival probabilities estimated or projected by the Actuary's Office for the cohort. It is known that survival probabilities are linked to workers' average lifetime earnings (Waldron 2007 and 2013), but we ignore this association in developing estimates of the expected value of future OAI pensions.

Similar calculations can be made of the discounted OASI taxes that workers pay through successive years of their careers as well as the cumulative discounted Social-Security-covered earnings that workers report through the same points in their career:

(2) OASI Taxes through age $X=\sum_{i=15}^{X} \frac{T_{i}}{(1+\delta)^{i-15}}$; and

(3) Covered earnings through age $X=\sum_{i=15}^{X} \frac{E_{i}}{(1+\delta)^{i-15}}$

where $\quad T_{i}=$ Estimated OASI tax at age $i$; and

$E_{i}=$ Reported Social-Security-covered earnings, including imputed employer contributions to OASDHI, at age $i$. 
Our estimate of the OASI tax reflects both employer and employee payroll contributions to OASI. ${ }^{7}$ Similarly, our estimate of Social-Security-covered compensation includes employer payroll tax contributions to the OASI, DI, and HI programs. Performing the calculations requires that we convert nominal earnings reported in the EPUF file, estimated OASI taxes, and nominal benefit amounts into constant 2010 dollars. We discount real annual amounts to age 15 using an assumed 1.5 percent discount rate.

The ratio of expected lifetime benefits accumulated through age $X$ to discounted earnings through age $X$ is the ratio (1) / (3), and the ratio of OASI taxes through age $X$ to discounted earnings through age $X$ is the ratio (2) / (3). The expected net payoff for a worker's OASI contributions is then $[(1)-(2)]$ / (3). If the real return on contributions is less than 1.5 percent, the average net payoff is negative. Of equal interest is the marginal payoff workers derive from making an additional year's OASI payroll tax contributions. Suppose the next age at which a worker earns Social-Security-covered wages is $Y$. The change in expected OAI benefits is

(4) Change in lifetime OAI benefits at age $Y=\sum_{i=65}^{100} \frac{\widehat{B(Y)}_{i}-\widehat{B(X)} i}{(1+\delta)^{i-15}} S_{i}$ where $S_{i}=$ Survival probability from age $Y$ up through age $i$.

The estimated OASI tax based on wages earned at age $Y$ is $T_{Y}$, and the marginal payoff to the additional year's tax contributions, measured as a fraction of earnings received at age $Y$, $E_{Y}$, is:

(5) Marginal payoff rate on age $Y$ tax contributions $=\frac{\sum_{i=65}^{100} \frac{\widehat{B(Y)} i_{i}-\overline{B(X)} i}{(1+\delta)^{i-15}} S_{i}-T_{Y}}{E_{Y}}$.

It is unrealistic to think workers would be aware of the lifetime OAI benefits they have accumulated at successive ages or that they would be able to calculate the marginal gain in lifetime benefits they derive from an additional year of work. Indeed, our estimates reflect approximations of those values and are based on information about historical earnings and price trends that would have been unknown to workers in a given past year. Even if workers

\footnotetext{
${ }^{7}$ This overstates the contributions of self-employed workers up through 1983. Before 1984, self-employed workers paid a tax rate that was about one-quarter below the combined employer-employee tax rate on wage earnings. Our calculations are thus accurate only for wage earners rather than for all earners covered by Social Security.
} 
understood the OAI benefit formula, they could not know how fast future wages would rise in relation to consumer prices over the course of their future careers. This information is necessary in order to gauge the value of earnings credits a worker has already accumulated and the value of additional earnings credits accumulated in the current year. Nonetheless, our calculations shed light on historical trends in the ex post and projected value of earnings credits accumulated by past generations of workers. The estimates are made simpler by the fact that OAI benefit payouts, after they begin, are indexed to consumer prices.

Empirical estimates of discounted benefits and taxes. Figures 14 and 16 show our estimates of discounted expected OAI benefits and estimated OASI taxes for workers in successive cohorts who were born between 1917 and 1950. Figure 14 displays the results for male workers, Figure 16 displays the results for women. To be included in the calculations, workers in all birth cohorts had to accumulate a minimum of 40 quarters of Social Security earnings credits. The top panel in the two figures shows our estimates of the expected discounted OAI benefits for a single retired worker measured as a percent of the workers’ discounted Social-Security-covered compensation (that is, Social-Security-covered wages plus employer OASDHI contributions on those covered wages). We display workers' expected benefit accumulations after they have worked in covered employment for 10, 20, 30, and 40 years. $^{8}$

For example, in Figure 14 we estimate that male workers born in 1917 who earned covered wages for exactly 10 years (or 40 quarters) had accumulated expected lifetime OAI benefits equal to 14.4 percent of their Social-Security-covered compensation. This calculation is based on our estimate of the expected lifetime OAI benefit after 10 years of OASI tax contributions for all workers who made OASI contributions for at least 10 years. Most of these workers contributed to OASI for far longer than 10 years, of course. ${ }^{9}$ For workers in this

\footnotetext{
${ }^{8}$ The great majority of workers attain 40 quarters by the time they work in covered employment for 10 years. However, workers with low annual earnings early in their careers required more than 10 years of earnings before meeting the 40-quarter minimum to become eligible for OAI benefits. For purposes of these calculations, we set years of covered employment to 10 years for all workers when they first attain 40 quarters of earnings coverage.

${ }^{9}$ Note that all our calculations are based solely on the contributions workers made starting in 1951, when the EPUF annual earnings data begin. Workers in the oldest cohorts, who were born before 1936, may have had SocialSecurity-covered earnings in years before 1951. We disregard pre-1951 contributions and earnings in calculating workers' benefit entitlements, lifetime tax contributions, and lifetime earnings. Only rarely will this omission mean that we underestimate workers' expected lifetime benefits, but in many cases we will have underestimated workers'
} 
estimation sample, the mean ratio of expected discounted benefits to discounted lifetime earnings was 14.4 percent. For male workers in the 1917 birth cohort who received covered earnings during at least 20 years after 1951, the average ratio of expected discounted benefits to discounted lifetime earnings was 11.9 percent. The PIA formula for basic retirement benefits is redistributive in favor of lower-wage workers, so the increase in workers' covered earnings between the $10^{\text {th }}$ and $20^{\text {th }}$ year of contribution does not yield a proportionate increase in their expected lifetime benefits. There are few workers in the 1917 birth cohort who worked for 30 years starting in 1951. For workers born in 1919 and later years, however, we can calculate expected lifetime OAI benefits at the 30-year mark relative to the lifetime compensation workers earned through the first 30 years of their covered employment. The sample is of course smaller than the samples that accumulated at least 10 years or at least 20 years of covered employment. Note that, as a percent of workers' discounted lifetime earnings, the benefit is somewhat lower after 30 years of employment than after 20 years' employment. For women, the benefit is still lower after 40 years of employment than after 30 years' employment (Figure 16). For men, however, the difference is so small that the results for 40 years of covered earnings are omitted from the chart; they are only slightly below the results at the 30-year mark.

A comparison of the lifetime benefit results for men and women shows that, for an identical number of years of covered earnings, women have higher expected benefits as a percentage of their earnings than do men. There are two reasons for the difference. First, the PIA benefit formula is redistributive in favor of workers with lower lifetime earnings. Since women on average have lower lifetime earnings than men, they will be favored by the redistributive tilt in the formula. Second, women have higher life expectancies than men. At any given age, women should expect to receive higher lifetime OAI benefits than a man born in the same year who is entitled to receive the same monthly benefit at age 65. For example, among men and women born in 1930 who are both 40 years old and entitled to receive the same retired worker benefit at age 65, a woman should expect to receive about 19 percent higher lifetime benefits than a man.

Figures 14 and 16 show that, measured as a percent of workers' lifetime covered compensation, expected OAI benefits declined for successive cohorts born after 1920, in the case

covered earnings and taxes. The error is sizeable for workers born before 1925 but is probably very small for workers born in the early and mid-1930s. 
of both women and men. This is partly an artifact of one of the limitations in our data. The EPUF annual earnings records begin only in 1951. We know the total amount but not the timing of covered earnings received before 1951. As a result, a sizeable portion of some workers' lifetime earnings are not counted in the calculation of the benefits-to-earnings ratio.

The lower panels in Figures 14 and 16 show the cumulative OASI taxes paid as a percent of the cumulative compensation earned after workers have been employed in covered jobs for 10, 20, 30, and 40 years. These results show, not surprisingly, that successive birth cohorts paid higher OASI tax rates over time. This follows from the fact that the OASI tax rate has been gradually raised over the past six decades. The charts also show that workers' cumulative tax rates are higher in the $20^{\text {th }}$ year of employment than in the $10^{\text {th }}$ year, are higher in the $30^{\text {th }}$ year than in the $20^{\text {th }}$ year, and are higher in the $40^{\text {th }}$ year than in the $30^{\text {th }}$ year. This result is also a logical implication of the gradual increase in OASI tax rates between 1951 and the present. Earners in a given birth cohort who have taxable income later on in their careers are likely to face a higher tax rate on those earnings compared with income earned at younger ages.

The cumulative net payoff on workers’ OASI contributions after 10, 20, 30, and 40 years of contributions is displayed in Figure 15 (for men) and Figure 17 (for women). The estimated net payoff fell for successive cohorts of both men and women born between 1917 and $1929 .^{10}$ The payoff for later male birth cohorts continued to fall, though more gradually than was the case for earlier birth cohorts. Among women, the net payoff gradually fell in later cohorts, but only for women whose covered employment lasted at least 30 years. Not surprisingly, the estimated net payoff for women born in a given year is higher than that for men born in the same year. For men born in 1935, the net payoff after 10 years of contributions was about 5.7 percent of the workers' accumulated Social-Security-covered compensation through that year. For women born in the same year, the net payoff after 10 years of contributions was about 8.5 percent of cumulative earnings through that year. ${ }^{11}$ As noted, women's estimated net payoff is higher than men's because they earn lower wages and derive greater benefit from the redistributive tilt in the PIA formula, and because they have longer life expectancy than men.

\footnotetext{
${ }^{10}$ For reasons already described, the exclusion of annual earnings amounts in years before 1951 will produce an underestimate of early career earnings and taxes and hence an overstatement of net expected returns for workers born between 1917 and 1935. The overstatement is largest for the oldest birth cohort.

${ }^{11}$ We calculated the average net return by calculating the net returns for each man or woman who accumulated at least 10 years of covered earnings and then computing the average net return for the men and women in the sample.
} 
One factor omitted from the calculation is that women, especially in the oldest birth cohorts, are more likely to receive OASI benefits as dependents or surviving spouses. This reduces the expected OAI benefits they will received based on their own OASI contributions.

The results displayed in Figure 15 show that males born after 1928 who accumulated at least 40 years of covered earnings obtained a negative net payoff on their OASI contributions. More precisely, their expected real return on contributions was lower than 1.5 percent. The same has been true of average male workers born after 1933 who accumulated at least 30 years of covered employment. In contrast, there are no birth cohorts or employment tenures with a negative payoff in Figure 17. If female workers obtained OAI pensions based solely on their own earnings records, the results in Figure 17 imply that on average these workers could expect to obtain a real return on their OASI contributions that exceeded 1.5 percent. For women with employment tenures of less than 30 years, workers' net real returns have comfortably exceeded 1.5 percent.

Figure 18 shows the relationship between workers’ net payoffs from their OASI contributions and their tenures in covered employment for average workers born in 1920, 1930, 1940, and 1945. Results for male workers in those birth cohorts are displayed in the top panel, while results for female workers are shown below. Workers' employment tenures are indicated by the horizontal axis, and their net real payoffs from OASI contributions are indicated on the vertical axis. Based on our calculations using earnings information in the EPUF dataset, average workers' net payoffs from their contributions fall continuously with each additional year of contributions. The falloff occurs for three reasons. First, the redistributive tilt in the PIA formula means that on average workers obtain a smaller payoff from their marginal contribution than they do on the average dollar of OASI contributions they made in earlier years of their career. Second, because of legislated changes in OASI tax rates, workers are likely to face a higher tax rate in later years of their careers than in earlier years. Finally, as our results in the previous section showed, within each birth year cohort, workers who accumulate more years of covered earnings tend to have higher average earnings per year worked compared with workers whose employment tenure is shorter (see Figure 11). The tabulations in Figure 18 show that women born in 1945 who accumulate 44 or more years of covered employment are the only female workers who obtain no net payoff on their OASI contributions. Among men born in the same year, those who accumulated 20 or more years of covered employment obtained zero or 
negative net payoffs on their contributions. Among men born in 1940, those accumulating 24 or more years of coverage obtained zero or negative net payoffs, and among men born in 1930, those who accumulated 38 or more years of coverage obtained zero or negative net payoffs.

Estimates of marginal net payoffs from contributions. The estimates in Figures 14-18 show the average expected payoffs that EPUF sample members received on their OASI contributions assuming a real discount rate of 1.5 percent. More pertinent for thinking about financial incentives is the marginal payoff workers obtain on their contributions for an additional year in covered employment. The formula for the marginal payoff is shown in equation 5 above. Figures 19 and 20 compare the average and marginal net payoffs for workers in the middle half of the lifetime earnings distributions who were born in 1920, 1935, and $1945 .{ }^{12}$ Results for men are displayed in Figure 19 and those for women in Figure 20. The heavy dark lines at the top of each panel show the average payoff obtained by workers based on their contributions through successive years of their employment tenures. For example, among men born in 1920 whose lifetime earnings placed them in the middle 50 percent of the AIME distribution, the average net payoff on workers' OASI contributions in their $11^{\text {th }}$ year of earnings was 8.0 percent of their cumulative earnings through that year. Among men born in the same year, those who accumulated at least 30 years of earnings had an average net payoff in their $30^{\text {th }}$ year of earnings equal to just 3.8 percent of their cumulative earnings through that year. For reasons already mentioned, the average payoff is lower at later stages of workers' careers than it is in the $10^{\text {th }}$ year of their careers.

The lower lines in each panel show the relationship between workers' marginal net payoff on OASI contributions and their tenure in Social-Security-covered employment. As expected, the marginal net payoff is sharply below the average net payoff. For men born in 1920, for example, the marginal net payoff for earnings accumulated in the $11^{\text {th }}$ year of an average workers' career was just 0.6 percent compared with the average net payoff of 8.0 percent. After the $12^{\text {th }}$ year of workers' tenure in covered employment, the marginal net payoff

\footnotetext{
${ }^{12}$ Our sample consists of workers who accumulated enough earnings credits to be eligible for an OAI pension. After calculating workers' AIMEs based on their covered earnings through age 61, we divided workers in each birth cohort (separately for men and women) into three groups - those in the bottom one-quarter of the AIME distribution, those in the middle 50 percent of the AIME distribution, and those in the top quarter of the AIME distribution. The results for the middle 50 percent of the AIME distribution are displayed in Figures 19 and 20. Results for the bottom and top quarters of the AIME distribution are presented in the appendix.
} 
is slightly negative. After the $26^{\text {th }}$ year of employment the net payoff turns sharply negative. The reason for the sharp falloff is that only the 26 years of highest indexed earnings were counted in determining the AIME for workers born in 1920. Consequently, the $27^{\text {th }}$ year of covered earnings affected workers' benefits only if it was greater than the lowest indexed earnings amount in the worker's previous 26 years of earnings. For workers born in 1935 and 1945, the discontinuous drop in the marginal payoff from additional OASI contributions occurs after the $35^{\text {th }}$ year of employment tenure. Workers born in those years used the highest 35 years of indexed earnings to determine OAI benefits.

It is evident in Figure 19 that men in the middle ranks of the AIME distribution derive zero or negative marginal payoffs from their OASI contributions starting soon after they have accumulated enough earnings credits to become entitled to an OAI pension. By the $45^{\text {th }}$ year of employment tenure, virtually the entire OASI contribution represents a pure tax on workers' earnings. The marginal payoff for female OASI contributors, displayed in Figure 20, is higher than it is for men, but even among women the marginal payoff is negligible or turns negative at job tenures of just 20 years. For women with job tenures of 45 years, nearly the entire OASI tax contribution represents a pure tax on workers' earnings. Workers who earn lower lifetime wages than workers in the middle half of the AIME distribution obtain higher payoffs from their marginal contributions, but workers who earn higher lifetime wages receive even lower marginal returns than those displayed in Figures 19 and 20 (see appendix).

The pattern of net and average returns we have inferred from the EPUF earnings records is a natural consequence of the redistributive nature of the OAI benefit formula. If benefits were strictly proportional to indexed lifetime earnings, we would see a gradual decline in the average and marginal payoffs on OASI contributions for successive cohorts, because later cohorts have faced increasing lifetime contribution rates. We would also see a modest decline in payoff rates with additional years of employment tenure within a single birth cohort, because in all cohorts we examine workers have faced higher OASI tax rates as they grew older. However, we would not see the sizeable declines in marginal and average payoff rates per year of job tenure that are traceable to the progressive PIA formula. For workers who accumulate the minimum required quarters of coverage, the PIA formula confers an advantage on workers with short careers rather than long ones, and it confers an advantage on workers with low rather than high average earnings in the years in which they have earned income. 


\section{Conclusion}

Compared with other sources of information about U.S. earnings patterns, the EPUF has distinctive strengths and weaknesses. Its main strength is that it permits us to look at individual workers' earnings patterns over a substantial portion of their careers. In addition, the sample is large enough to yield considerable precision in estimation. Further, the annual earnings reports are likely to be highly reliable compared with earnings reported in household surveys. The limitation of the file is the absence of earnings information for jobs not covered by Social Security and for wages and self-employment income above the annual earnings cap. Secondarily, the file also lacks crucial demographic information, including data on the presence and ages of dependents, as well as actual Social Security benefits, the age of disability onset, and the age at death of the workers in the sample.

Nonetheless, the availability of earnings information covering full careers permits us to examine relationships that are invisible in files covering much shorter time spans. One striking relationship uncovered in this paper is the link between age of entry into employment and workers' earnings in the middle of their careers. Young men and women who enter the workforce at age 15 earn considerably higher labor incomes during their 40s than do men and women who enter the workforce after age 20. Similarly, workers who exit the workforce between 60 and 65 tend to earn higher labor incomes in the middle of their careers than workers who exit in their 50s. For workers who attained age 65 in the 1980s, those who retired after age 65 tended to have somewhat lower mid-career earnings than those who exited the workforce between ages 60 and 65. For workers who attained 65 after the early 1990s, however, we see little falloff in the mid-career earnings of workers who exit the workforce after 65 . Instead, workers who leave covered employment after age 62 had uniformly higher mid-career earnings than workers born in the same year who left the workforce before 62. This pattern suggests that workers with higher mid-career earnings may be leading the charge toward later workforce exit.

Though the EPUF annual earnings data have limits, especially for workers earning consistently high wages, they permit us to explore the relationship between workers' annual earnings level and the duration of workers' careers. For each birth cohort and for both sexes, we document the strong statistical relationship between the two variables. Workers who have high levels of earnings in years when they are employed also tend to have the longest careers. Our findings on the statistical association between early labor force entry and average mid-career 
earnings and on the association between late labor force exit and average mid-career earnings show why the relationship might exist. People who start to work at younger ages earn higher incomes at the peak of their careers, and workers with higher peak career earnings tend to retire at more advanced ages.

If Social Security retirement benefits were proportional to workers' career earnings, workers with longer careers would tend to receive retirement benefits that are proportionately higher than workers born in the same year who have shorter careers. That is because workers with longer careers tend to earn higher wages in years when they are employed than do workers who have shorter careers. Workers who have higher earnings in a given year would also tend to receive retirement benefits that are proportionately larger than workers the same age who have lower earnings in that year. The reason, again, is that workers who earn higher wages tend to have longer careers than workers born in the same year who earn lower wages. The PIA formula is explicitly redistributive, however. Our tabulations, not surprisingly, show that workers with longer careers receive benefits that represent a smaller percentage of their career earnings than is the case for workers with shorter careers. Workers earning above-average wages tend to receive lifetime benefits that are smaller as a percentage of their lifetime earnings than workers born the same year who earn lower wages. These calculations ignore dependents' and survivors' benefits and the positive association between average earnings and workers' life expectancies. To take those factors into account, however, requires more data on workers and their dependents than is available in the EPUF file. 


\section{References}

Bell, Felicitie C., and Michael L. Miller. 2005. Life Tables for the United States Social Security Area, 1900-2100. Actuarial Study No. 120. Office of the Chief Actuary. Washington, DC: U.S. Social Security Administration.

Bosworth, Barry, Gary Burtless, and Eugene Steuerle. 2000. "Lifetime Earnings Patterns, the Distribution of Future Social Security Benefits, and the Impact of Pension Reform.”Social Security Bulletin 63(4): 74-98.

Compson, Michael. 2011. “The 2006 Earnings Public-Use Microdata File: An Introduction.” Social Security Bulletin 71(4): 33-59.

U.S. Social Security Administration. 2013. Annual Statistical Supplement to the Social Security Bulletin, 2012. Washington, DC.

Waldron, Hilary. 2007. “Trends in Mortality Differentials and Life Expectancy for Male Social Security-Covered Workers, by Socioeconomic Status.” Social Security Bulletin 67(3): 128.

. 2013. "Mortality Differentials by Lifetime Earnings Decile: Implications for Evaluations of Proposed Social Security Law Changes.” Social Security Bulletin 73(1): 137. 
Figure 1. Age Profile of Median Capped Earnings in Selected Years

Male Median Earnings (2010 \$)

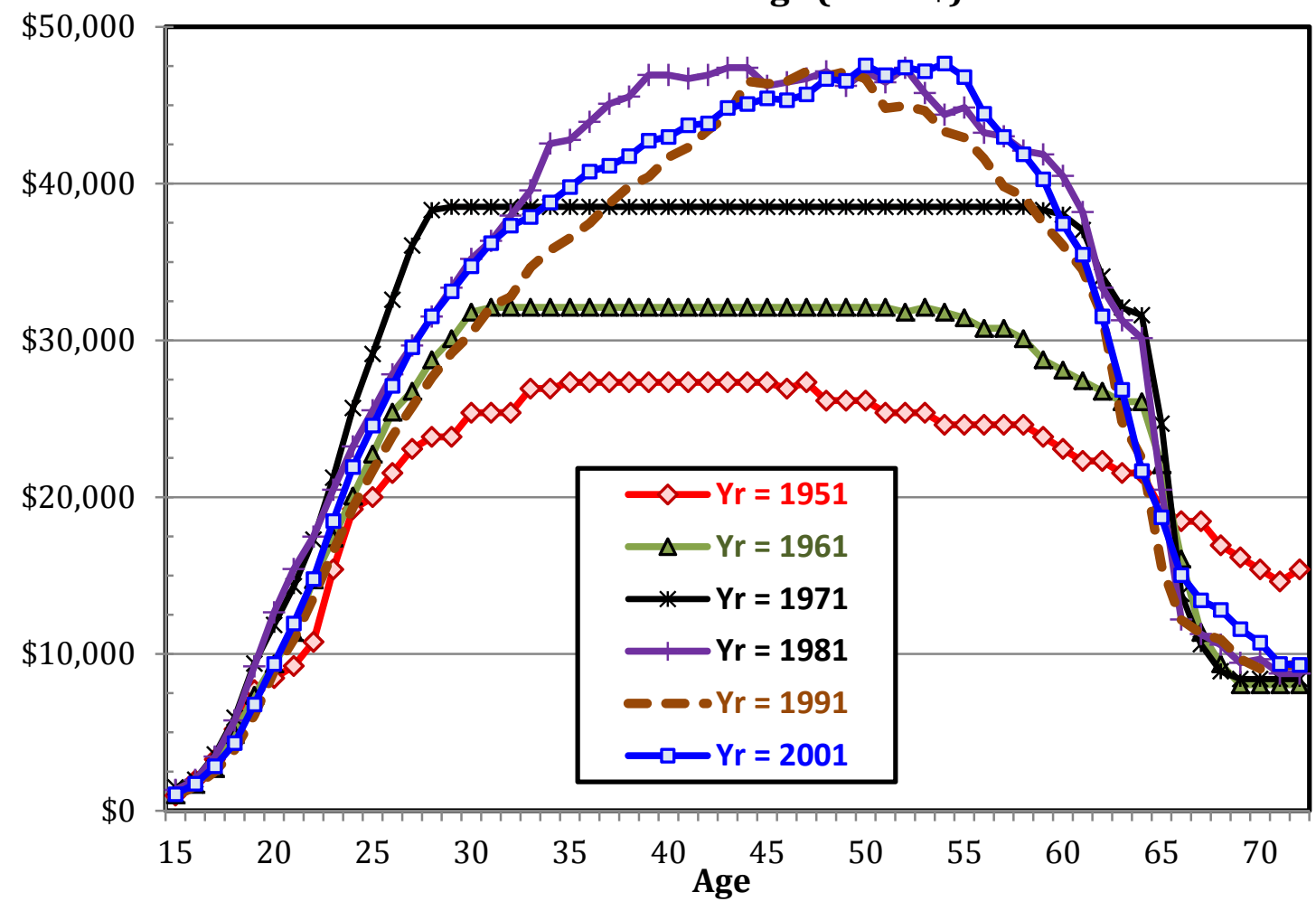

Female Median Earnings (2010 \$)

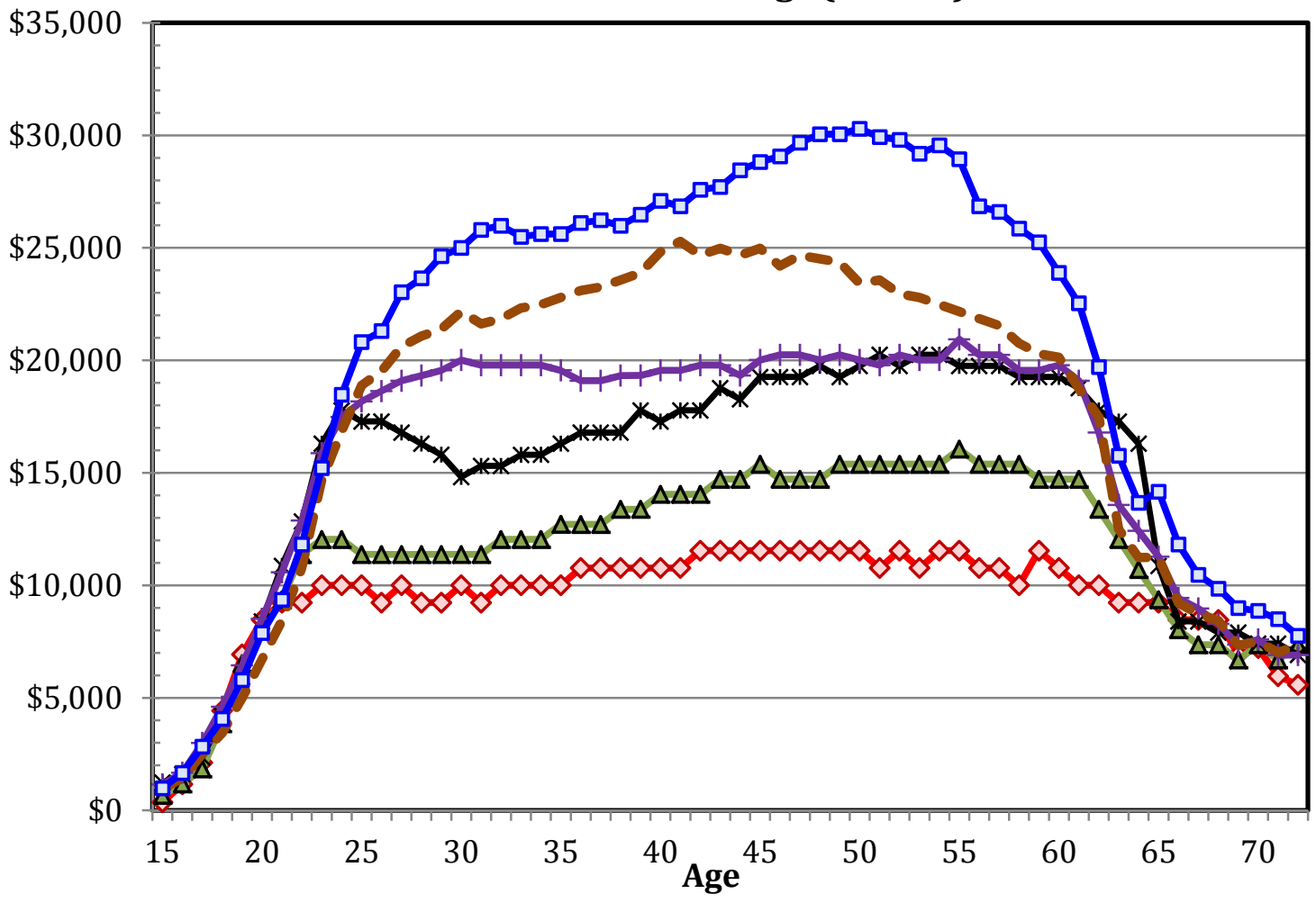


Figure 2. Mean, Median, and Maximum Capped Earnings of Workers Born in 1936, by Year of Age

\section{Men}

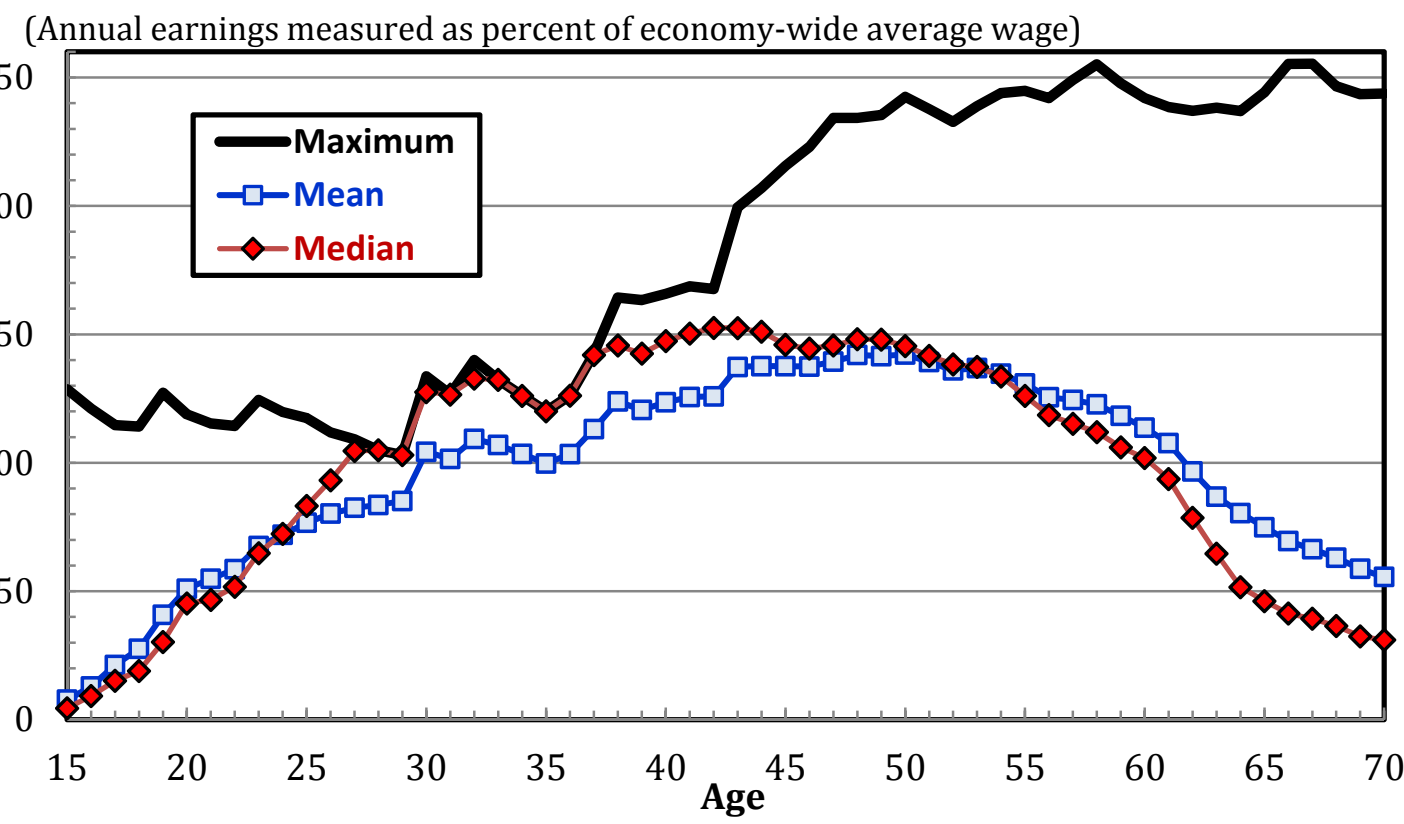

\section{Women}

(Annual earnings measured as percent of economy-wide average wage)

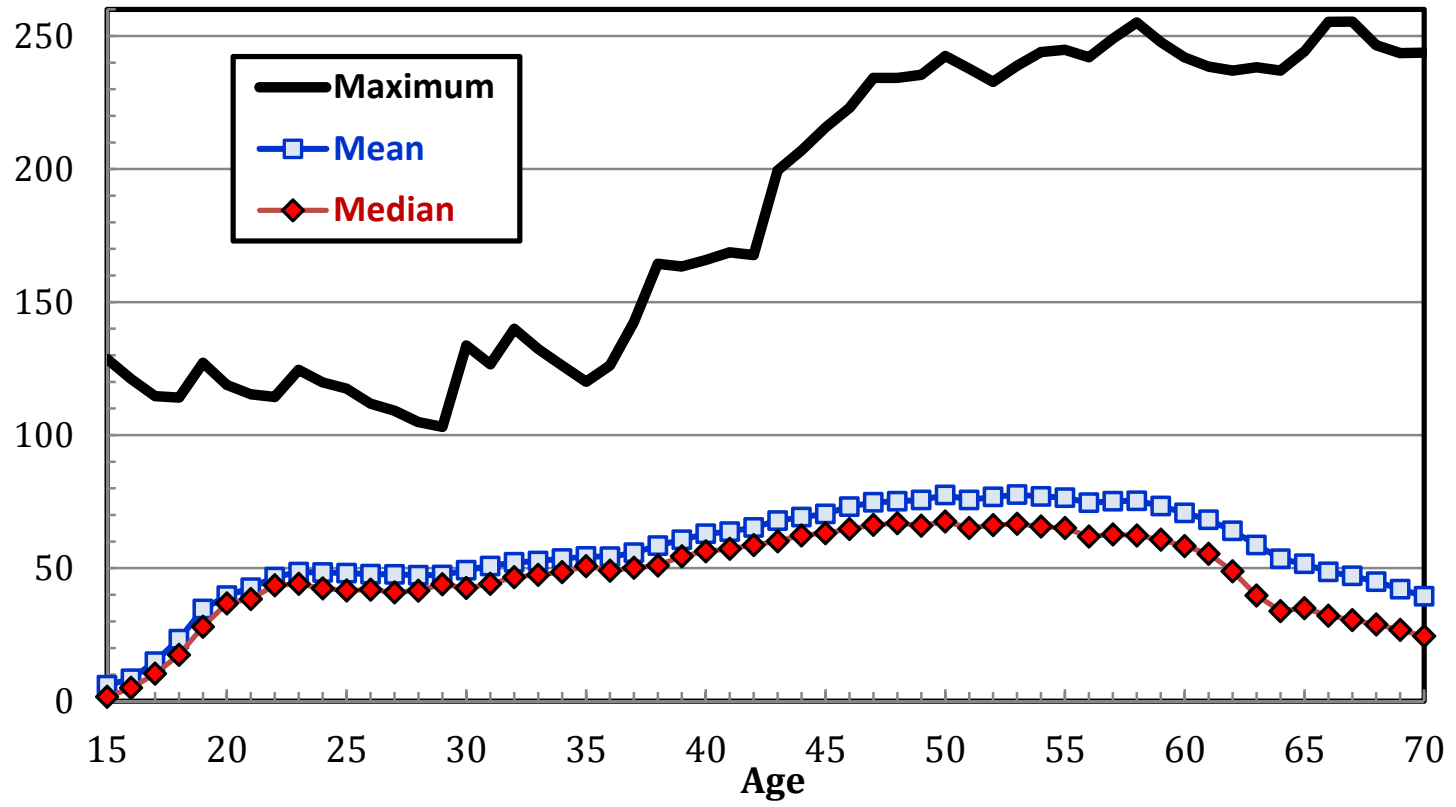


Figure 3. Age-Earnings Profiles of Successive Birth Cohorts

Male median earnings at indicated ages

(Economy-wide average wage in year $=100)$

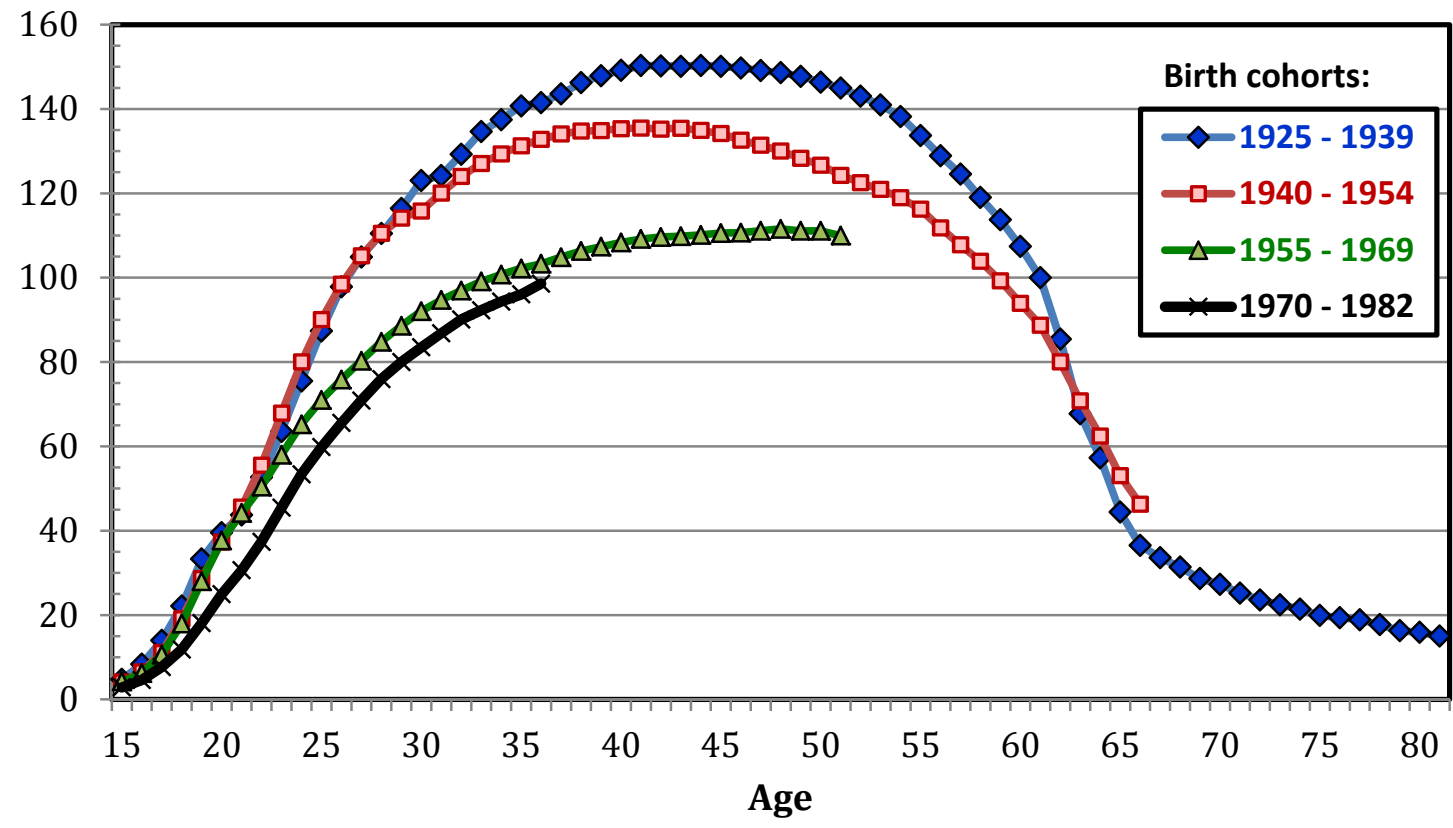

Female median earnings at indicated ages

$($ Economy-wide average wage in year $=100)$

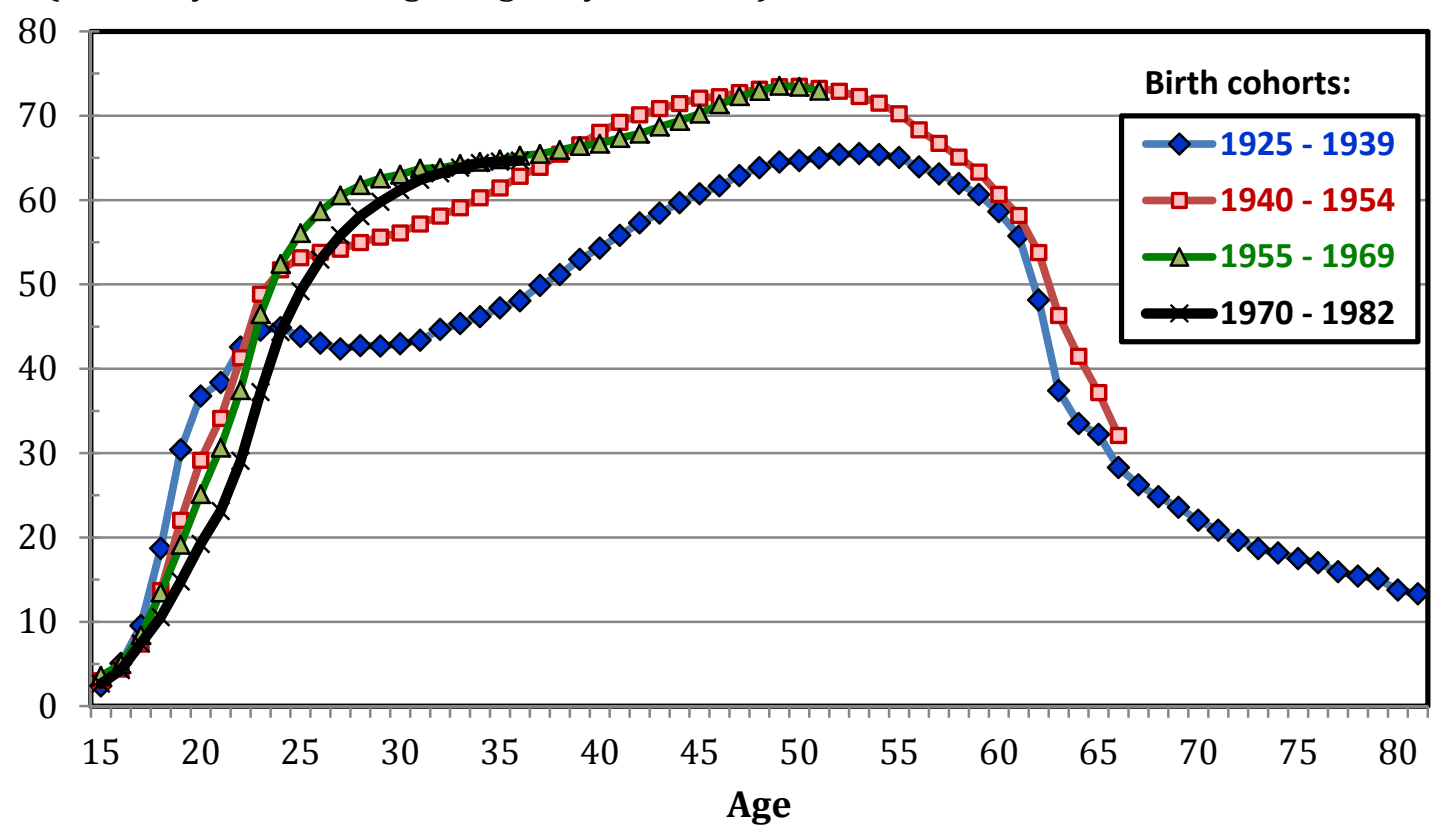


Figure 4. Female Median Earnings as a Fraction of Male Median Earnings at Successive Ages, by Birth Cohort

Female median wage as a percent of male median wage at the indicated age

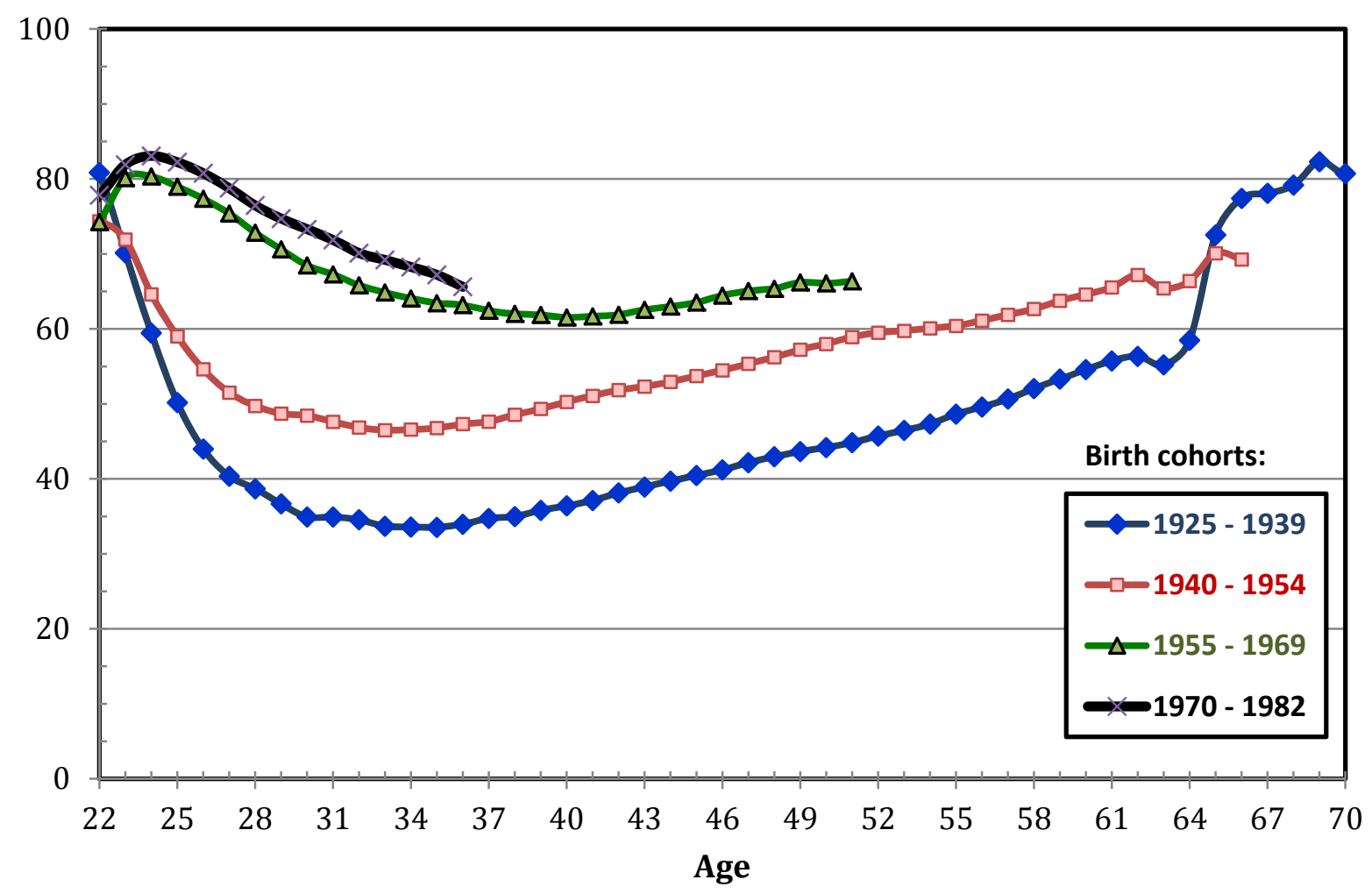


Figure 5. Ratio of Female to Male Earnings at Selected Positions of the Female and Male Earnings Distributions, 1951-2006

Ratio of female to male earnings at indicated position of the distribution, 1951-2006

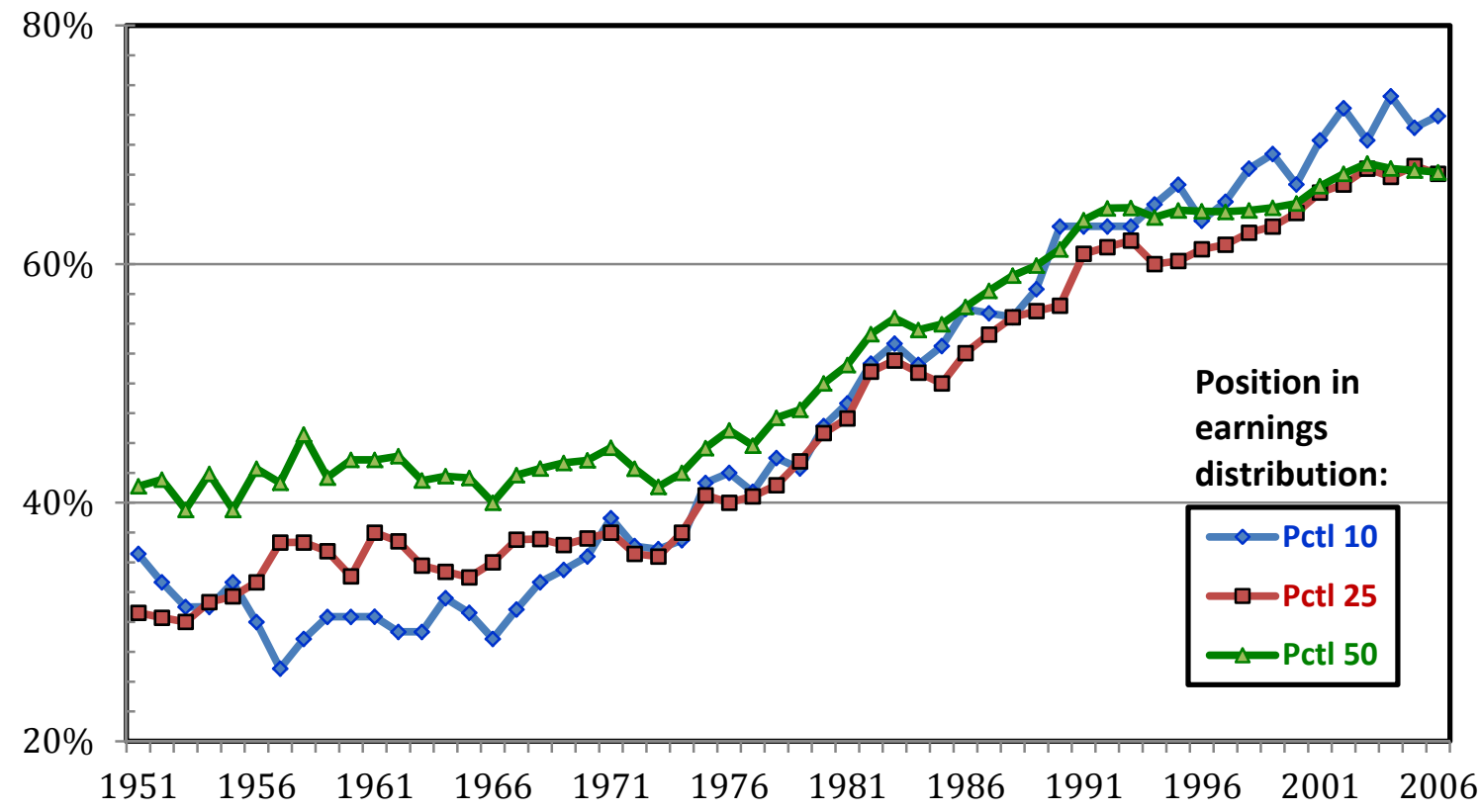

Ratio of female to male earnings at indicated position of the distribution, 1975-2006

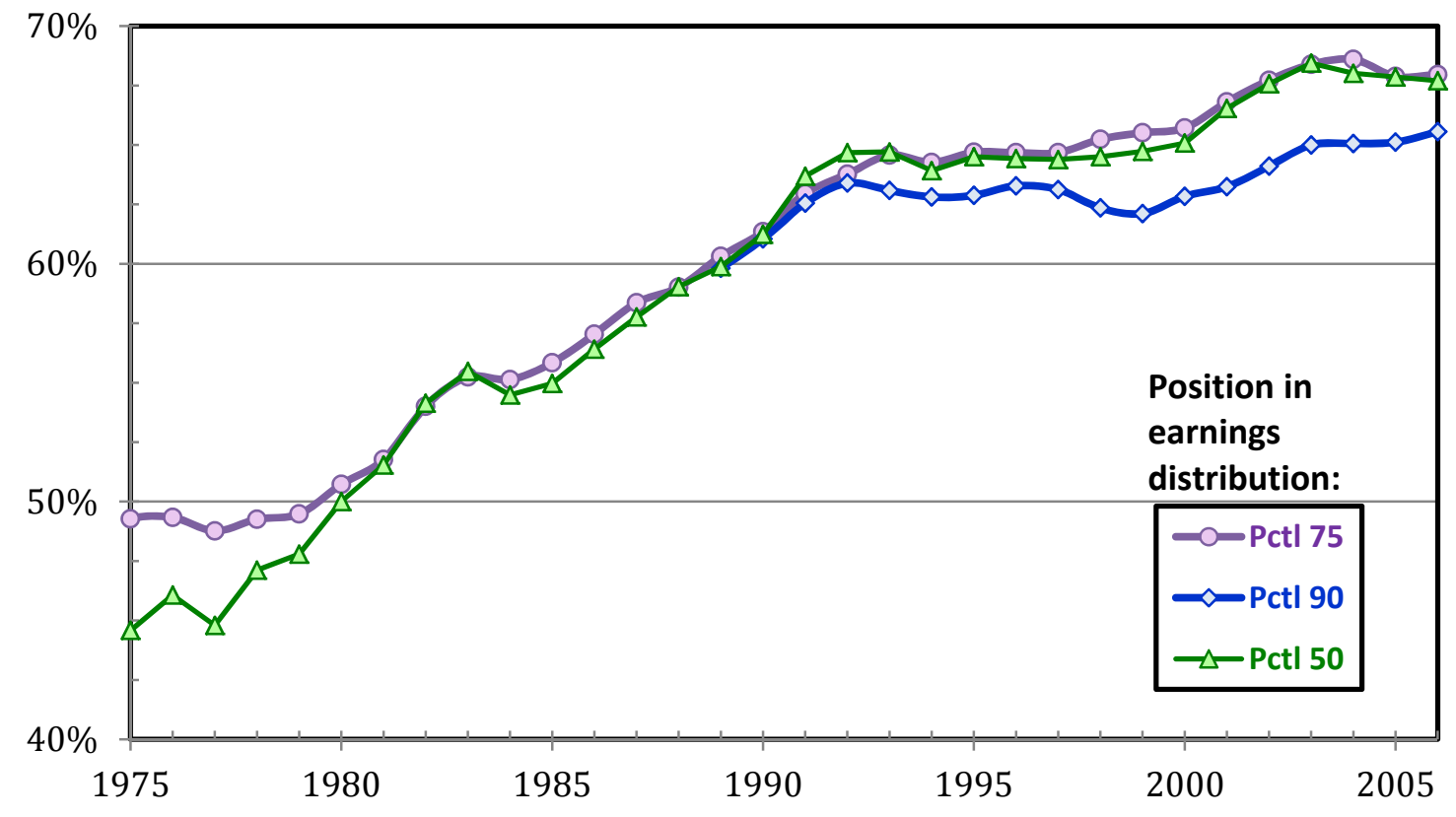


Figure 6. Average Age of First Social-Security-Covered Earnings, by Birth Cohort

Age in years of first earnings

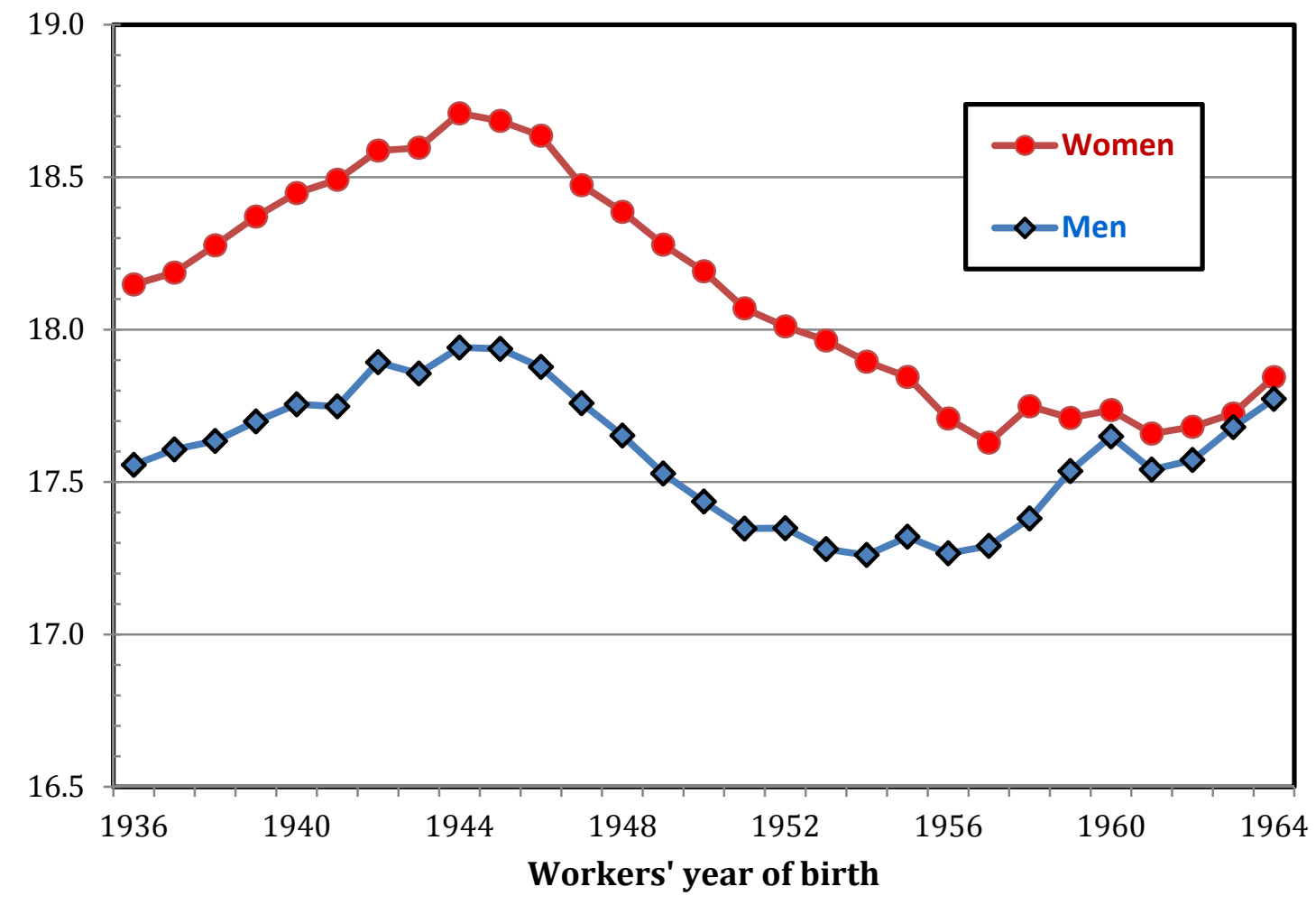

Note: Youngest age with recorded earnings on EPUF is 15. Earnings received by workers under 15 are not reported in the file. To be included in estimation sample, workers must report covered earnings by age 30 . 
Figure 7. Frequency Distribution of Years with Covered Earnings among Workers Born between 1933 and 1944, by Gender

Percent of all workers who have at least 1 year of Social-Securitycovered earnings

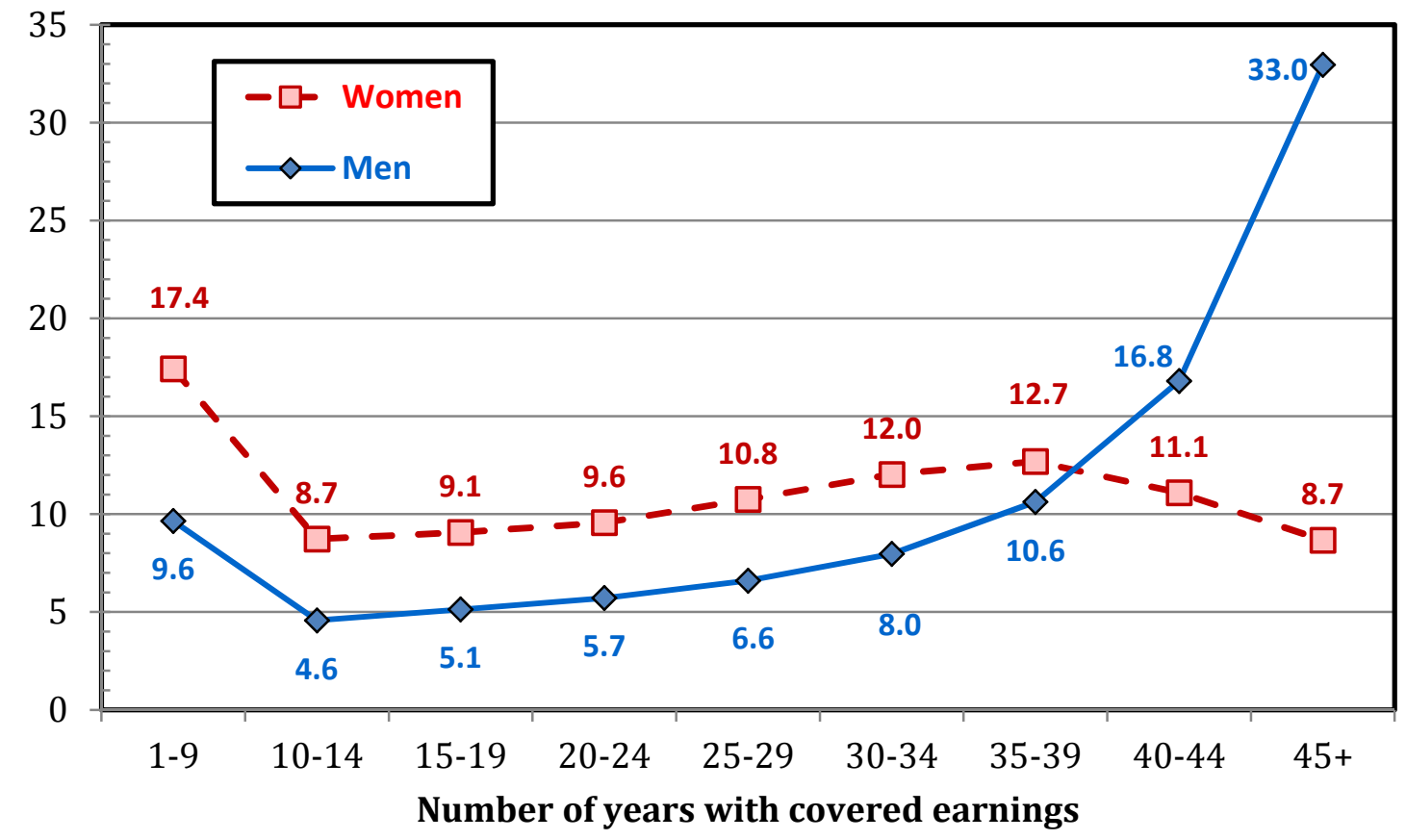


Figure 8. Frequency Distribution of Workers' Last Age with Covered Earnings, Selected Birth Cohorts

\section{Men}

Percent of all workers with last earnings records between ages 50 and 70

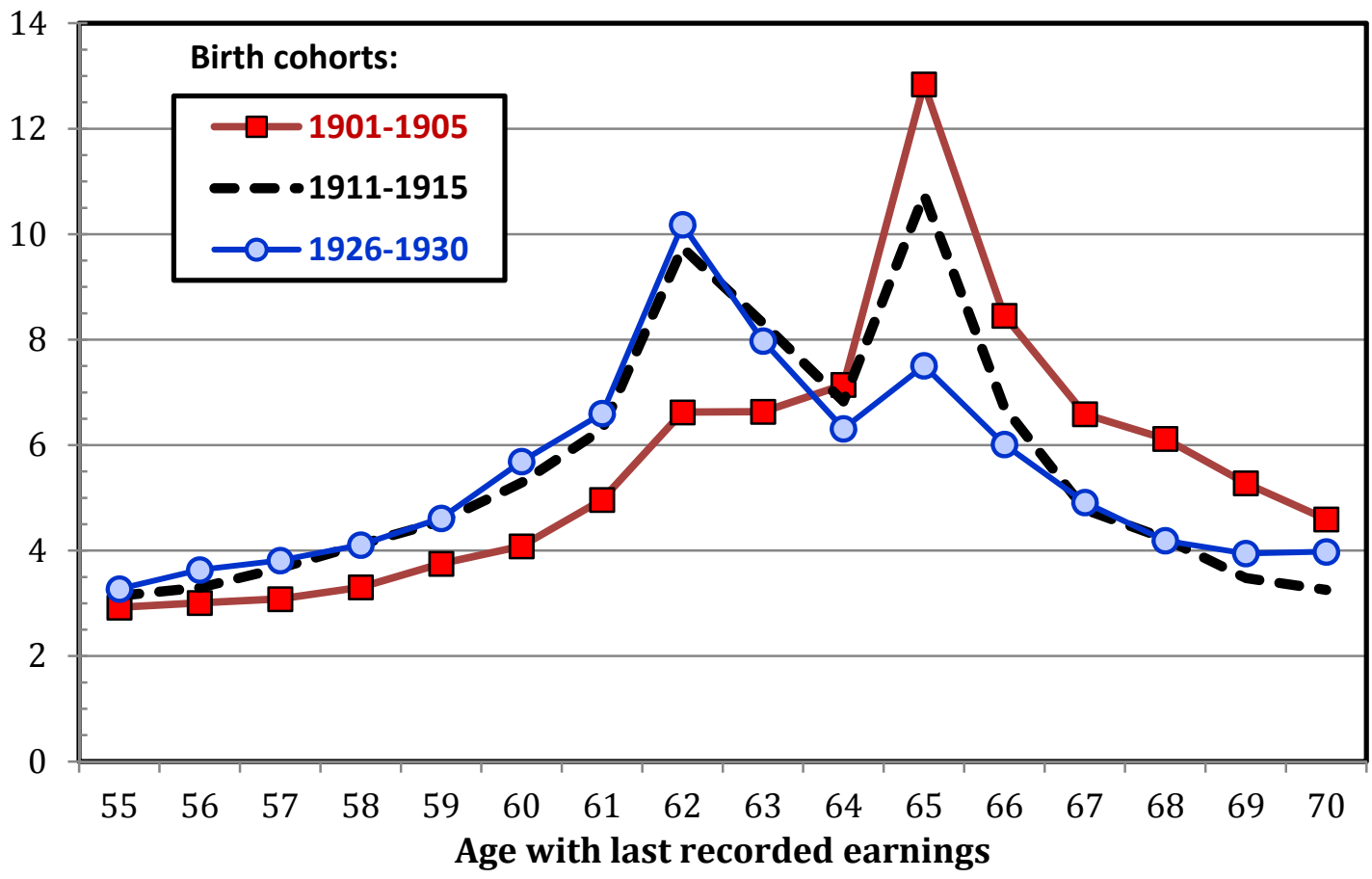

Women

Percent of all workers with last earnings records between ages 50 and 70

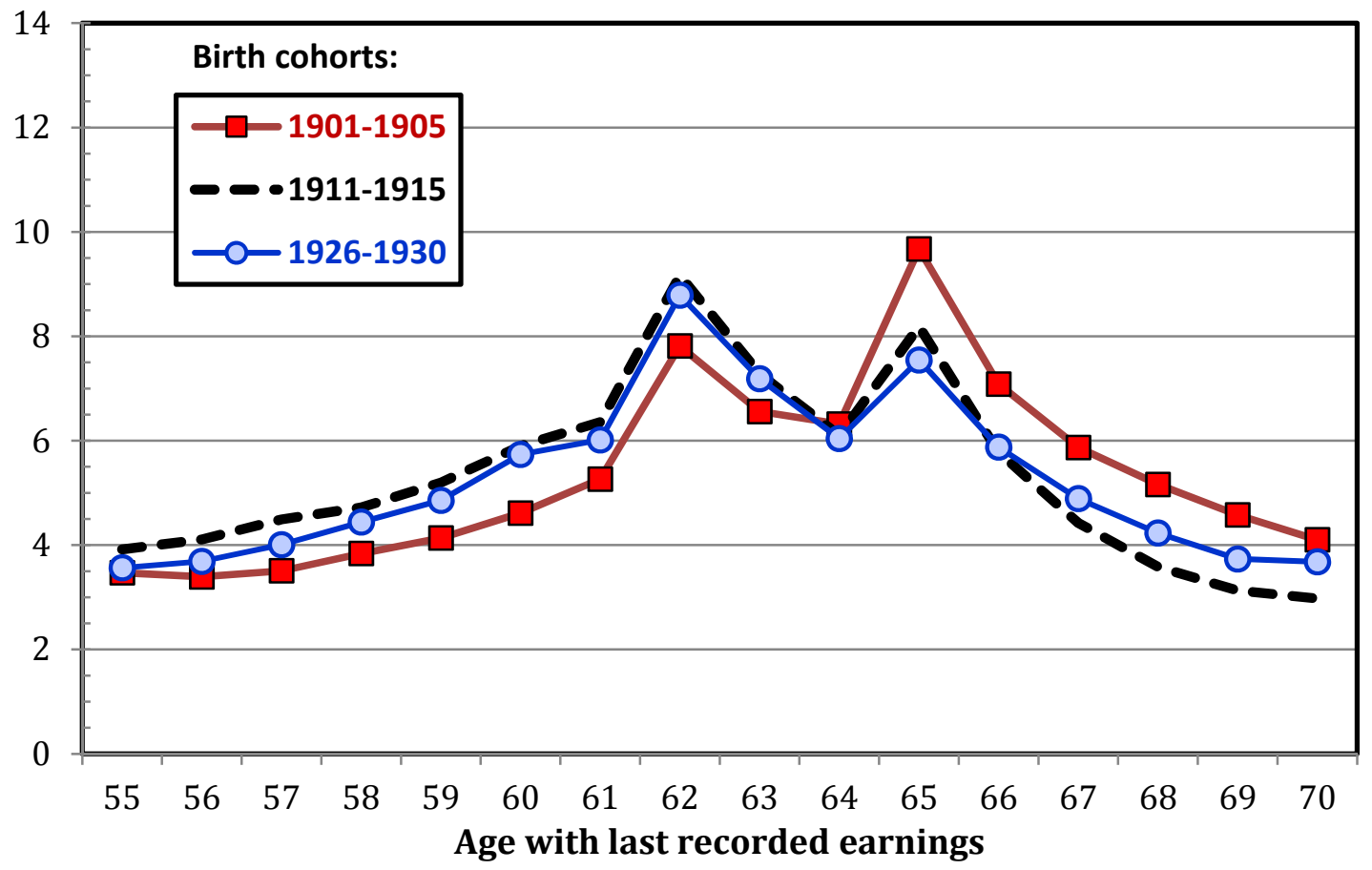


Figure 9. Relation between Age at Workforce Entry and Average Earnings between Ages 40 and 49 among Workers Born between 1936 and 1950

\section{Male workers}

Earnings measured as a percent of economy-wide wage*

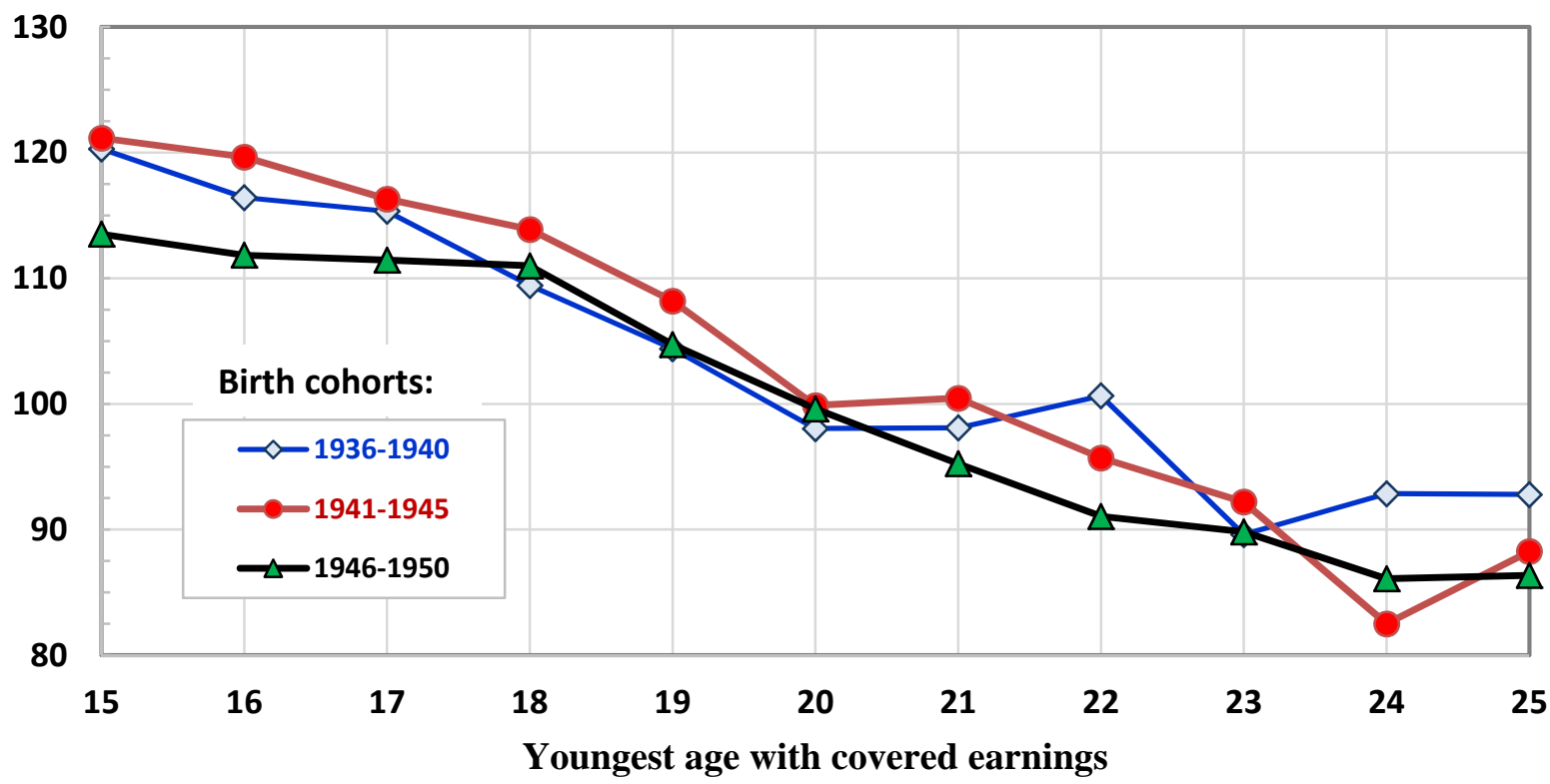

\section{Female workers}

Earnings measured as a percent of economy-wide wage*

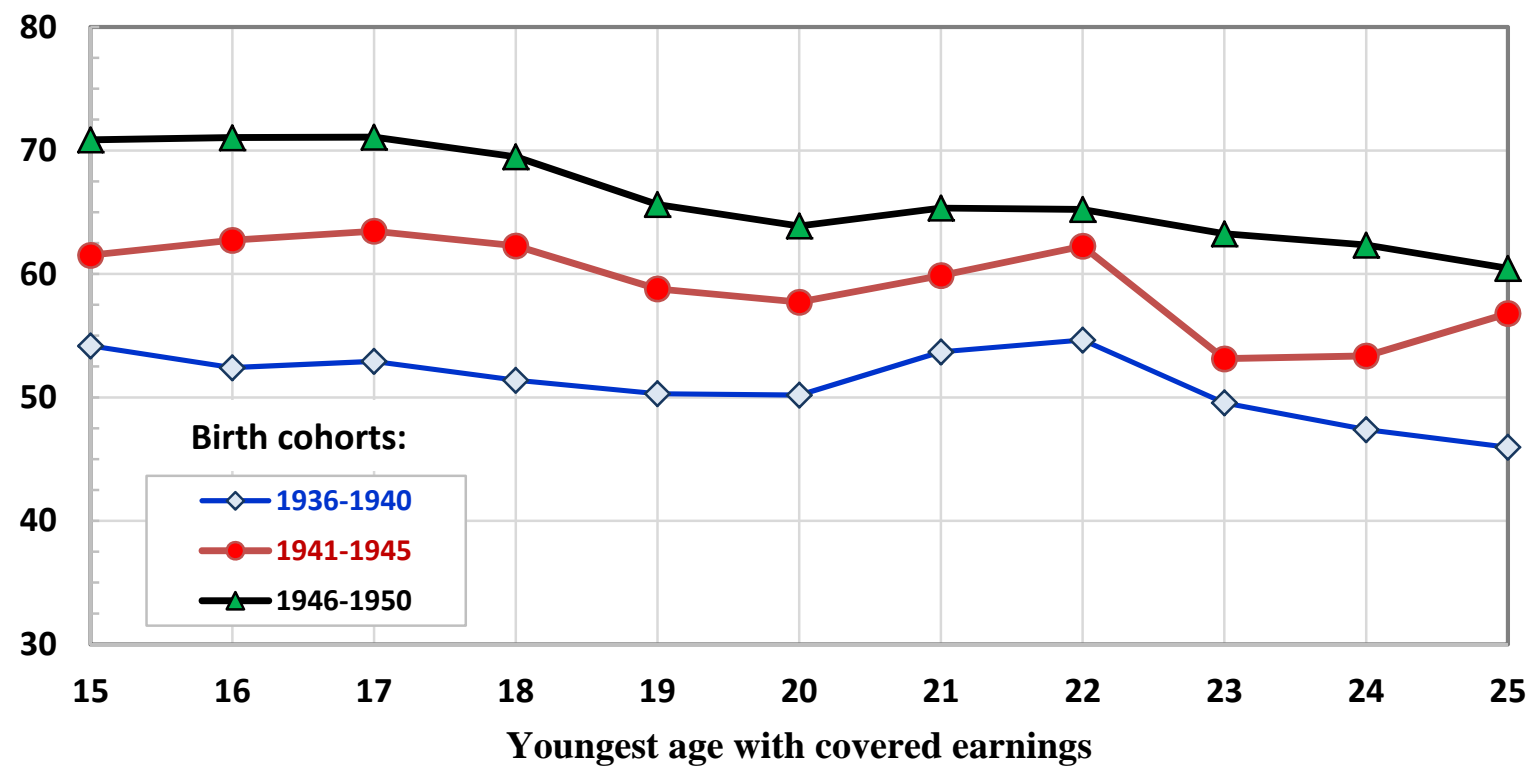

* Workers' earnings in each year from age 40 through age 49 are measured as a percent of the economy-wide average wage for the calendar year. The resulting average of those percentages is then used to determine each worker's average earnings between ages 40 to 49 .

Note: To be included in estimation sample, workers must have at least 10 years of Social-Securitycovered earnings. 
Figure 10. Relation between Age at Workforce Exit and Average Earnings between Ages 40 and 49 among Workers Born between 1921 and 1935

\section{Male workers}

Earnings measured as a percent of economy-wide wage*

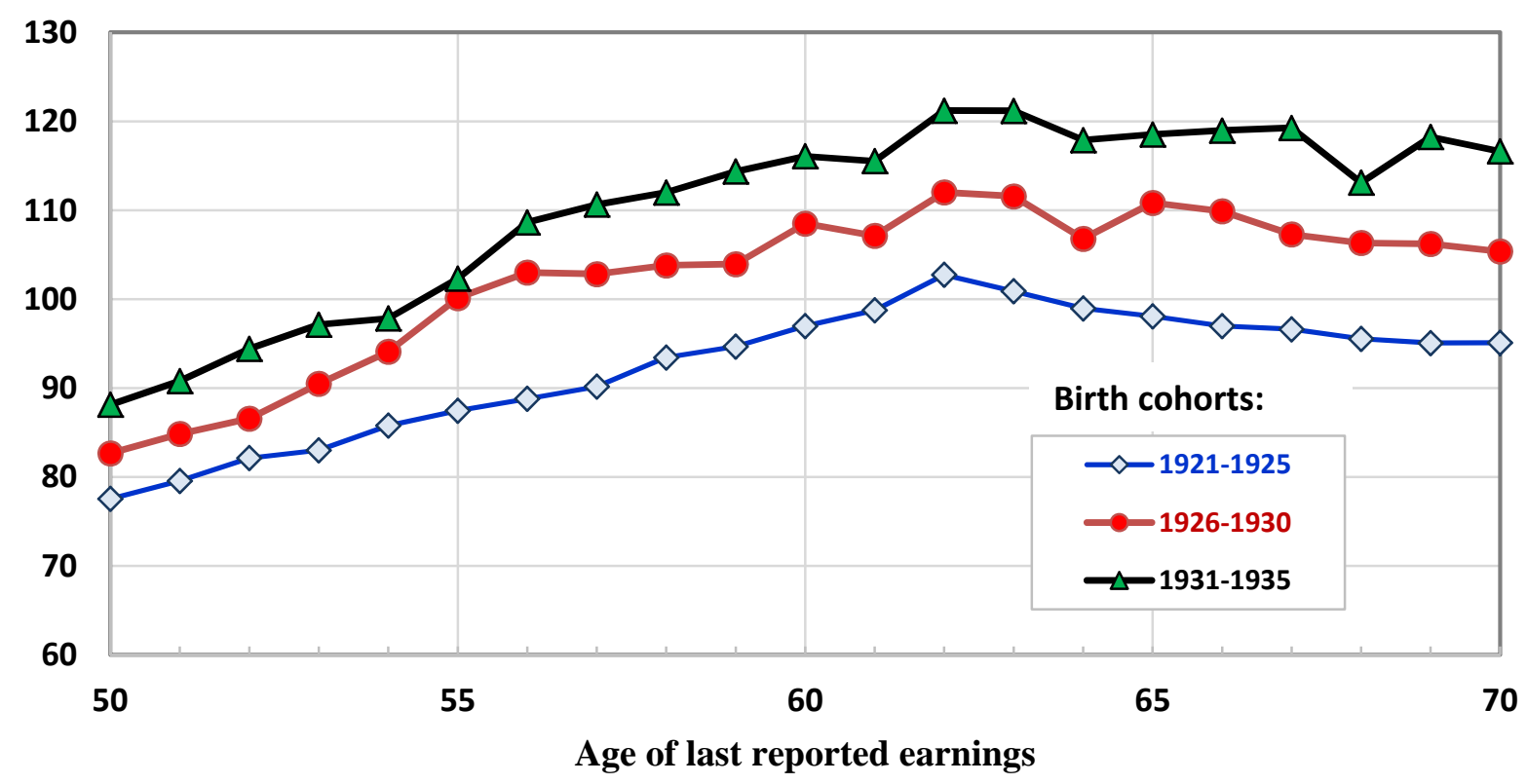

\section{Female workers}

Earnings measured as a percent of economy-wide wage*

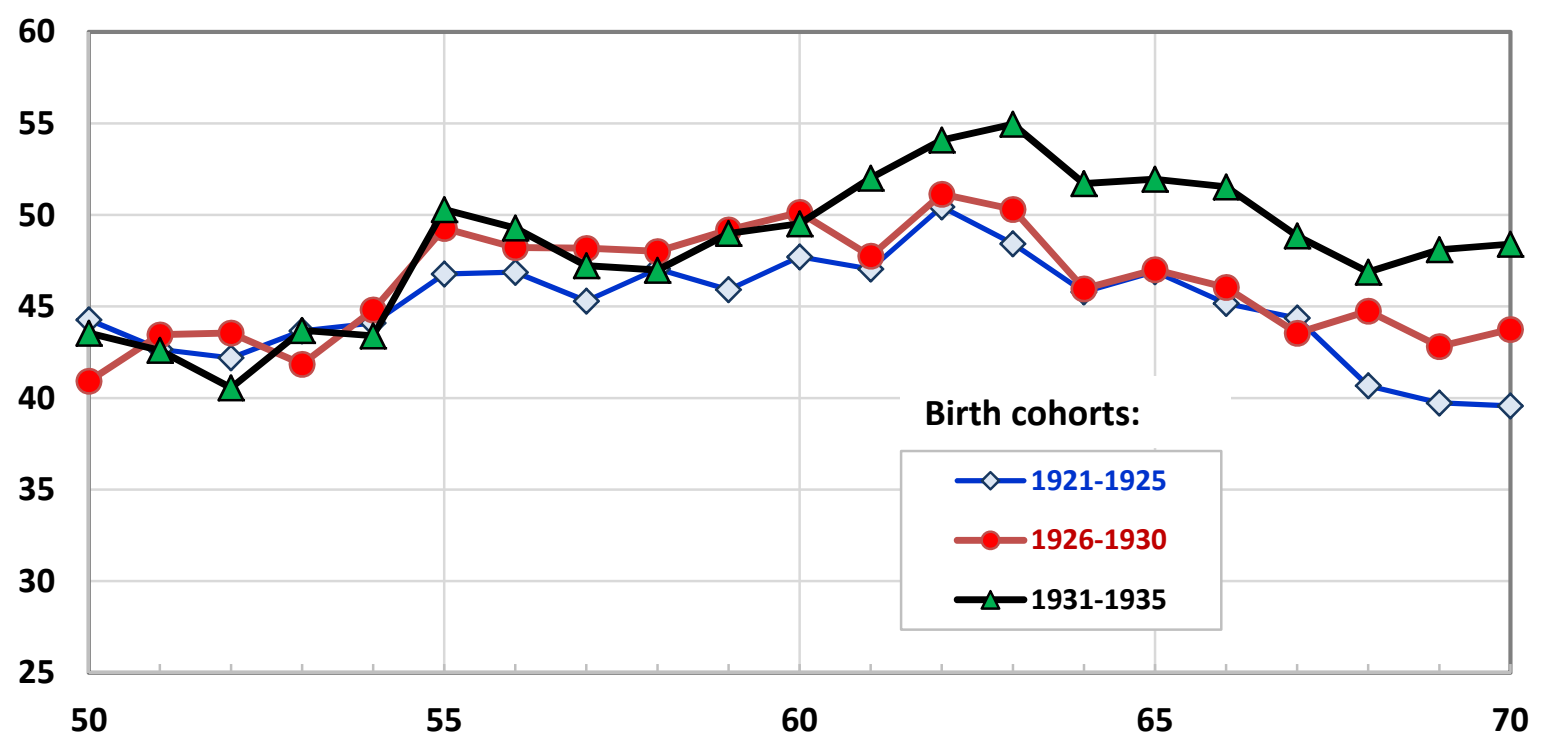

Age of last reported earnings

* Workers' earnings in each year from age 40 through age 49 are measured as a percent of the economy-wide average wage for the calendar year. The resulting average of those percentages is then used to determine each worker's average earnings between ages 40 to 49 .

Note: To be included in estimation sample, workers must have at least 10 years of Social-Securitycovered earnings. 
Figure 11. Relation between Average Annual Earnings and Number of Years with Positive Covered Earnings, Workers in Selected Birth Cohorts

Annual earnings of male workers

$(2010$ \$)

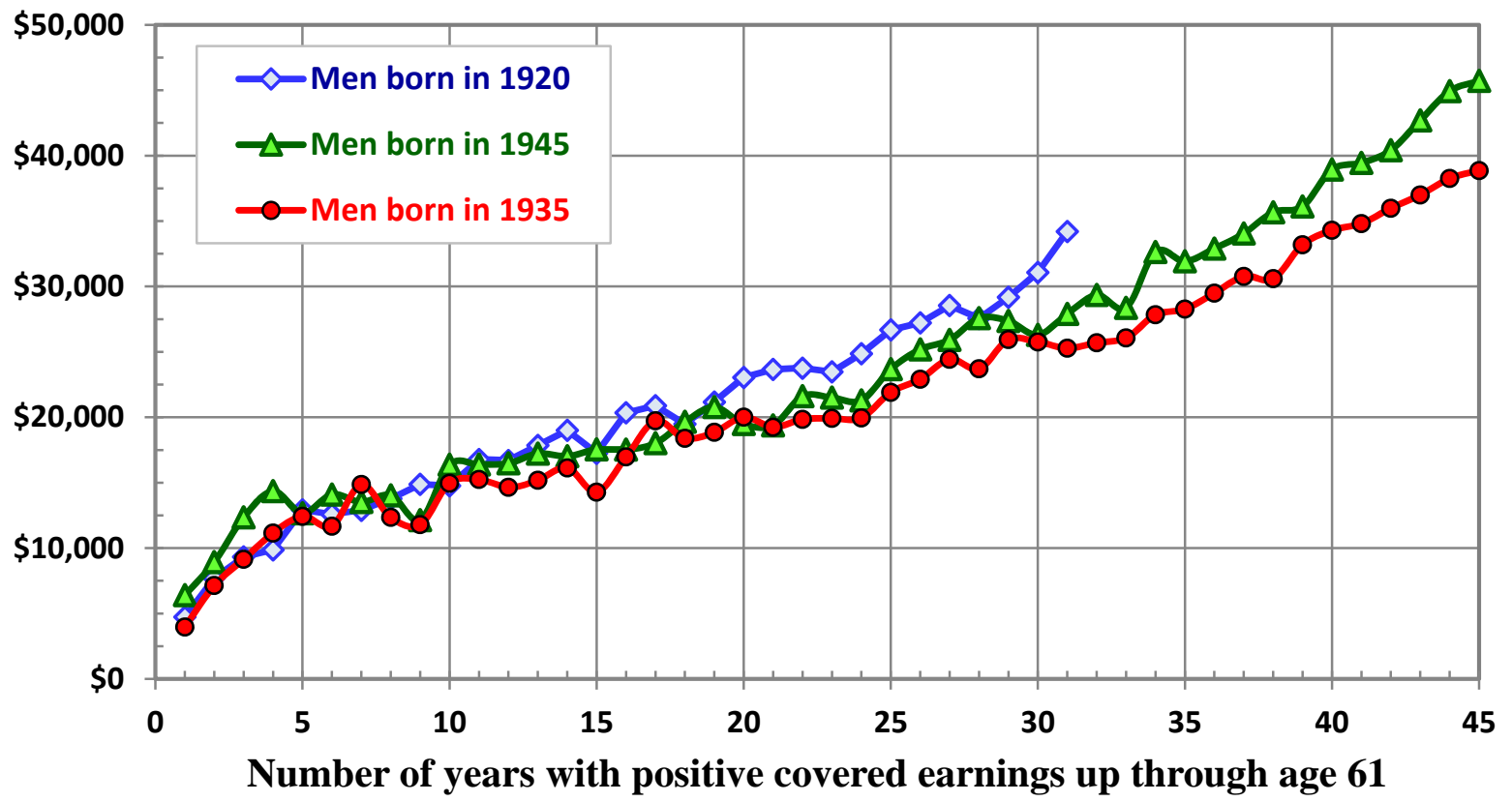

Annual earnings of female workers

(2010 \$)

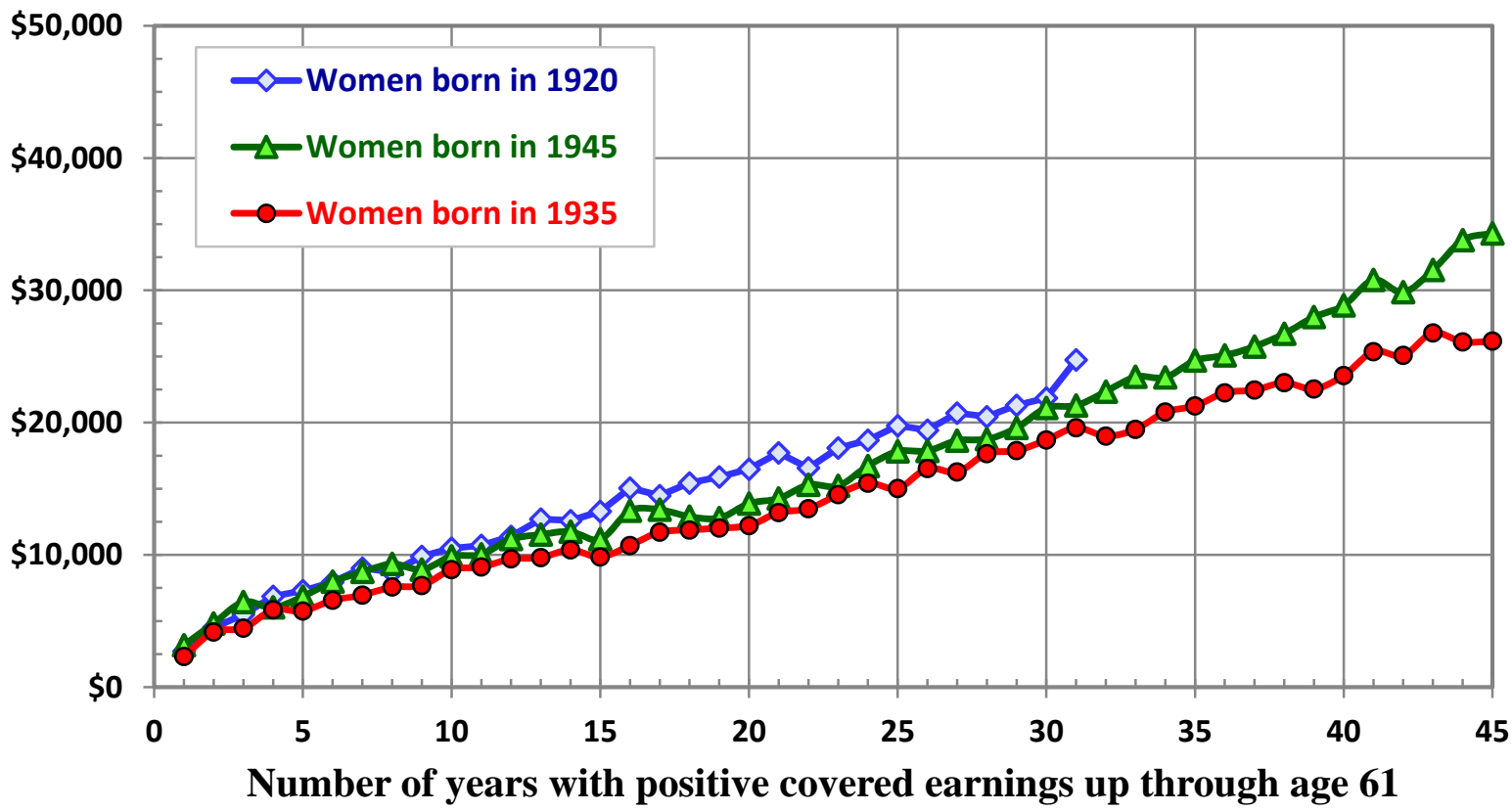

Note: The average earnings amounts shown in the figure reflect average earnings in calendar years when workers report a positive earnings amount. To be included in estimation sample, workers must have at least one year of Social-Security-covered earnings. 
Figure 12. Relation between Average Annual Earnings and Number of Years with Positive Covered Earnings, by Birth Year Cohort

\section{Increase in average earnings*}

(2010\$)

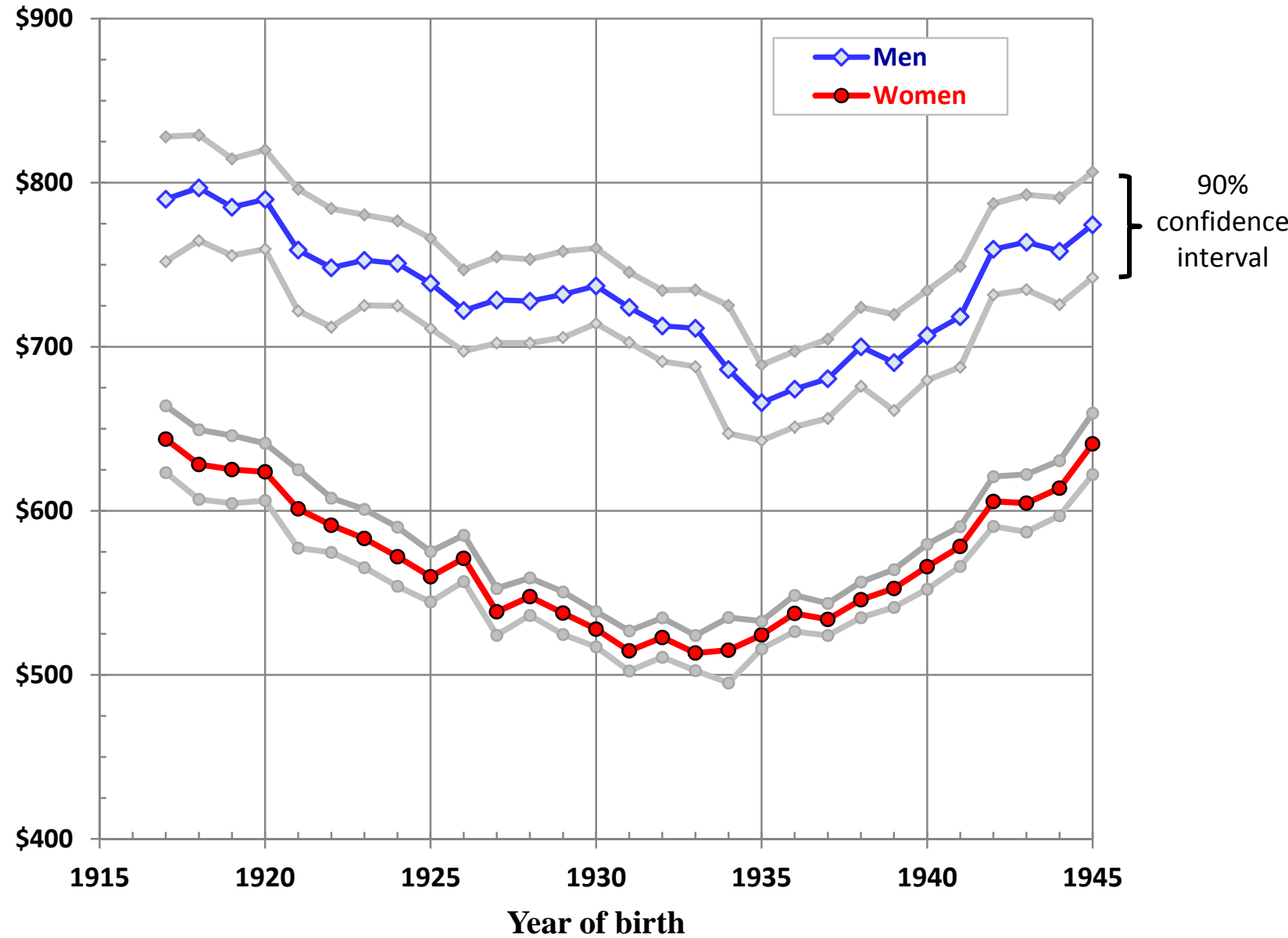

* The increase in average earnings is the slope coefficient of a regression of average annual lifetime earnings on number of years in which a worker has positive covered earnings. Average annual earnings reflect workers' average earnings only in those years when they have positive earnings. Regressions were separately run for each sex and birth year cohort.

Note: To be included in estimation sample, workers must have at least one year of Social-Securitycovered earnings. 
Figure 13. Relation between Average Indexed Monthly Earnings (AIME) and Number of Years with Positive Covered Earnings in Selected Birth Cohorts

Average indexed monthly earnings of male workers $(2010$ \$)

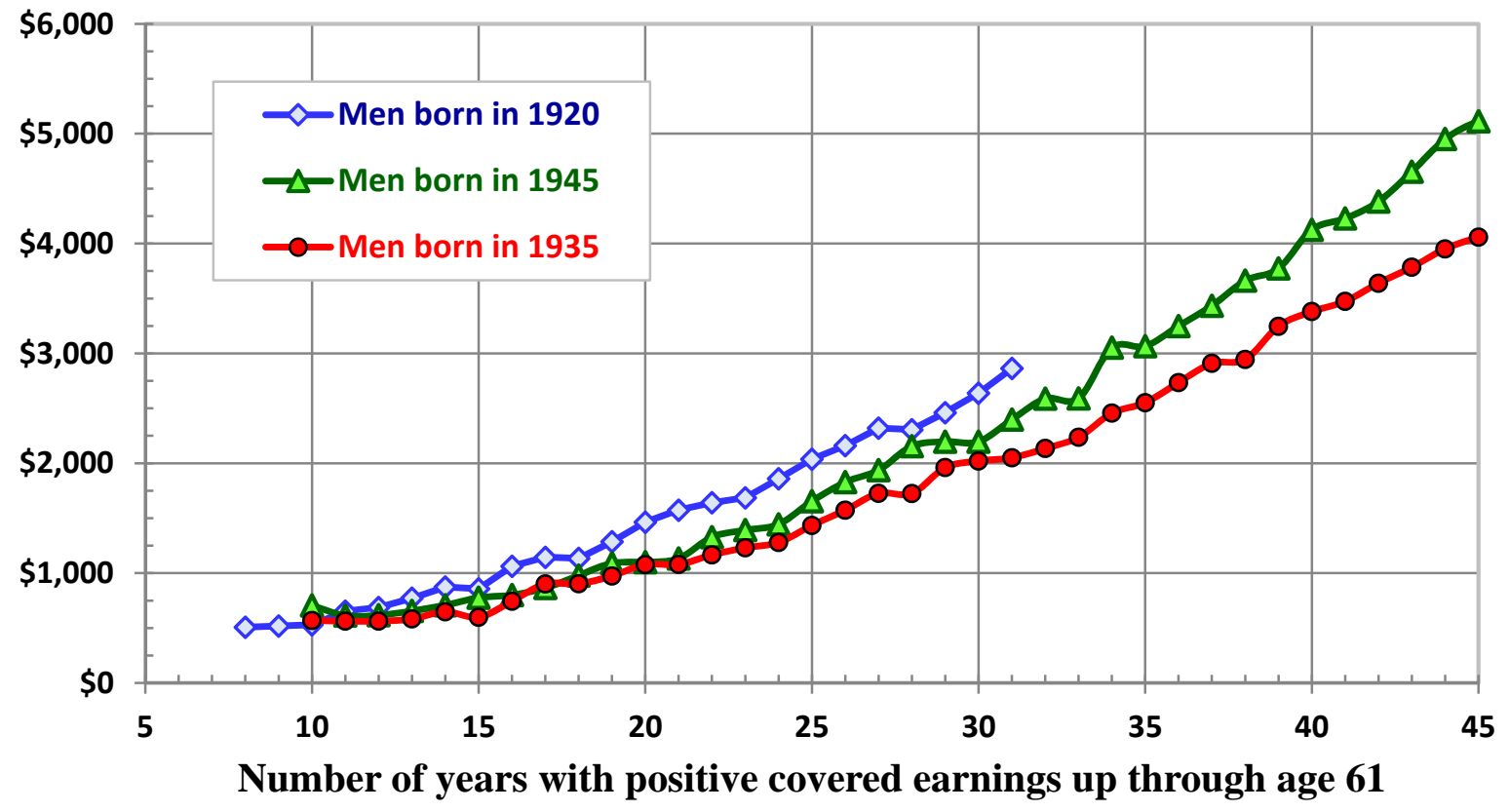

Average indexed monthly earnings of female workers (2010\$)

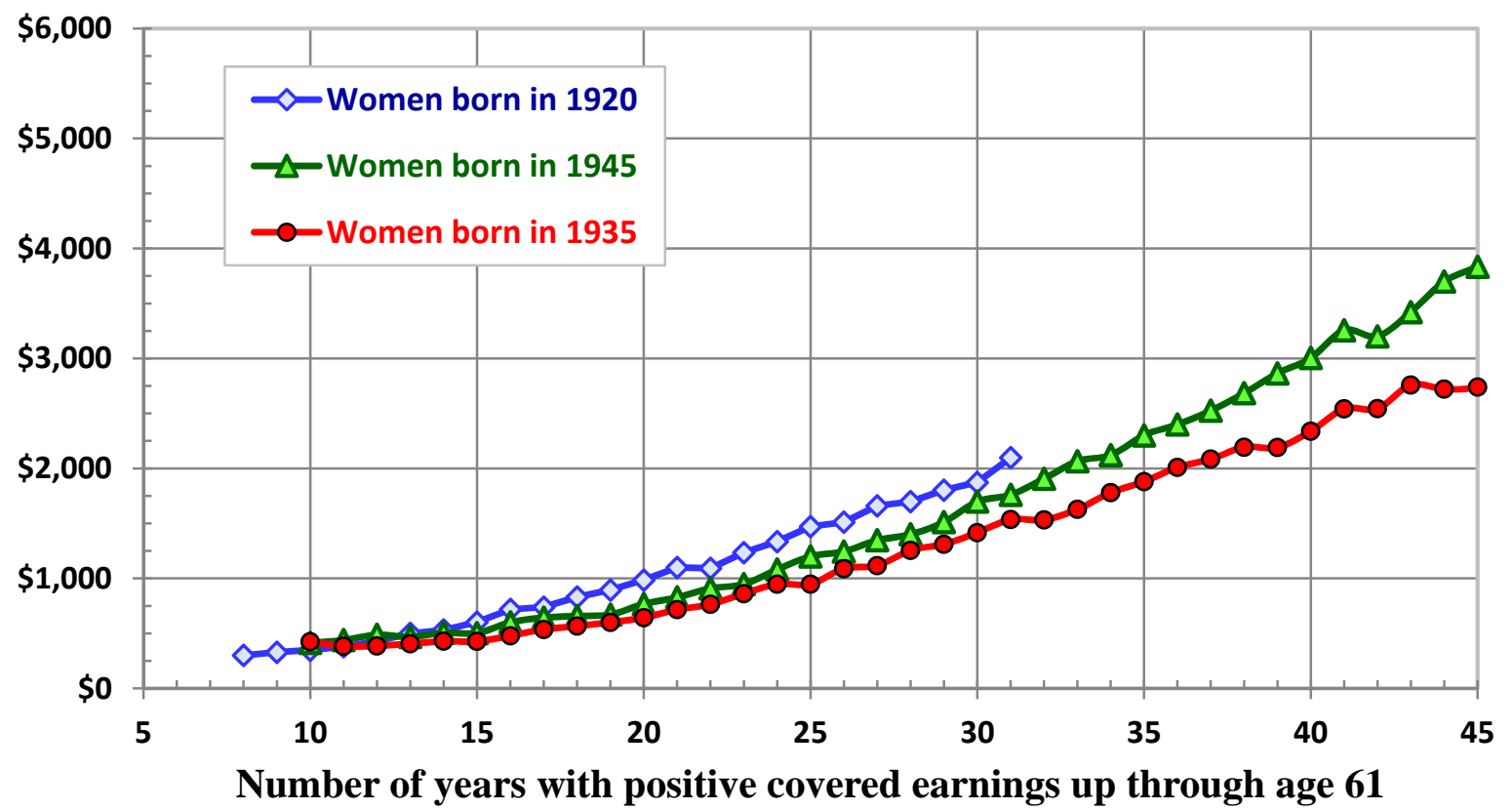

Note: To be included in estimation sample, workers must have accumulated enough earnings credits by age 62 to be eligible for Old-Age Insurance (retired worker) benefits. 
Figure 14. Discounted Lifetime OAI Benefits and OASI Taxes as Percent of Discounted Earnings for Male Workers attaining the Indicated Years of Covered Earnings, by Birth Cohort

Predicted discounted lifetime OAI benefits as percent of discounted earnings: Male workers

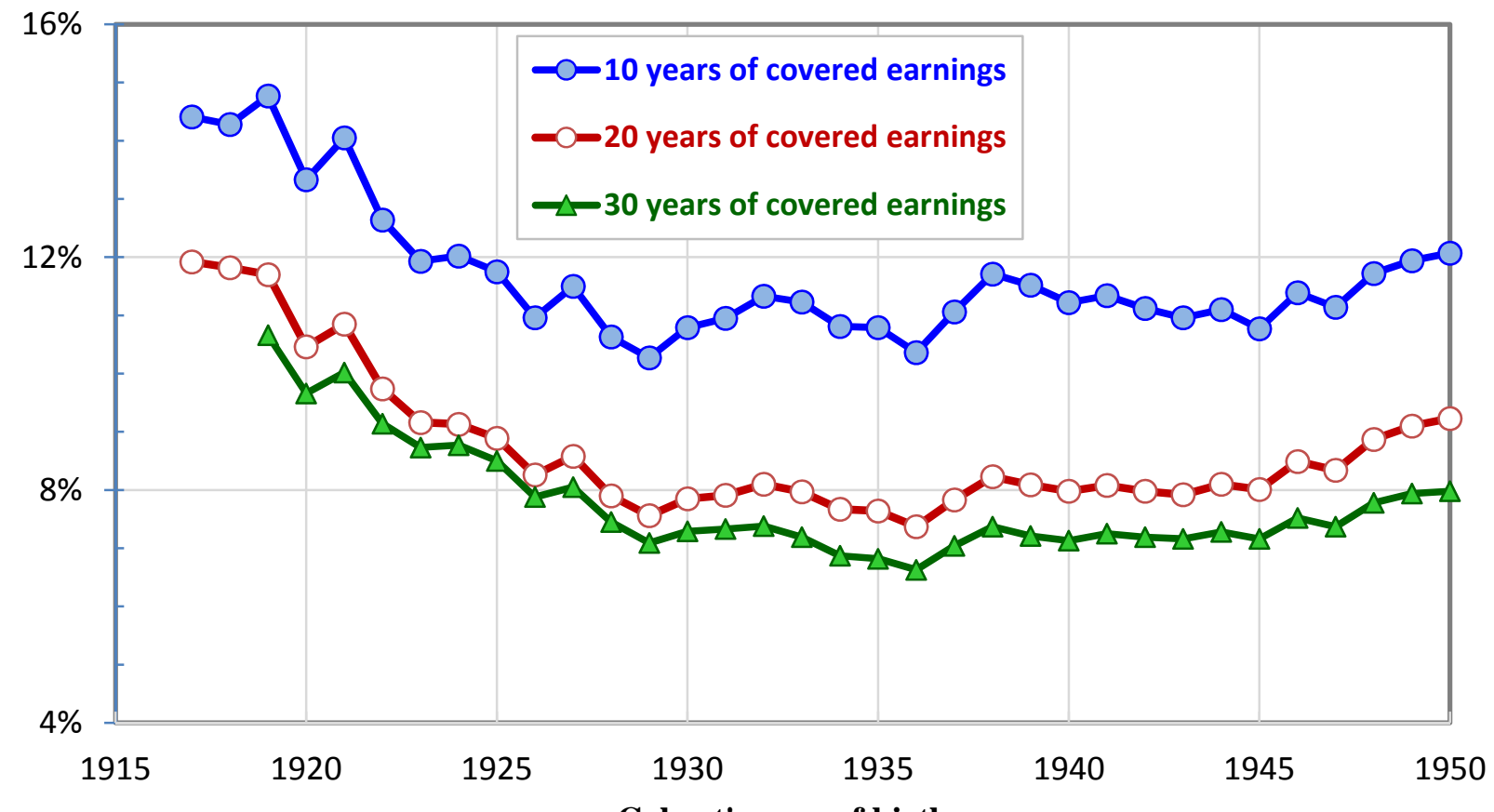

Discounted lifetime OASI taxes as percent of discounted earnings:

Male workers

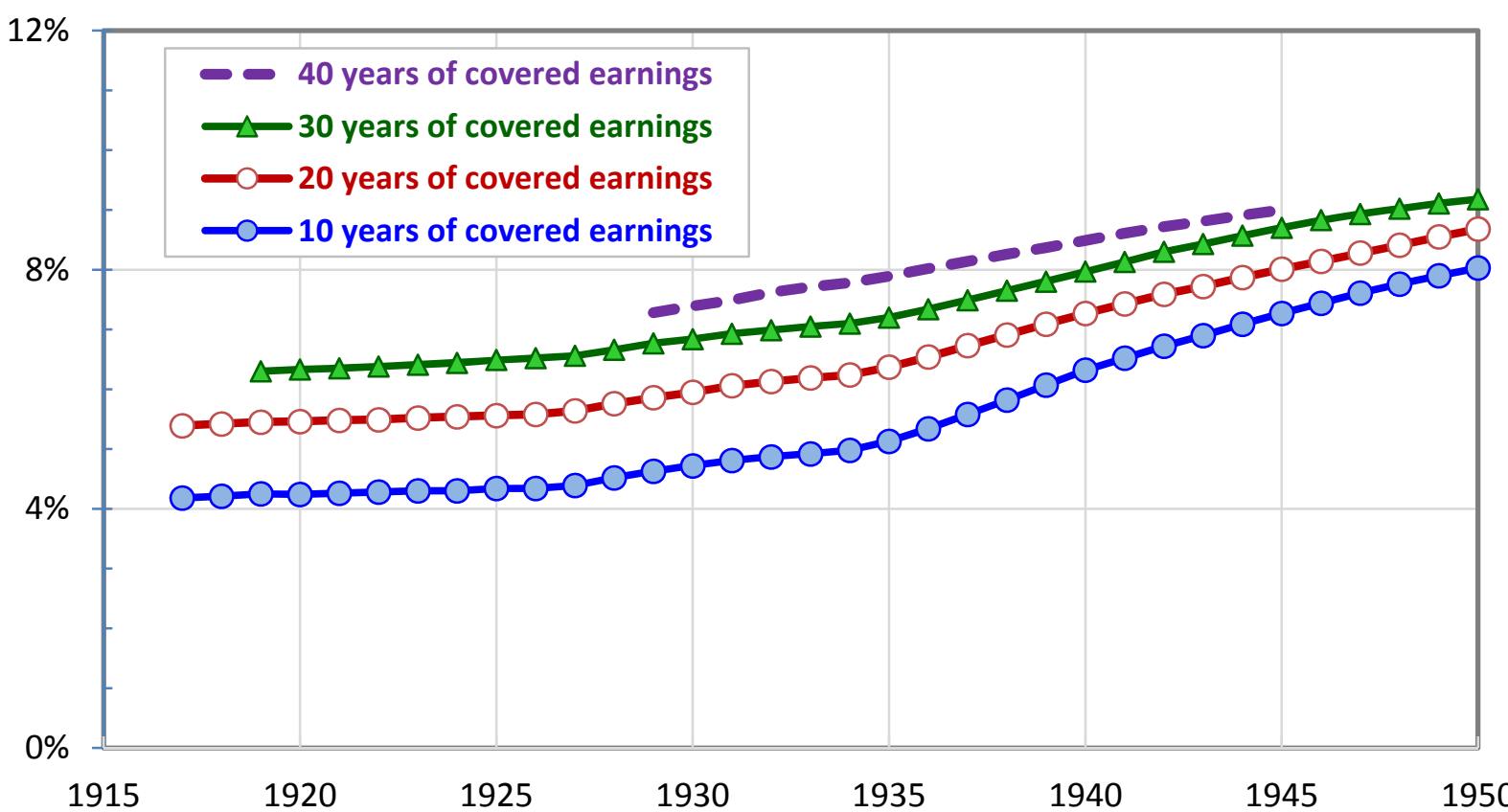

Cohort's year of birth

Note: To be included in tabulations, workers must have accumulated at least 40 quarters of covered earnings between 1951 and the year they attained age 62. Real discount rate is $1.5 \%$. 
Figure 15. Discounted Lifetime OAI Benefits Minus OASI Taxes as

Percent of Discounted Earnings for Male Workers Attaining the

Indicated Years of Covered Earnings, by Birth Cohort

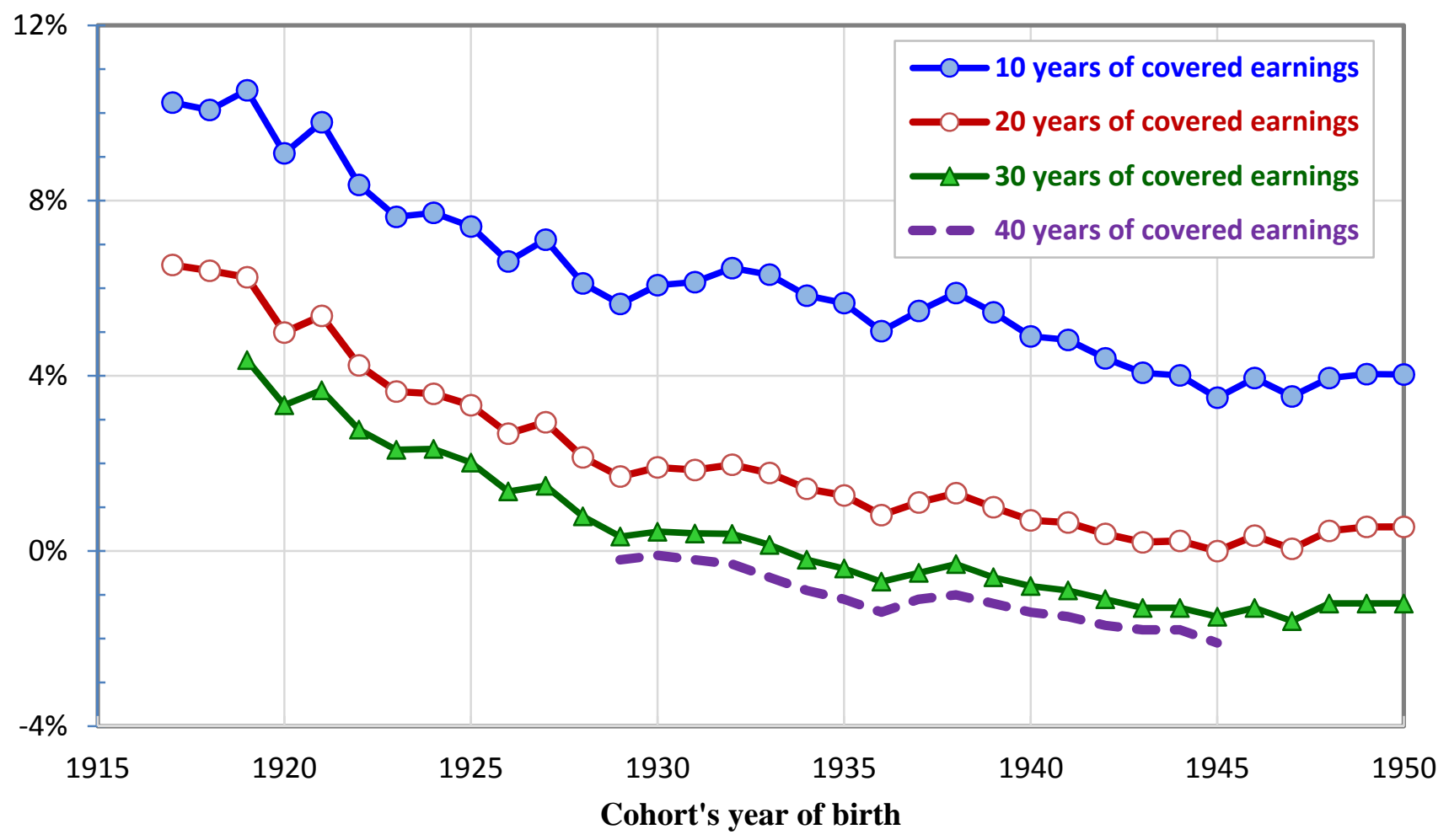

Note: To be included in tabulations, workers must have accumulated at least 40 quarters of covered earnings between 1951 and the year they attained age 62. Assumed real discount rate is $1.5 \%$. 
Figure 16. Discounted Lifetime OAI Benefits and OASI Taxes as Percent of Discounted Earnings for Female Workers Attaining the Indicated Years of Covered Earnings, by Birth Cohort

Predicted discounted lifetime OAI benefits as percent of discounted earnings: Female workers

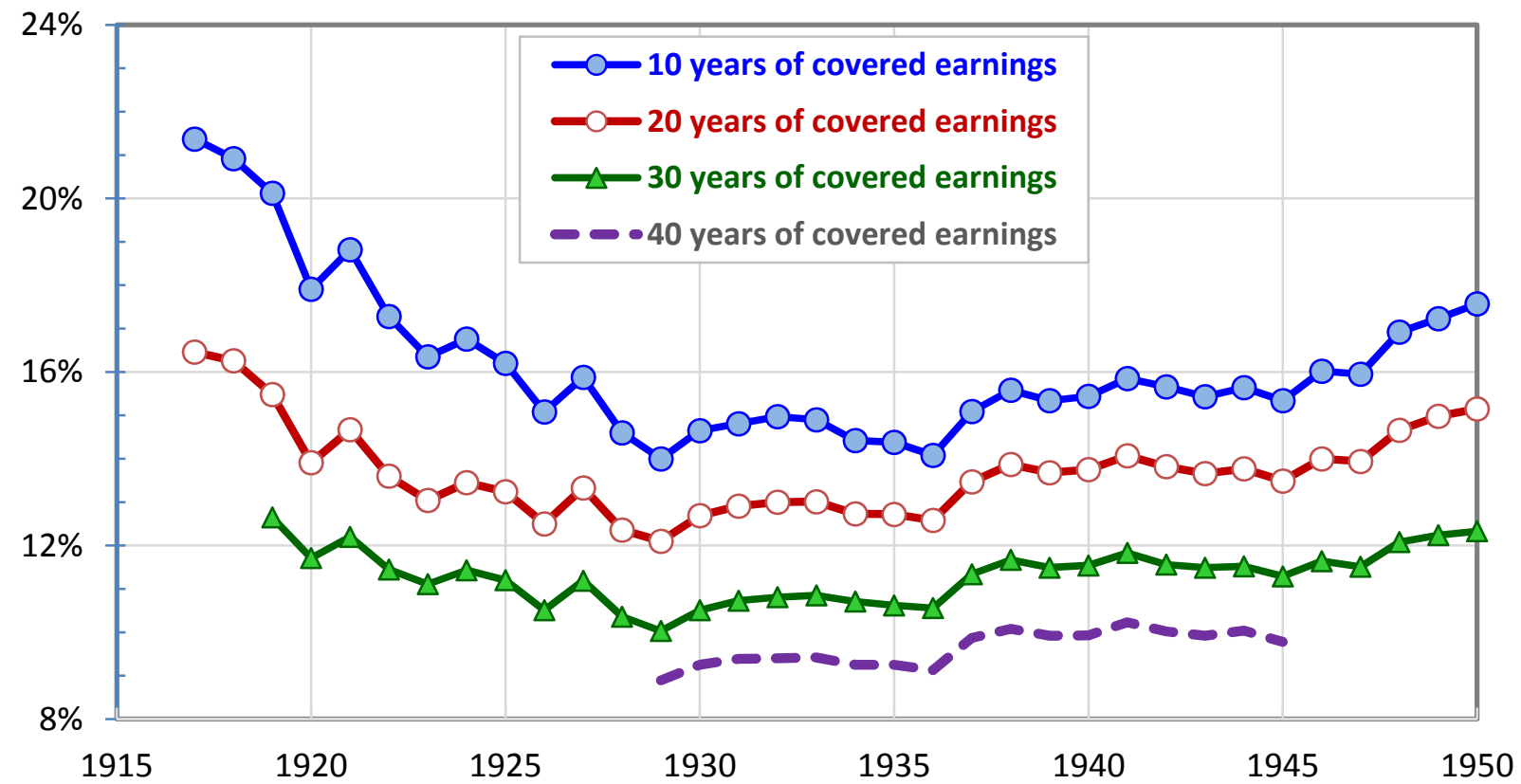

Cohort's year of birth

Discounted lifetime OASI taxes as percent of discounted earnings:

Female workers

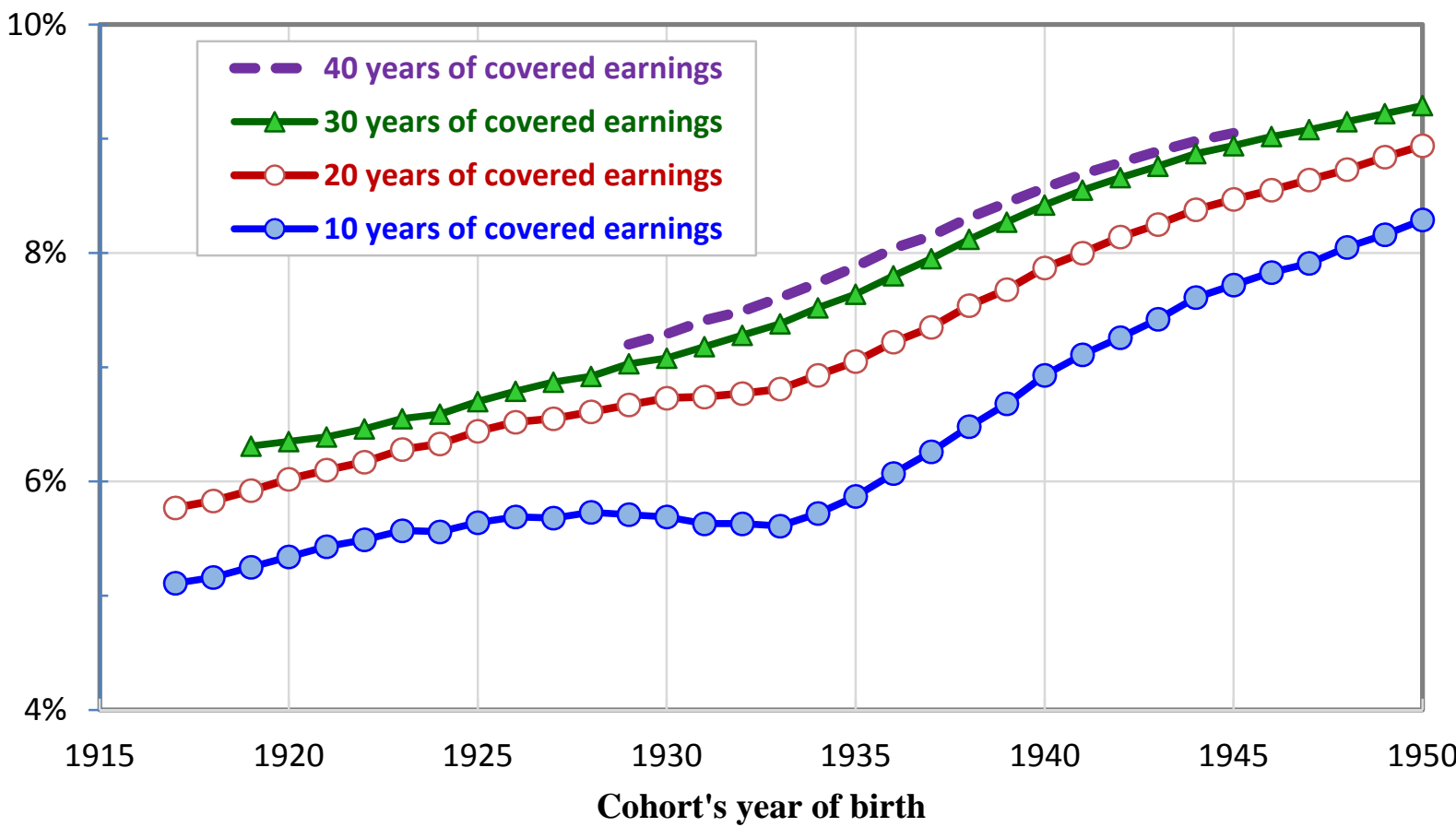

Note: To be included in tabulations, workers must have accumulated at least 40 quarters of covered earnings between 1951 and the year they attained age 62. Real discount rate is $1.5 \%$. 
Figure 17. Discounted Lifetime OAI Benefits Minus OASI Taxes as Percent of Discounted Earnings for Female Workers Attaining the Indicated Years of Covered Earnings, by Birth Cohort

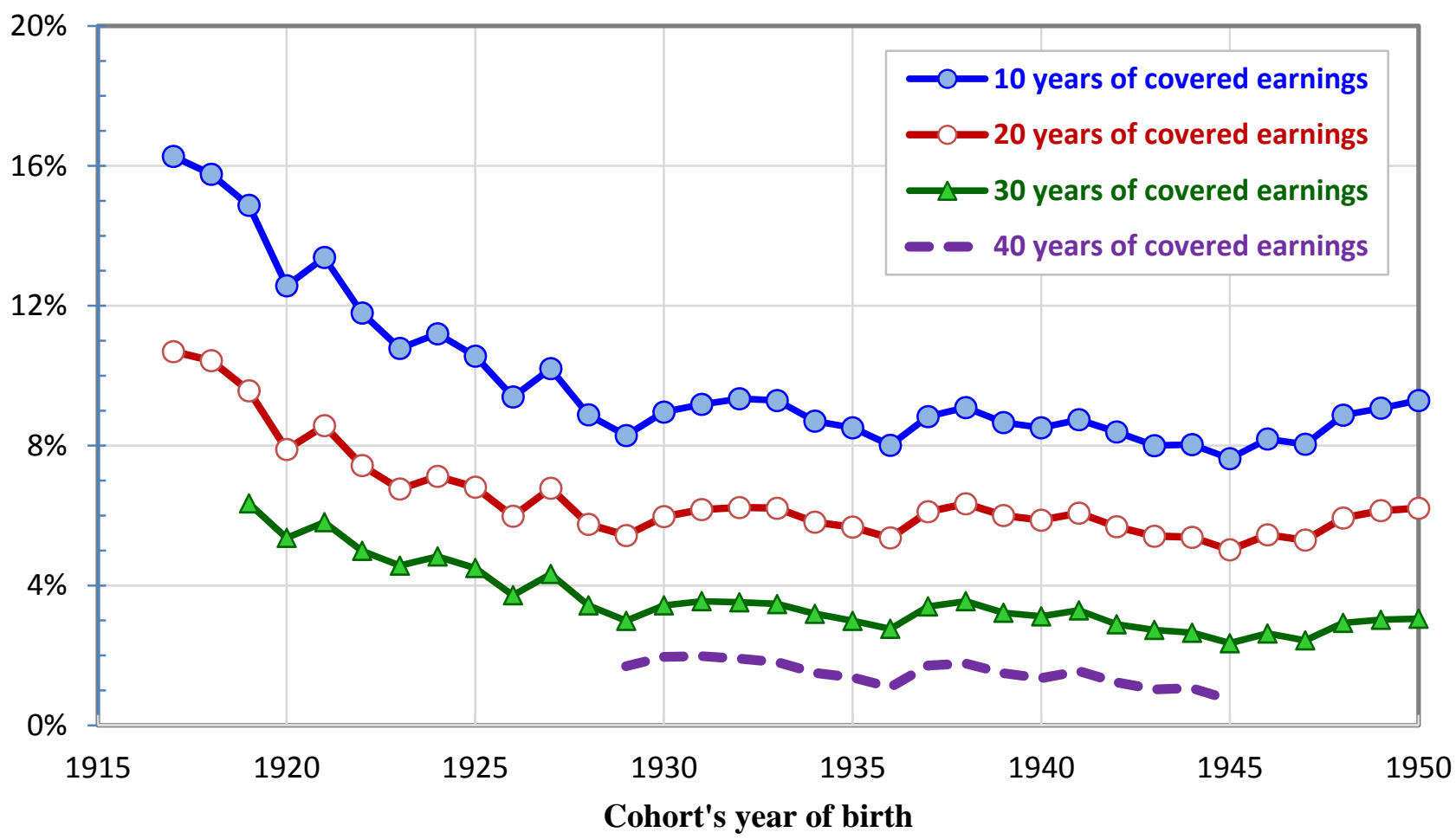

Note: To be included in tabulations, workers must have accumulated at least 40 quarters of covered earnings between 1951 and the year they attained age 62. Assumed real discount rate is $1.5 \%$. 
Figure 18. Discounted Lifetime OAI Benefits minus OASI Taxes as Percent of Discounted Earnings for Workers attaining the Indicated Years of Covered Earnings, by Selected Birth Cohorts

Ratio of net (OAI benefits - OASI taxes) to discounted earnings: Males (Percent)

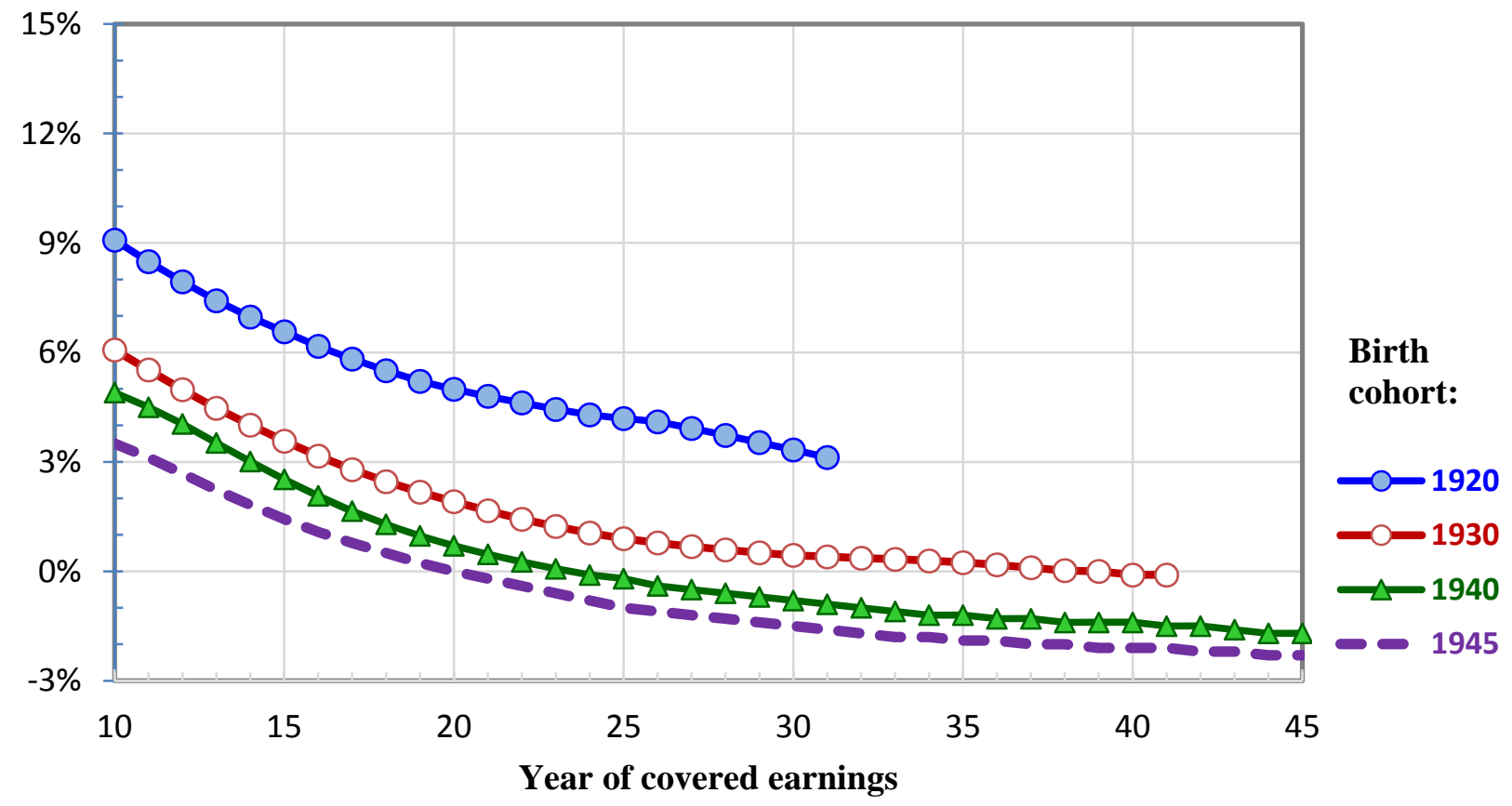

Ratio of net (OAI benefits - OASI taxes) to discounted earnings: Females (Percent)

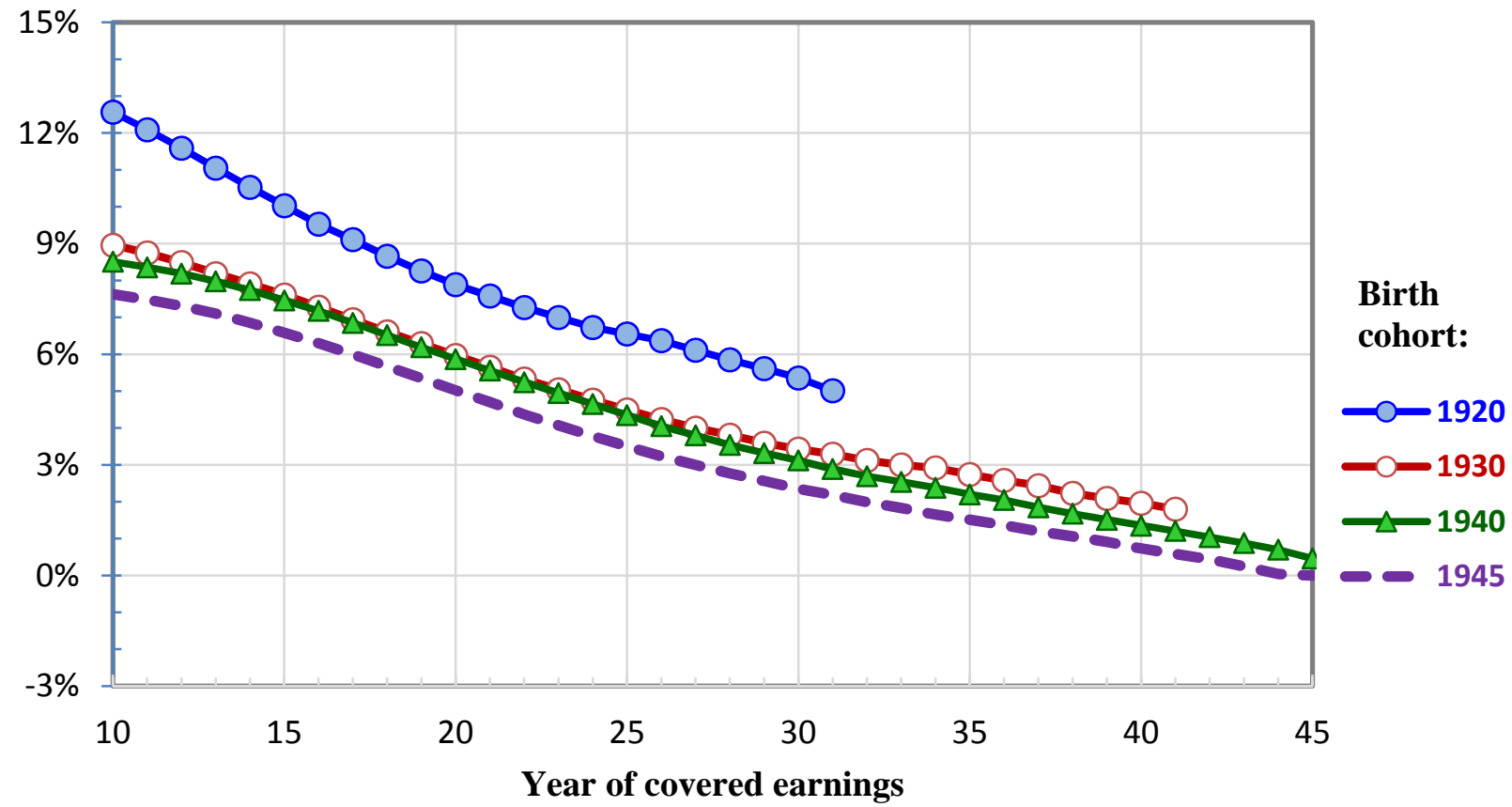

Note: To be included in tabulations, workers must have accumulated at least 40 quarters of covered earnings between 1951 and the year they attained age 62. Assumed real discount rate is $1.5 \%$. 
Figure 19. Average and Marginal Net Gain on OASI Contributions by Year of Worker's Covered Earnings: Male Workers in Middle of AIME Distribution
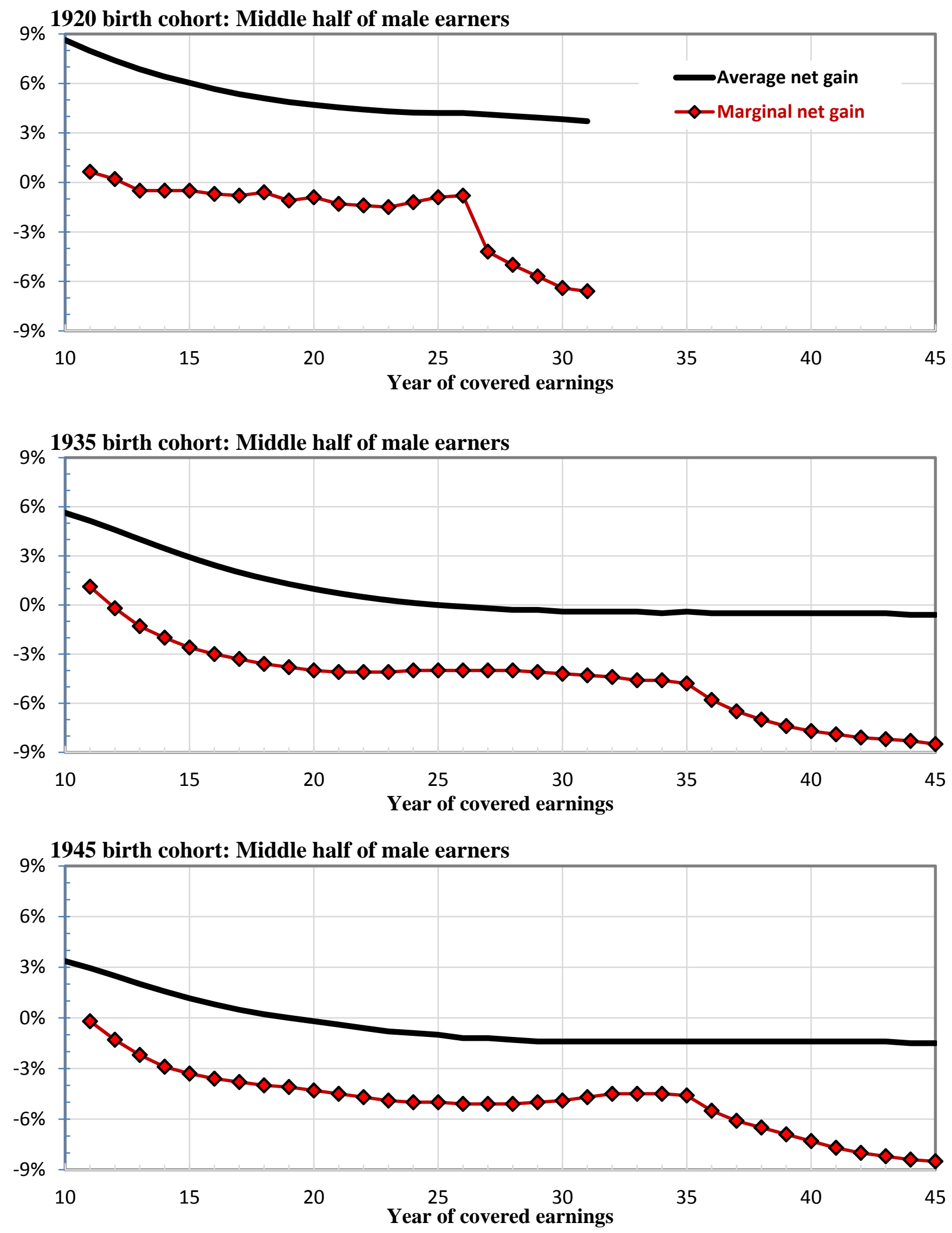
Figure 20. Average and Marginal Net Gain on OASI Contributions by Year of Worker's Covered Earnings: Female Workers in Middle of AIME Distribution
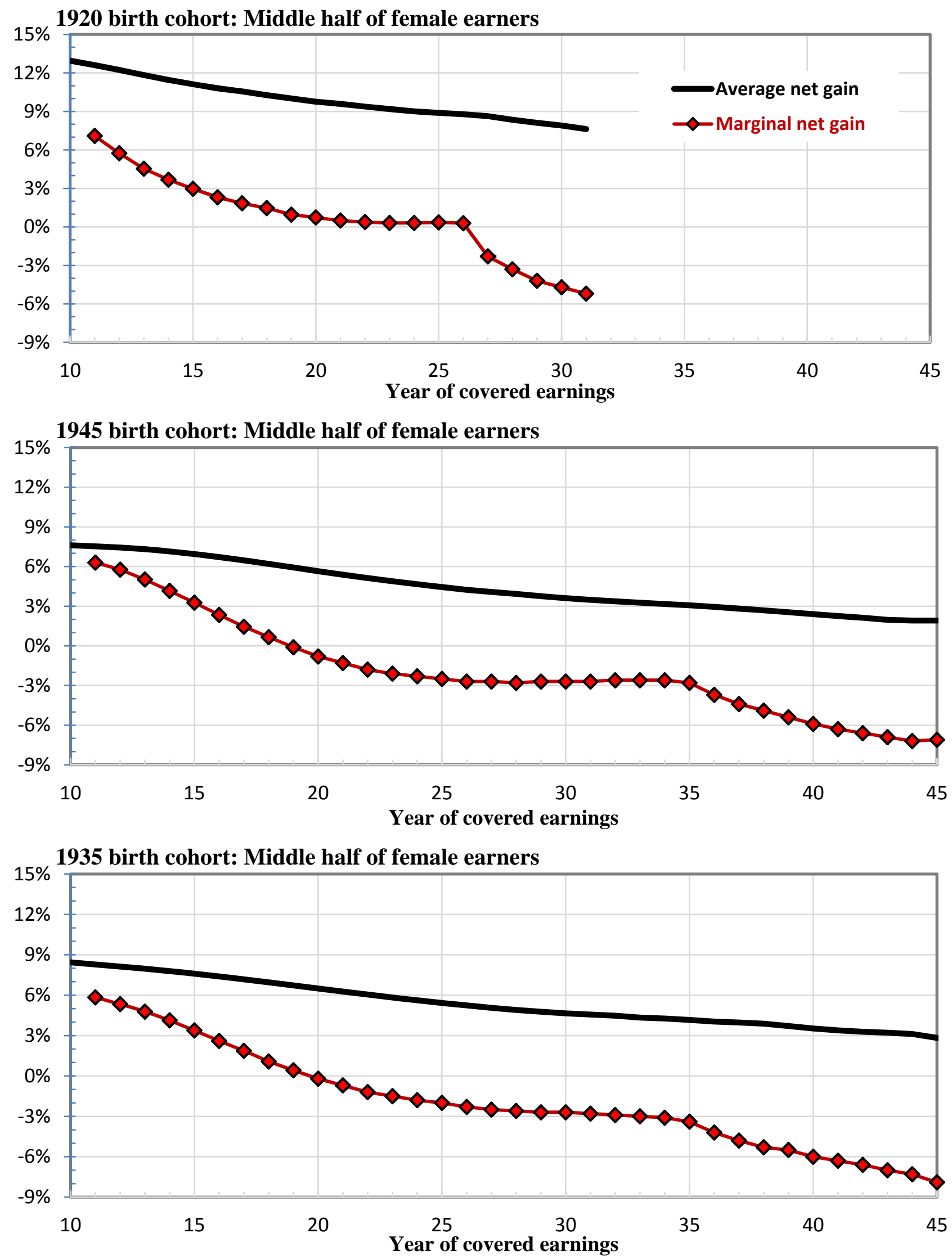
Appendix Table 1a. Average and Marginal Net Gain on OASI Contributions by Year of Worker's Covered Earnings: Male Workers in Bottom Quarter of AIME Distribution

1920 birth cohort: Bottom quarter of male earners

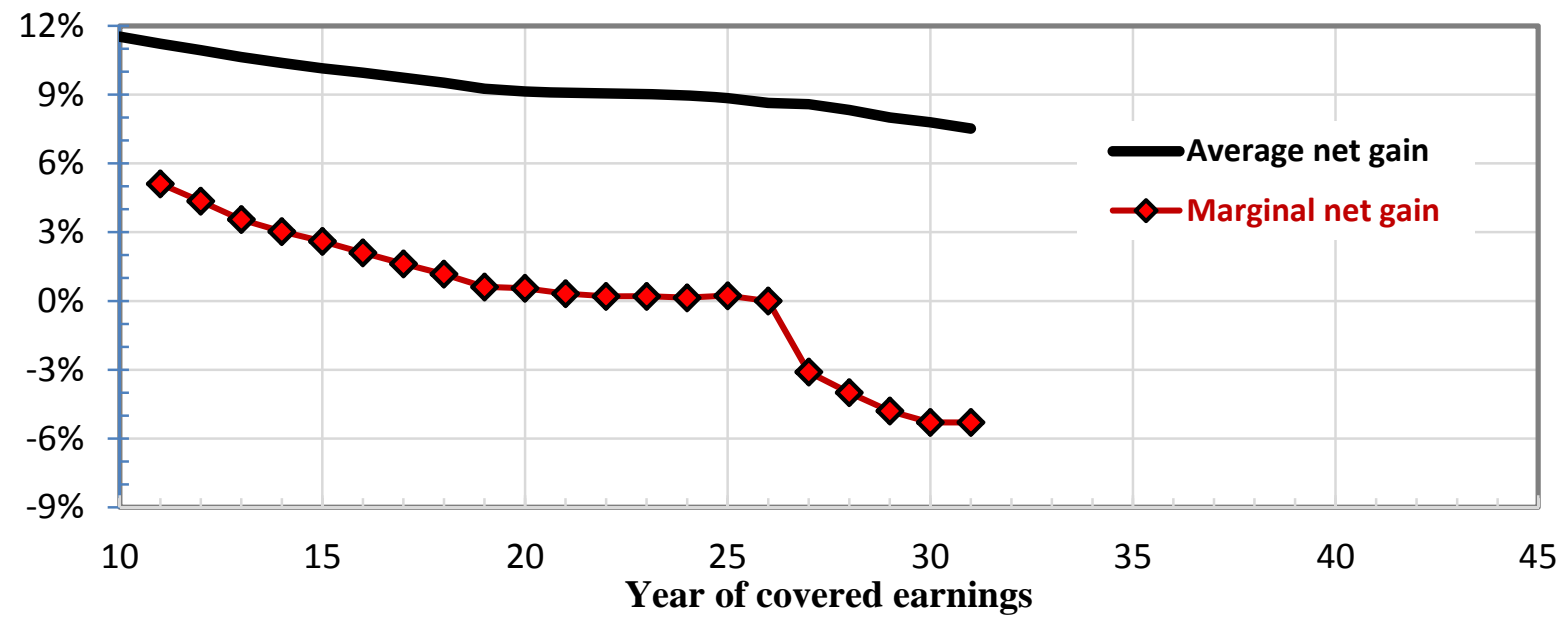

1935 birth cohort: Bottom quarter of male earners

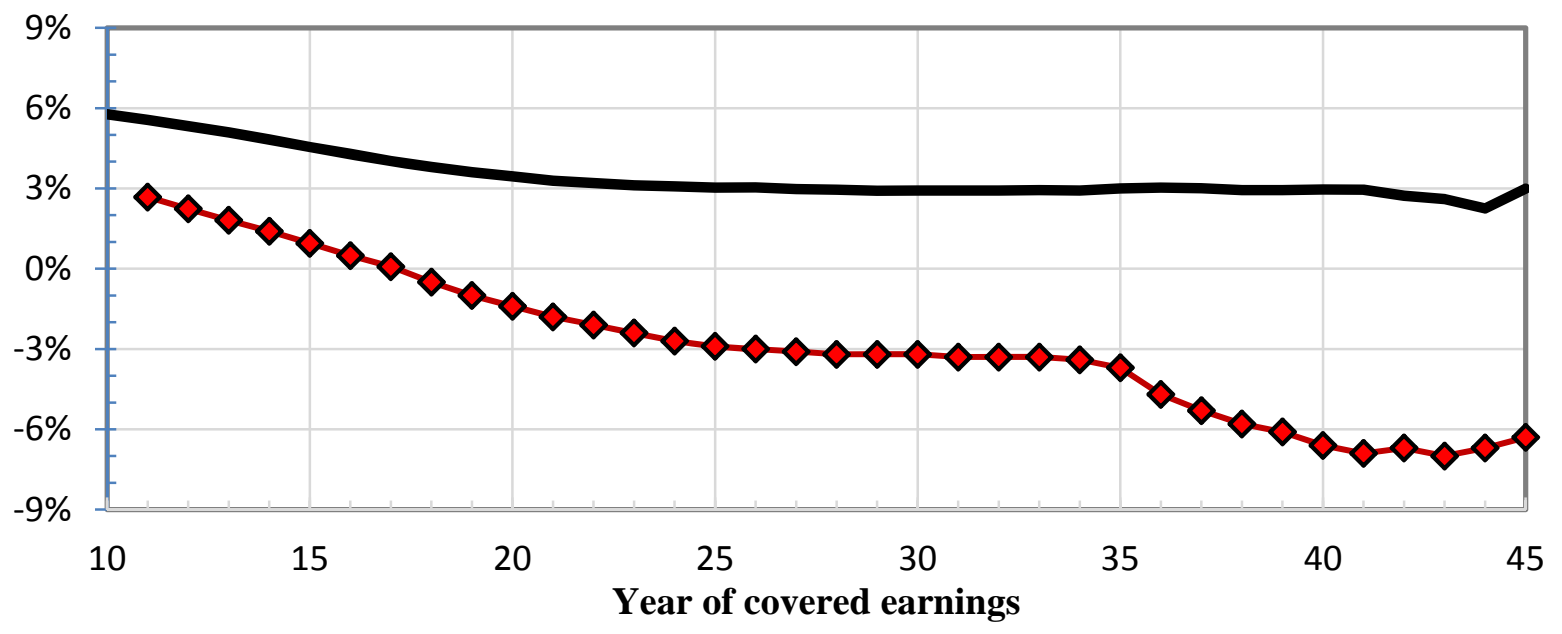

1945 birth cohort: Bottom quarter of male earners

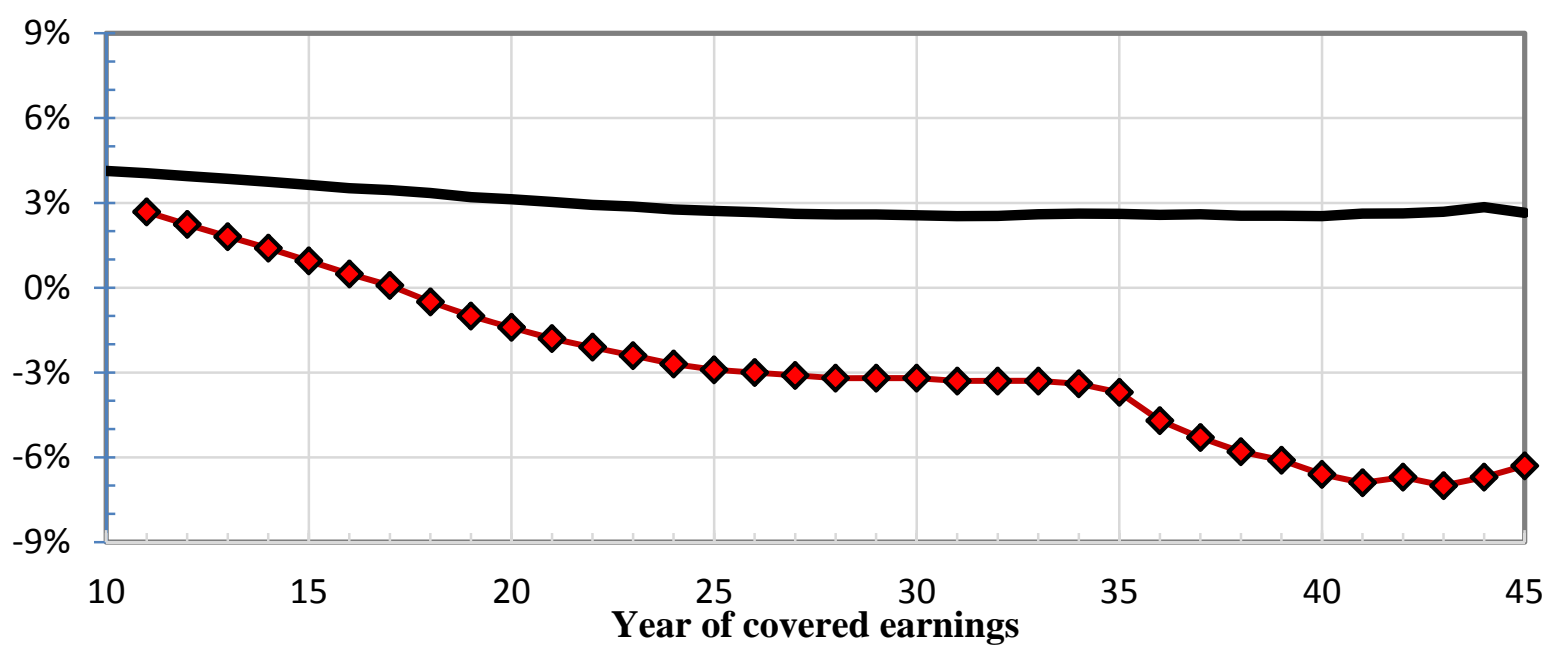

Note: To be included in tabulations, workers must have accumulated at least 40 quarters of covered earnings between 1951 and the year they attained age 62 . 
Appendix Table 1b. Average and Marginal Net Gain on OASI Contributions by Year of Worker's Covered Earnings: Male Workers in Top Quarter of AIME Distribution

1920 birth cohort: Top quarter of male earners

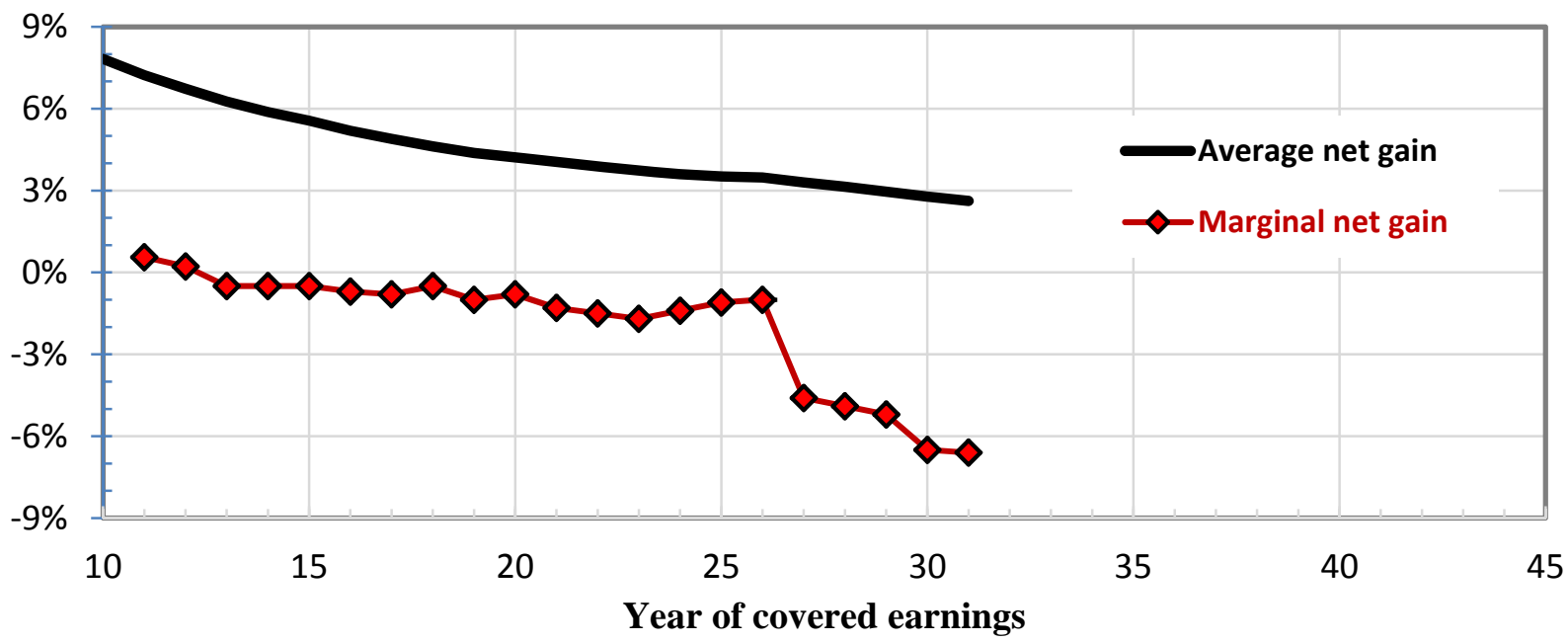

1935 birth cohort: Top quarter of male earners

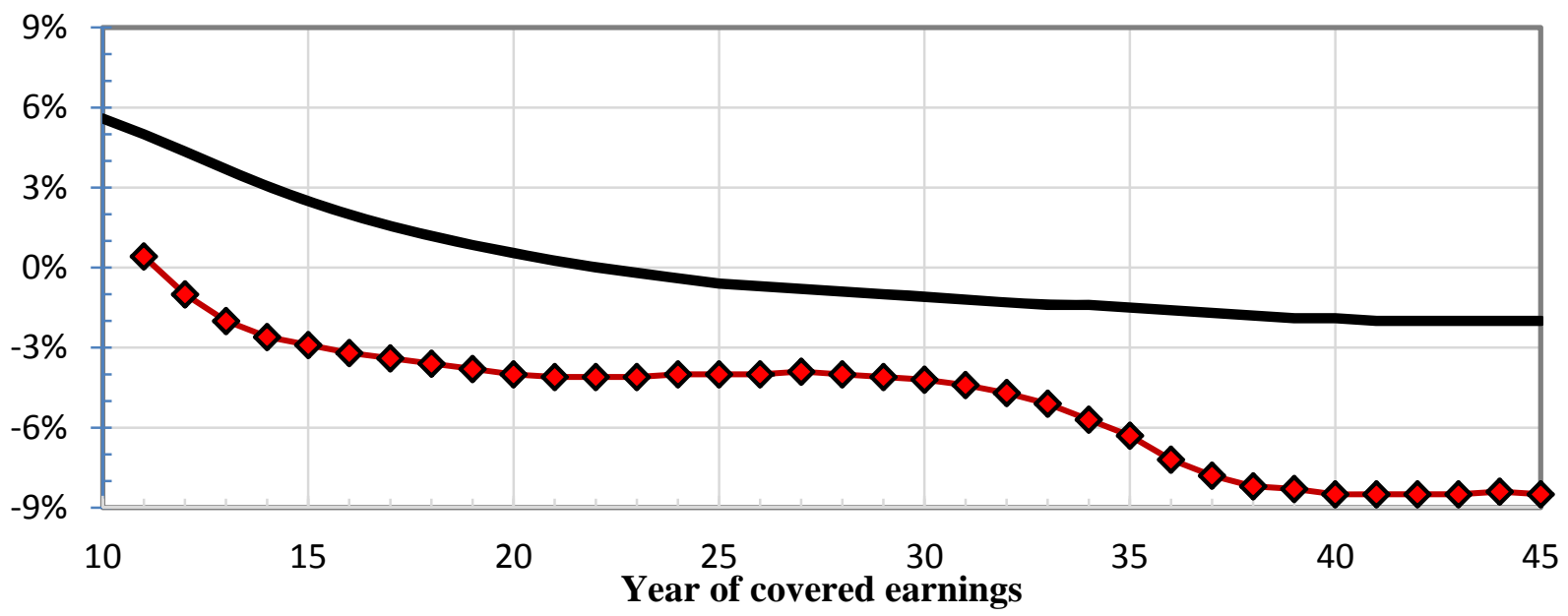

1945 birth cohort: Top quarter of male earners

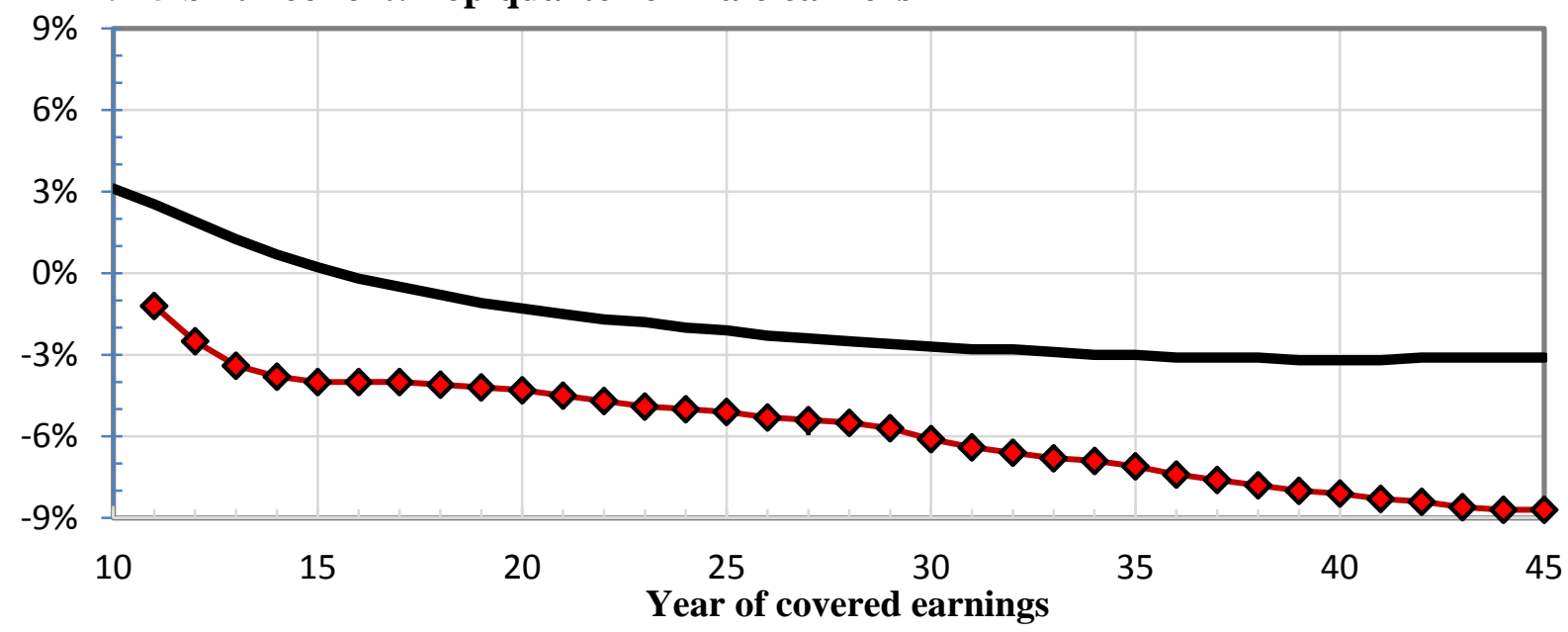

Note: To be included in tabulations, workers must have accumulated at least 40 quarters of covered earnings between 1951 and the year they attained age 62 . 
Appendix Table 2a. Average and Marginal Net Gain on OASI Contributions by Year of Worker's Covered Earnings: Female Workers in Bottom Quarter of AIME Distribution

1920 birth cohort: Bottom quarter of female earners

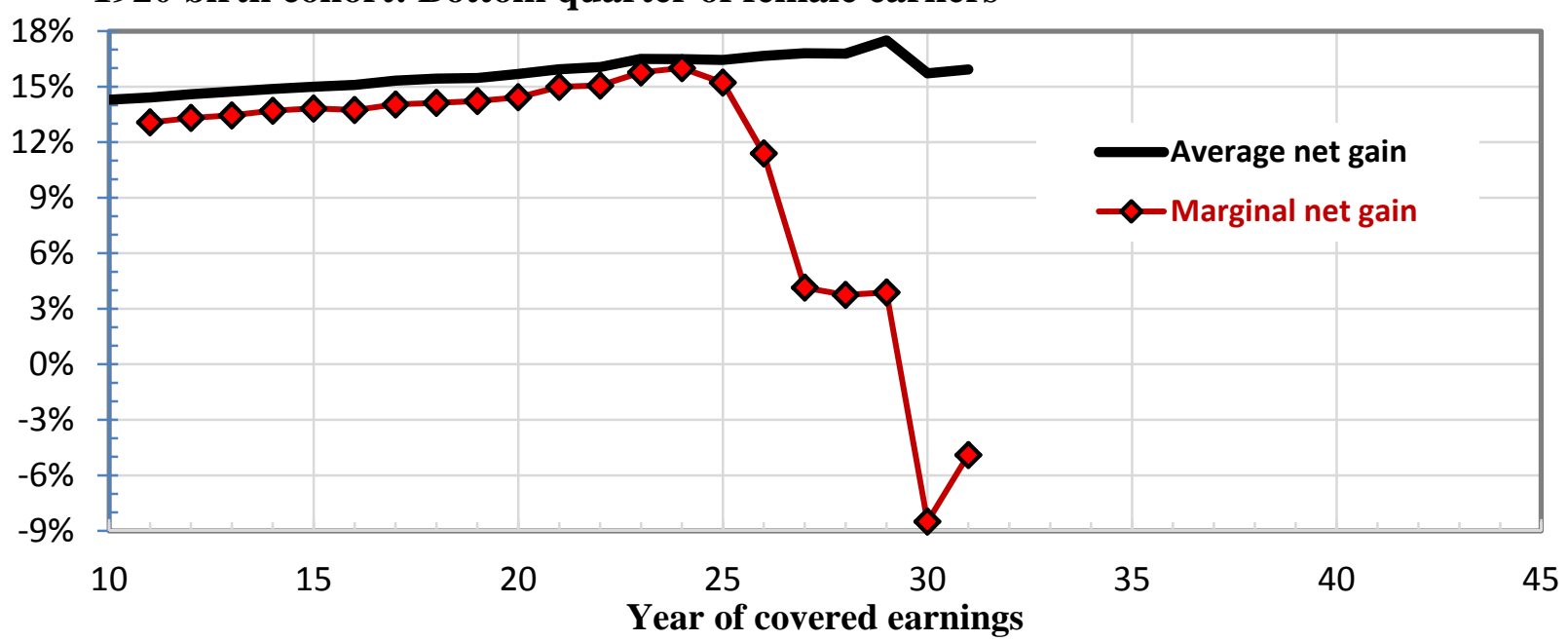

1935 birth cohort: Bottom quarter of female earners

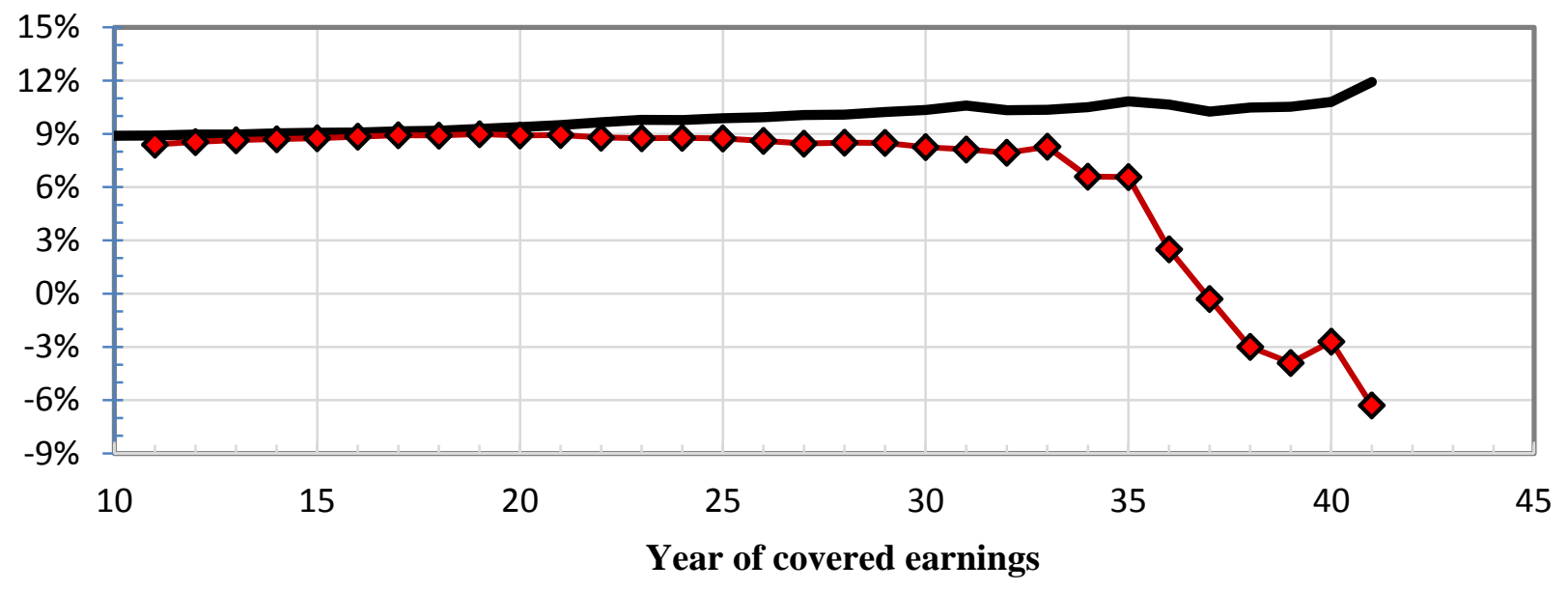

1945 birth cohort: Bottom quarter of female earners

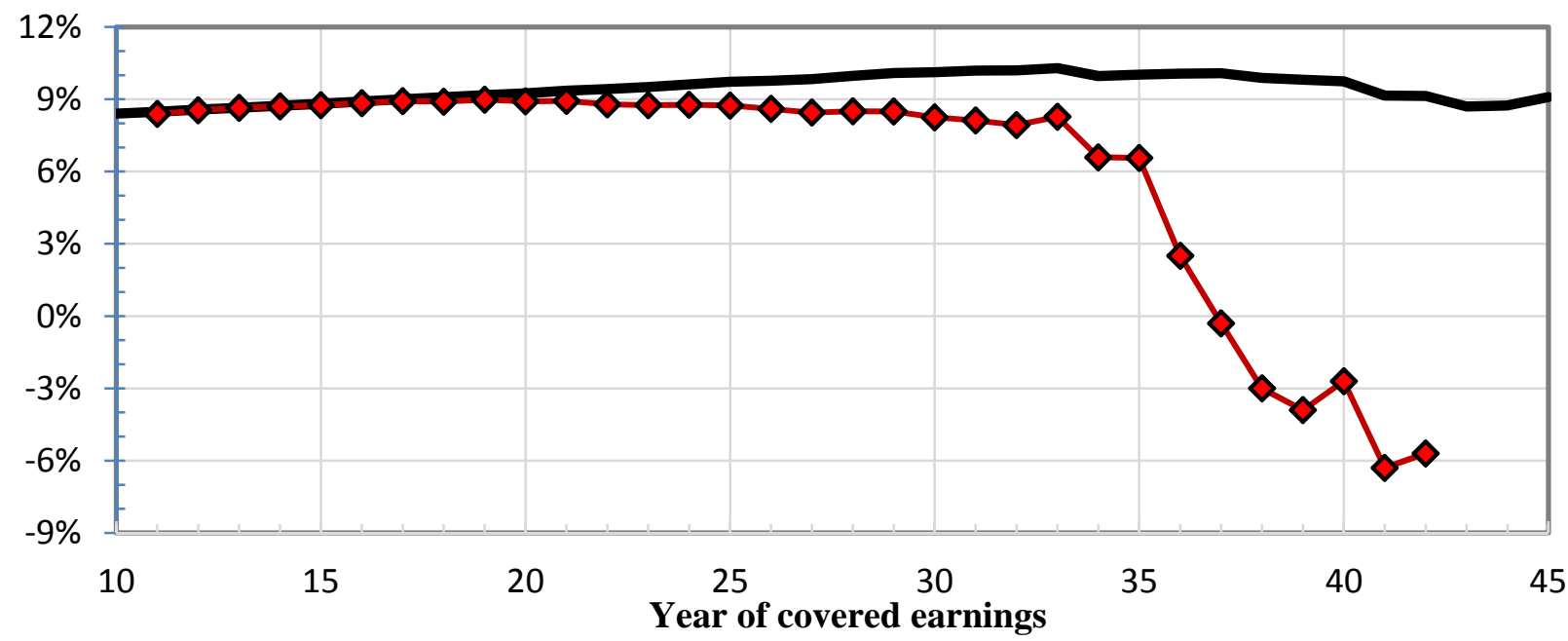

Note: To be included in tabulations, workers must have accumulated at least 40 quarters of covered earnings between 1951 and the year they attained age 62 . 
Appendix Table 2b. Average and Marginal Net Gain on OASI Contributions by Year of Worker's Covered Earnings: Female Workers in Top Quarter of AIME Distribution

1920 birth cohort: Top quarter of female earners

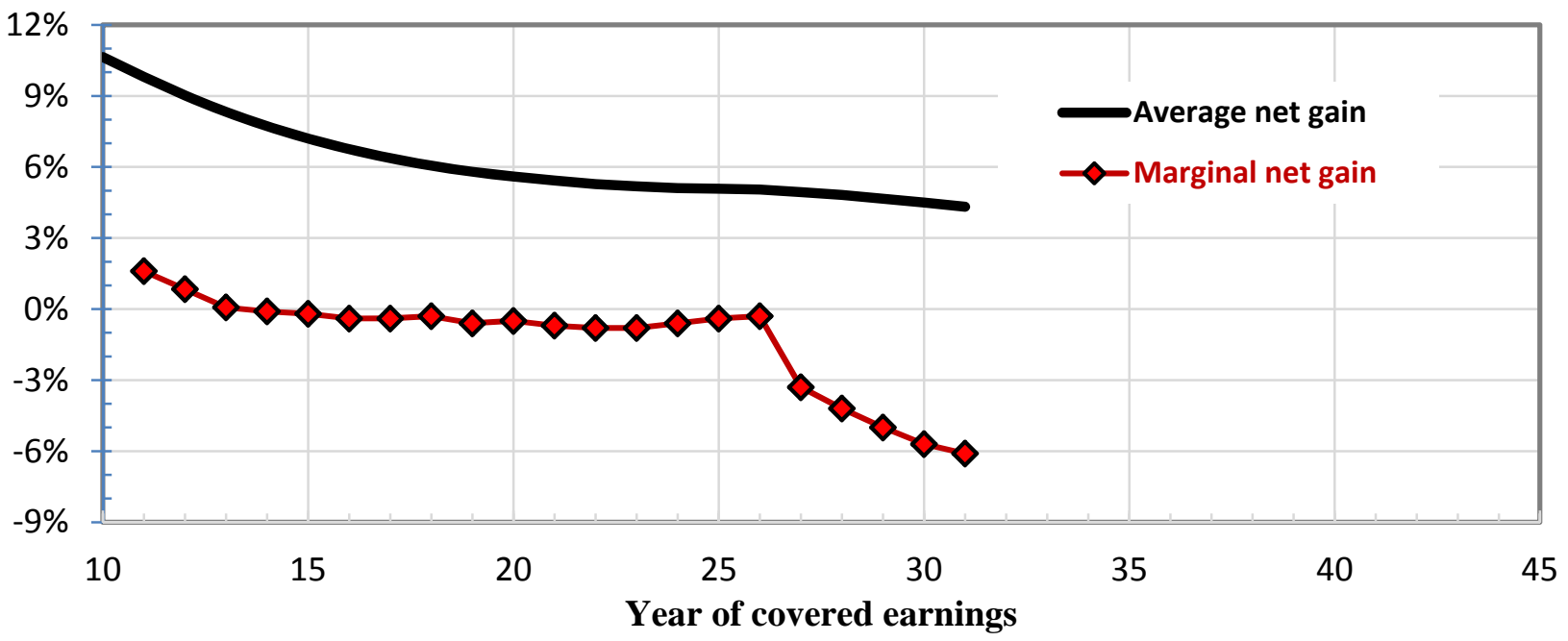

1935 birth cohort: Top quarter of female earners

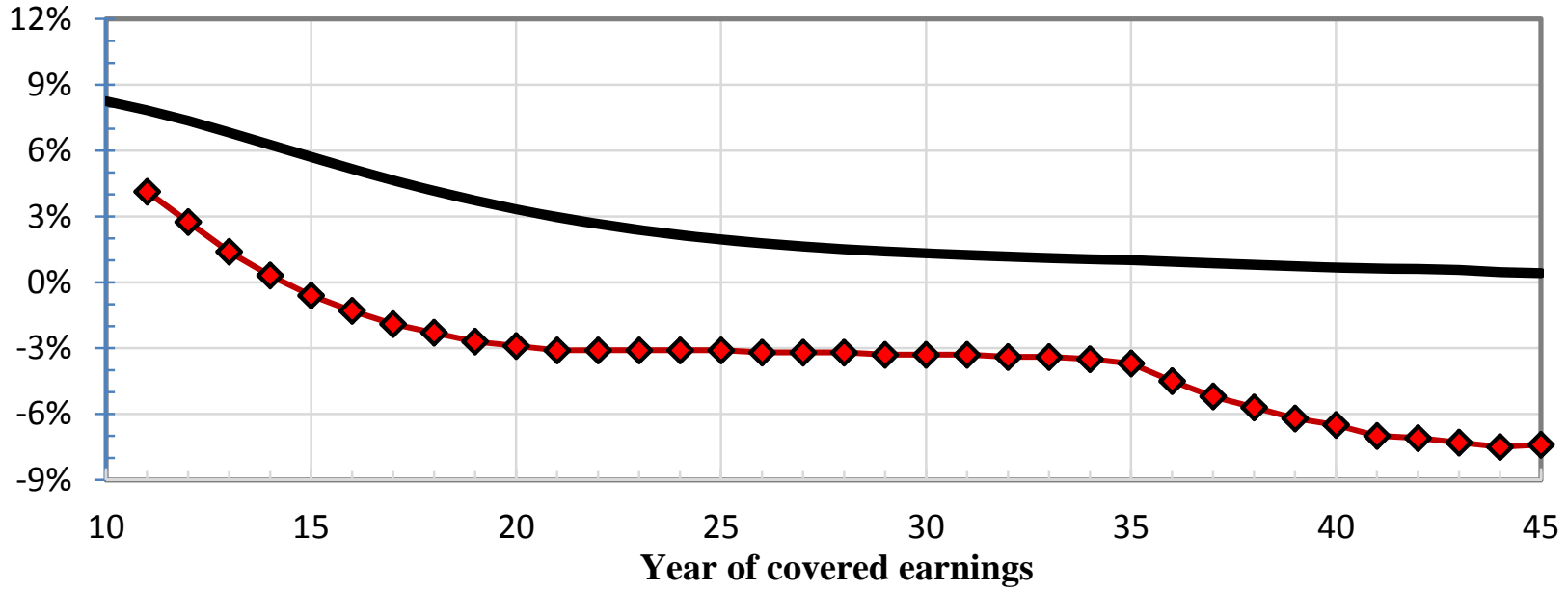

1945 birth cohort: Top quarter of female earners

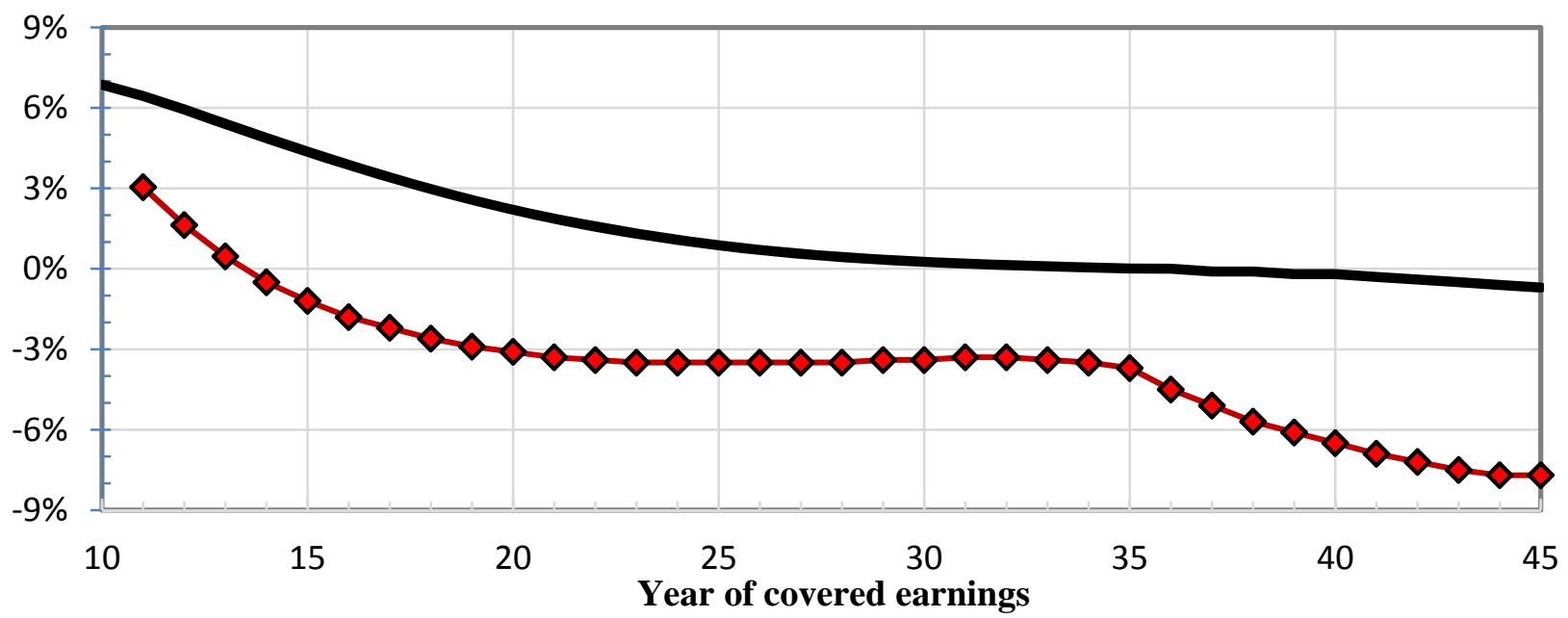

Note: To be included in tabulations, workers must have accumulated at least 40 quarters of covered earnings between 1951 and the year they attained age 62 . 


\section{RECENT WORKING PAPERS FROM THE CENTER FOR RETIREMENT RESEARCH AT BOSTON COLLEGE}

Improving Employees’ Life and Disability Insurance Benefit Decisions: Results of an Employer Survey

Anek Belbase, Norma B. Coe, and Matthew S. Rutledge, June 2015

Overcoming Barriers to Life Insurance Coverage: A Behavioral Approach

Anek Belbase, Norma B. Coe, and April Yanyuan Wu, June 2015

How Do People Decide on Life Insurance and Long-Term Disability Insurance Coverage? Norma B. Coe and Anek Belbase, June 2015

What Do Subjective Assessments of Financial Well-Being Reflect?

Steven A. Sass, Anek Belbase, Thomas Cooperrider, and Jorge D. Ramos-Mercado, March 2015

The Impact of Leakages from 401(k)s and IRAs

Alicia H. Munnell and Anthony Webb, February 2015

Recruiting and Retaining High-Quality State and Local Workers: Do Pensions Matter? Alicia H. Munnell, Jean-Pierre Aubry, and Geoffrey T. Sanzenbacher, January 2015

Do Tax Incentives Increase 401(k) Retirement Saving? Evidence from the Adoption of Catch-Up Contributions

Matthew S. Rutledge, April Yanyuan Wu, and Francis M. Vitagliano, November 2014

Are Retirees Falling Short? Reconciling the Conflicting Evidence

Alicia H. Munnell, Matthew S. Rutledge, and Anthony Webb, November 2014

Lifetime Job Demands, Work Capacity at Older Ages, and Social Security Benefit Claiming Decisions

Lauren Hersch Nicholas, November 2014

Who Is Internationally Diversified? Evidence from 296 401(k) Plans

Geert Bekaert, Kenton Hoyem, Wei-Yin Hu, and Enrichetta Ravina, November 2014

The Causes and Consequences of Financial Fraud Among Older Americans

Keith Jacks Gamble, Patricia Boyle, Lei Yu, and David Bennett, November 2014

New Evidence on the Risk of Requiring Long-Term Care

Leora Friedberg, Wenliang Hou, Wei Sun, Anthony Webb, and Zhenyu Li, November 2014

All working papers are available on the Center for Retirement Research website (http://crr.bc.edu) and can be requested by e-mail (crr@bc.edu) or phone (617-552-1762). 